NATALIA GOMES GONÇALVES

\title{
Síndrome metabólica e declínio cognitivo: papel do exercício \\ físico
}

\author{
Tese apresentada à Faculdade de \\ Medicina da Universidade de São \\ Paulo para obtenção do título de \\ Doutor em Ciências \\ Programa de Patologia \\ Orientador: Prof. Dr. Chin Jia Lin
}

Versão corrigida. Resolução CoPGr 6018, de 13 de outubro de 2011.

A versão original está disponível na Biblioteca da FMUSP.

São Paulo 


\title{
Síndrome metabólica e declínio cognitivo: papel do exercício físico
}

\author{
Tese apresentada à Faculdade de \\ Medicina da Universidade de São \\ Paulo para obtenção do título de \\ Doutor em Ciências \\ Programa de Patologia \\ Orientador: Prof. Dr. Chin Jia Lin
}

Versão corrigida. Resolução CoPGr 6018, de 13 de outubro de 2011.

A versão original está disponível na Biblioteca da FMUSP.

São Paulo 


\section{Dados Internacionais de Catalogação na Publicação (CIP)}

Preparada pela Biblioteca da

Faculdade de Medicina da Universidade de São Paulo

Creprodução autorizada pelo autor

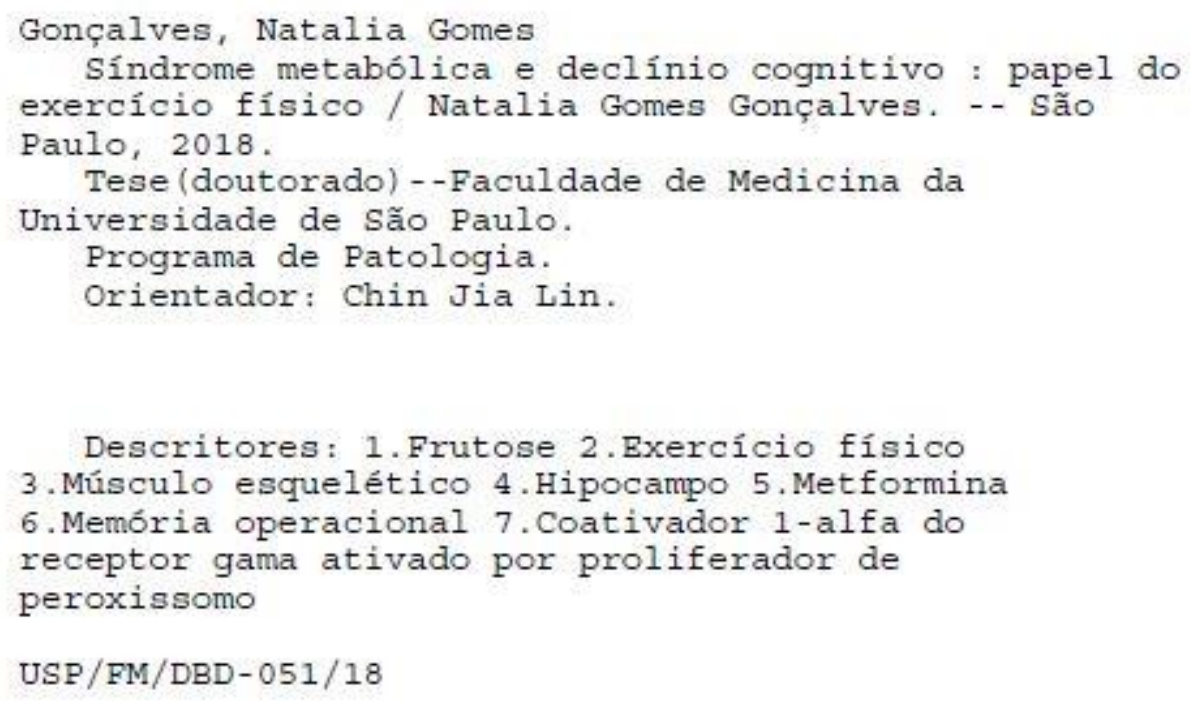

Responsável: Kátia Maria Bruno Ferreira - CRB-8/6008 


\title{
Metabolic syndrome and cognitive decline: role of physical
} exercise

\author{
Thesis presented to the Faculdade de \\ Medicina, Universidade de Sao Paulo \\ to obtain the degree of Doctor in Science \\ Graduate Program in Pathology \\ Advisor: Prof. Dr. Chin Jia Lin
}

São Paulo 



\section{Table of Contents}

List of Figures

List of Tables

List of Abbreviations

Resumo

Abstract

1. Introduction 1

1.1 Background 1

1.2 Skeletal muscle and Metabolic Syndrome $\quad 7$

1.3 Fructose metabolism and Metabolic Syndrome 12

$\begin{array}{ll}\text { 1.4 Role of fructose in cognitive decline } & 15\end{array}$

2. Aims and Objectives 18

3. Methods 19

3.1 Animals 19

$\begin{array}{ll}3.2 \text { Treadmill exercise protocol } & 20\end{array}$

$\begin{array}{ll}\text { 3.3 Barnes Maze } & 20\end{array}$

$\begin{array}{ll}\text { 3.4 Tissue collection and Biochemical analysis } & 23\end{array}$

3.5 RNA extraction and gene expression analysis 25

3.6 Protein extraction and Western Blot 25

$\begin{array}{ll}\text { 3.7 Statistical analysis } & 26\end{array}$

4. Results 28

$\begin{array}{ll}\text { 4.1 Body weight and metabolic profile } & 28\end{array}$

4.2 Effect of Exercise in Physical Fitness 29

$\begin{array}{ll}\text { 4.3 Barnes Maze } & 30\end{array}$ 
4.4 Fructose does not impair insulin signaling in the hippocampus

4.5 Effect of fructose in brain plasticity 32

4.6 Fructose attenuates expression of PGC1 $\alpha$ and FNDC5

4.7 Effect of fructose in upstream regulators and downstream targets of PGC1 $1 \alpha$

4.8 Effect of fructose in muscle autophagy

4.9 Effect of fructose and metformin in the working memory 41

4.10 Effect of fructose and metformin in muscle metabolism 42

4.11 Effect of fructose and metformin in the brain 43

5. Discussion $\quad 45$

6. Conclusion 53

7. References $\quad 54$

8. Published article $\quad 63$ 


\section{List of Figures}

Figure 1. Signaling pathways activated by muscle contraction

Figure 2. Exercise-induced activation of autophagy

Figure 3. Fructose and glucose metabolism

Figure 4. Insulin- and NMDA-signaling in the neuron

Figure 5. Overview of the experimental protocol

Figure 6. Treadmill exercise training

Figure 7. Barnes Maze

Figure 8. Maximal exercise capacity test

Figure 9. Evaluation of working memory in the Barnes Maze test

Figure 10. Effect of fructose on accumulation of IR and IRS protein in hippocampus

Figure 11. Effect of fructose on Akt and GSK3 $\beta$ protein concentration in hippocampus

Figure 12. Effect of fructose on BDNF and synaptophysin protein content in hippocampus

Figure 13. Effect of fructose ingestion and exercise training on expression of PGC1 11 and FNDC5 in skeletal muscle and hippocampus

Figure 14. Expression of regulators and downstream targets of PGC1 $1 \alpha 1$ in skeletal muscle in the context of fructose ingestion and aerobic exercise

Figure 15. Effects of fructose and exercise training on expression of the Atg family genes 
Figure 16. Expression of genes involved in the final steps of autophagy pathway under the effects of fructose loading and exercise training

Figure 17. Expression of ubiquitin ligases Murf-1 and MAFBx in the context of fructose loading and chronic aerobic exercise

Figure 18. Effects of chronic fructose ingestion and aerobic training on expression of mitochondrial function regulator Bnip3

Figure 19. Effect of fructose and metformin in the working memory

Figure 20. Effect of fructose and metformin on expression of GLUT4, PGC1 $\alpha$, FNDC5, CPT1a and CS in skeletal muscle

Figure 21. Effect of fructose and metformin in PGC1 $\alpha$, FNDC5 and BDNF expression levels in the hippocampus 


\section{List of Tables}

Table 1. Criteria for definition of Metabolic Syndrome according to

Table 2. Primer pairs used in Real Time PCR experiments

Table 3. Metabolic profile of animals 8 weeks after experimental treatment 


\section{List of Abbreviations}

A $\beta \quad \quad \beta$ amyloid

$\mathrm{AD}$

Alzheimer`s disease

ADDL

Amyloid beta-derived diffusible ligand

$\mathrm{Akt} / \mathrm{PKB}$

Protein kinase B

AMPK

5' adenosine monophosphate-activated protein kinase

APP

Amyloid precursor protein

Atg

Autophagy-related protein

ATP

Adenosine triphosphate

BDNF

Brain-derived neurotrophic factor

Bnip3

BCL2 interacting protein 3

CAMK IV

Calcium/calmodulin-dependent protein kinase type IV

CREB

cAMP response element-binding protein

CNS

Central nervous system

CPT1a

Carnitine palmitoyltransferase $1 \mathrm{~A}$

CS

Citrate synthase

Ctsl

Cathepsin L

DM2

Diabetes Mellitus type 2

Erra

Estrogen-related receptor alpha

FNDC5

Fibronectin type III domain-containing protein 5

FoxO Forkhead box class $\mathrm{O}$

GLUT4 Glucose transporter 4

GSK3 Glycogen synthase kinase 3

IDE Insulin degrading enzyme

IDF International Diabetes Federation 


\begin{tabular}{|c|c|}
\hline IGF-1 & Insulin-like growth factor 1 \\
\hline IKK & Inhibitor of $\mathrm{NF}-\kappa \mathrm{B}$ kinase \\
\hline IR & Insulin receptor \\
\hline IRS1 & Insulin receptor substrate 1 \\
\hline JNK & c-Jun N-terminal kinase \\
\hline Lamp-2 & Lysosome-associated membrane protein 2 \\
\hline LC3 & Microtubule-associated proteins 1A/1B light chain 3B \\
\hline MAFBx & Muscle atrophy F-box \\
\hline MetS & Metabolic syndrome \\
\hline Murf-1 & Muscle ring finger-1 \\
\hline NCEP-ATP III & National Cholesterol Education Program Adult Treatment Panel \\
\hline NEFA & Non-esterified fatty acids \\
\hline NFT & Neurofibrillary tangles \\
\hline NMDA & n-methyl-d-aspartate \\
\hline NHANES & National Health and Nutrition Examination Survey \\
\hline NR4A3 & Nuclear receptor subfamily 4 group A member 3 \\
\hline PDK4 & Pyruvate dehydrogenase lipoamine kinase isozyme 4 \\
\hline PI3K & Phosphatidyilinositol 3-kinase \\
\hline PGC1 $\alpha$ & PPAR $\gamma$ coactivator alpha \\
\hline $\operatorname{PPAR} \delta$ & Peroxisome proliferator-activated receptor delta \\
\hline $\operatorname{PPAR} \gamma$ & Peroxisome proliferator-activated receptor gamma \\
\hline PTP1B & Protein tyrosine phosphatase $1 \mathrm{~B}$ \\
\hline $\mathrm{RR}$ & Relative risk \\
\hline SEM & Standard error of the mean \\
\hline $\mathrm{TNF} \alpha$ & Tumor necrosis factor alpha \\
\hline
\end{tabular}


VLDL

WHO
Very low density lipoprotein

World Health Organization 


\section{RESUMO}

Gonçalves NG. Síndrome metabólica e declínio cognitivo: papel do exercício físico [tese]. São Paulo: Faculdade de Medicina, Universidade de São Paulo; 2018.

Evidências disponíveis na literatura sugerem uma conexão entre ingestão de frutose, síndrome metabólica e declínio cognitivo. Na sociedade ocidental, o aumento de casos de síndrome metabólica ocorreu em paralelo ao aumento do consumo de excesso de frutose na dieta. Além disso, animais que consomem excesso de frutose em sua dieta apresentam alterações típicas de resistência à insulina em seus cérebros, além de desenvolverem declínio cognitivo. Sabe-se que exercício físico é capaz de prevenir atrofia do hipocampo e atenuar declínio cognitivo. O objetivo desse estudo foi avaliar se exercício aeróbico é capaz de prevenir o declínio cognitivo associado a um excesso de frutose na dieta e investigar os mecanismos pelos quais isso poderia ocorrer. Ratos Wistar machos foram divididos em quatro grupos: controle sedentário, exercício, frutose sedentário e frutose+exercício. A memória operacional foi testada através do labirinto de Barnes. A sinalização de insulina e de moléculas relacionadas ao exercício foram avaliados no hipocampo e no músculo quadríceps através de Western Blot e PCR em tempo real. A ingestão de excesso de frutose induziu declínio cognitivo que não foi atenuado pelo exercício. O hipocampo dos animais que ingeriram frutose não apresentou deficiência na sinalização de insulina, mas apresentou leve diminuição em BDNF e sinaptofisina, o que foi acompanhado de diminuição significativa da expressão de PGC1 $1 \alpha$ tanto no músculo quanto no hipocampo. O musculo quadríceps dos animais alimentados com frutose também mostrou uma diminuição significativa na expressão da miocina irisina (FNDC5) e de genes ligados à autofagia, ao transporte de glicose (GLUT4)

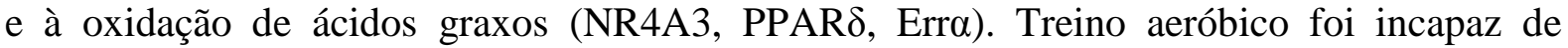
reverter todas essas alterações. Em contraste, tratamento metformina foi capaz de prevenir o 
declínio cognitivo de animais que ingeriram excesso de frutose. Podemos concluir que ingestão de frutose prejudicou a expressão de genes críticos à adaptação do músculo ao exercício e, como resultado, atenuou efeitos benéficos do exercício no cérebro. Tratamento com metformina preveniu a queda na expressão de FNDC5 e BDNF e, consequentemente, o declínio cognitivo em ratos alimentados com frutose através de uma ação direta no cérebro, apesar de não prevenir os efeitos deletérios da frutose no músculo esquelético.

Descritores: frutose; exercício físico; músculo esquelético; hipocampo; metformina; memória operacional; coativador 1-alfa do receptor gama ativado por proliferador de peroxissomo 


\begin{abstract}
Gonçalves NG. Metabolic syndrome and cognitive decline: role of physical exercise [thesis].São Paulo: “Faculdade de Medicina, Universidade de São Paulo”; 2018.
\end{abstract}

Available evidence in the literature suggests a link between fructose ingestion, Metabolic Syndrome and cognitive impairment. In Western society, the rise in the frequency of Metabolic Syndrome was paralleled by a rise in consumption of a high fructose diet. Moreover, molecular alterations typically related to insulin resistance have been found in brains of fructose-induced insulin-resistant rats, and these rodents also develop cognitive deterioration. Physical exercise is well known to prevent hippocampal atrophy and to attenuate cognitive decline. The objective of this study was to evaluate if aerobic training can ameliorate cognitive decline associated with excessive fructose ingestion and to investigate the pathways through which this might occur. Male Wistar rats were divided into four groups: sedentary control, exercise, sedentary fructose, fructose+exercise. Working memory was assessed on the Barnes Maze. Intracellular insulin and exercise-related signaling molecules of the hippocampus and quadriceps femori were assayed using Western blot and Real time PCR. Fructose ingestion induced cognitive decline which was not attenuated by exercise. Insulin signaling was not impaired in the hippocampus in the fructose-fed animals, but there was a slight decrease in BDNF and synaptophysin in the hippocampus, accompanied by a significant decrease in exercise-induced expression of PGC1 $\alpha$ both in the hippocampus and the muscle of exercised animals that ingested fructose. The quadriceps femori of fructose-fed animals also showed a significant decrease in expression of the myokine irisin (FNDC5) and of genes related to autophagy, glucose transport (GLUT4) and fatty acid oxidation (NR4A3, PPAR $\delta$, Err $\alpha$ ). Exercise training was unable to reverse all of these alterations. Contrarily, metformin administration ameliorated cognitive decline in fructose-fed rats. We conclude that fructose feeding impaired expression of genes that are 
critical to skeletal muscle adaptation to exercise, which in turn attenuated the beneficial effects of exercise in the brain. Treatment with metformin was able to prevent the decline in expression of FNDC5 and BDNF ameliorating cognitive decline in fructose fed rats by direct action in the brain, despite being unable to reverse the effects of fructose feeding in the muscle.

Descriptors: fructose; exercise training; muscle, skeletal; hippocampus; metformin; working memory; peroxisome proliferator-activated receptor gamma coactivator 1-alpha 

1 Introduction 


\section{Introduction}

\subsection{Background}

The contribution of chronic diseases in morbidity and mortality in most countries in the world experienced and will probably continue to experience a substantial and progressive rise in the next decade (1). As an illustration, chronic diseases were estimated to be responsible for more than $60 \%$ (35 million) of all deaths in low- and middle-income countries in 2005 (2). Among chronic diseases, a group - namely cardiovascular disease, diabetes, cancer and chronic respiratory disease - stand out. This group is estimated to account for $52 \%$ of all deaths in low and middle income countries in 2005 and this proportion will probably rise to $62 \%$ in 2030 , in the case of unchanged epidemiologic panorama (2). These diseases were not segregated in a group in an artificial manner. All of them have in common the fact that they are strongly associated to lifestyle or environmental factors and are not caused by infectious agents. Additionally, there is apparently an underlying pathophysiological bond among cardiovascular disease, diabetes and cancer, which is suggested by the association of central adiposity with elevated risk of type 2 Diabetes Mellitus (DM2), atherosclerosis progression and coronary heart disease. Thus, Metabolic Syndrome (MetS) - a condition characterized by the co-occurence of abdominal obesity, impaired glucose tolerance, atherogenic dyslipidemia and high blood pressure (Table 1) (3) might be the condition that unifies the great causes of morbidity and mortality in the world with a shared underlying pathophysiological background.

MetS is a major public health problem. Estimates using data from to the National Health and Nutrition Examination Survey (NHANES) from 1988 to 1994, the prevalence of MetS in the adult population was $23.7 \%$ when the definition of the National Cholesterol Education Program Adult Treatment Panel (NCEP-ATP III) was used and 25.1\% if one uses the World Health Organization (WHO) definition (4). It is worthy of note that about $25 \%$ of 
the United States population has MetS regardless how it is defined. Brazil is in no better condition: most surveys conducted in the Brazilian population point to a MetS frequency of about $30 \%$ (5-14) with extreme values of $19 \%$ in the urban population of Salvador, BA (13) and alarming 56.1\% among people residing in the city of São Paulo, SP (14) . This places MetS as one of the most prevalent conditions in our population.

Table 1. Criteria for definition of Metabolic Syndrome according to the International Diabetes Federation (IDF)

\begin{tabular}{|c|c|}
\hline \multicolumn{2}{|c|}{$\begin{array}{l}\text { According to the IDF definition, for a person to be defined as having the Metab } \\
\text { must have: } \\
\text { Central obesity (defined as waist circumference with ethnicity specific values) } \\
\text { Plus any two of the following four factors: }\end{array}$} \\
\hline Raised triglycerides & $\begin{array}{l}\geq 150 \mathrm{mg} / \mathrm{dL}(1.7 \mathrm{mmol} / \mathrm{L}) \text { or treatment for this } \\
\text { lipid abnormality }\end{array}$ \\
\hline Reduced HDL cholesterol & $\begin{array}{l}<40 \mathrm{mg} / \mathrm{dL}(1.03 \mathrm{mmol} / \mathrm{L}) \text { in males } \\
<50 \mathrm{mg} / \mathrm{dL}(1.29 \mathrm{mmol} / \mathrm{L}) \text { in females } \\
\text { or treatment for this lipid abnormality }\end{array}$ \\
\hline Raised blood pressure & $\begin{array}{l}\text { Systolic } \mathrm{BP} \geq 130 \mathrm{mmHg} \text { or diastolic } \mathrm{BP} \geq \\
85 \mathrm{mmHg} \text { or treatment for previously diagnosed } \\
\text { hypertension }\end{array}$ \\
\hline Raised fasting plasma glucose & $\begin{array}{l}\geq 100 \mathrm{mg} / \mathrm{dL}(5.6 \mathrm{mmol} / \mathrm{L}) \text { or previously } \\
\text { diagnosed type } 2 \text { diabetes }\end{array}$ \\
\hline
\end{tabular}

Modified from The IDF consensus worldwide definition of the Metabolic Syndrome (3)

The label of MetS brings important implications. A patient with MetS is an individual with high risk of developing DM2 (relative risk (RR) of 3.5 to 5.2, depending on which criterion is used, (15)) and that also presents high risk of adverse cardiovascular events (RR of 1.5 to 2 (16)). Although other clinical and laboratorial features are more efficient than presence or absence of MetS in the prediction of risk in developing cardiovascular events or DM2, the diagnosis of MetS allows for the identification of a subset of patients that present higher cardiometabolic risk due to a shared pathophysiology which also confers high risk for other chronic diseases (17). The MetS patients have a significantly higher risk of developing non-alcoholic fatty liver disease (18), cholelithiasis (19), obstructive sleep apnea (20), breast 
cancer in post-menopausal women (21), prostate cancer (22) and pancreatic adenocarcinoma (23). Even more, patients with MetS frequently exhibit endocrine and reproductive alterations compatible with polycystic ovary syndrome (24). These associations show that MetS is not limited to cardiometabolic risk and suggests that due to the shared underlying pathophysiological background, the correction of metabolic abnormalities of MetS has the potential to reduce the risk for other chronic diseases.

Recently, several lines of evidence have shown a connection between MetS and cognitive decline and dementia. Dementia is a phenotype caused by neuropathological processes that result in severe loss of cognitive function that interferes in a person's social and/or occupational activities $(25,26)$. The causes of dementia include neurodegenerative processes or vascular lesions such as multiple infarcts, subcortical ischemia or strategic infarction (27). Alzheimer`s disease (AD) is the most common cause of dementia in the elderly, being accountable for 50 to $70 \%$ of all cases (28). $\mathrm{AD}$ is a progressive neurodegenerative disease that affects mainly cerebral cortex, including the hippocampus, leading to cognitive decline, especially in memory and executive functions followed by complete dependence for care and death $(25,29,30)$. Dementia and AD may be considered typical diseases of the elderly. More than $33 \%$ of women and $20 \%$ of men aged 65 and over will eventually develop dementia (31) and the frequency of dementia increases exponentially from this age on. Interestingly, there is a parallel between the frequency of dementia and that of MetS as the prevalence of the latter also rises considerably from 60 years of age (32).

The coincidence between cognitive decline and MetS goes beyond the fact that both are more frequent in the elderly. Epidemiologic studies suggest that hypertension $(33,34)$, glucose intolerance (35), dyslipidemia (36), obesity (37) and central obesity (38) are associated with increased risk of cognitive decline. 
All of the alterations mentioned above are individual components of MetS. When MetS is examined in the light of cognitive decline, an estabilished diagnosis of MetS increased the risk of cognitive decline, especially if the patient showed high concentrations of inflammatory markers (interleukin 6 and C-reactive protein (36)). Similar results were found among Hispanic-American elderly (with high prevalence of MetS (39)) and among the Dutch (31) . It is worthy of note that both studies identify that the most important predictor of cognitive decline was the alteration in glucose metabolism (fasting hyperglycemia or DM). This fact suggests that insulin resistance - which, along with visceral adiposity, is one of the sine qua non conditions of MetS (17) - might be detrimental to cognition.

The two major neuropathological characteristics of $\mathrm{AD}$ are extracellular plaques of $\beta$ amyloid (A $\beta$ ) and intracellular neurofibrillary tangles (NFT) of hyperphosphorylated tau protein (29). The $\beta$ amyloid peptide results from cleavage of the amyloid precursor protein (APP). APP is cleaved by enzymes $\gamma$-secretase and $\alpha$-secretase, resulting in a fragment of 40 amino acids $\left(\mathrm{A} \beta_{1-40}\right)$ in the non-amyloidogenic pathway, or by enzymes $\gamma$-secretase and $\beta$ secretase, resulting in a neurotoxic fragment of 42 amino acids $\left(A \beta_{1-42}\right)$, in the amyloidogenic pathway (40). The major component of NFT is tau protein - a stabilizer of microtubules which is soluble under normal conditions. According to the amyloid cascade hypothesis the central event in $\mathrm{AD}$ is the imbalance between production and removal of the $\mathrm{A} \beta_{1-42}$ fragment in the brain, leading to insoluble plaques. Under toxic concentrations of $A \beta$, soluble monomers of tau protein aggregate and form NFTs. The accumulation of amyloid plaques as well as the formation of NFTs are deleterious to the structure and function of neurons, resulting in neuronal loss and clinical manifestations of $\operatorname{AD}(40,41)$.

AD shares many pathophysiological characteristics with DM2, including insulin resistance and glucose intolerance, oxidative stress, inflammation and amyloid aggregation in the pancreas (in DM2) or in the central nervous system (in AD) (42). These shared alterations 
suggest that the same pathways might be disrupted in both diseases. It is not yet clear if the insulin signaling disruption is the cause or the consequence of cognitive decline or if it just accompanies it. There is however evidence that insulin resistance in the central nervous system (CNS) and the cognitive deficit might be concurrent with the insulin resistance in peripheral tissues and that CNS insulin resistance has a major role in AD. Peripheral insulin resistance is frequent in $\mathrm{AD}$ patients (43) and the induction of peripheral insulin resistance in experimental animals attenuates the insulin receptor activation in the CNS $(44,45)$. Also, brain tissue of $\mathrm{AD}$ patients, even the non-diabetic ones, show resistance to both insulin and insulin-like growth factor 1 (IGF-1) (46). Finally, presence of peripheral insulin resistance is associated with increased accumulation of amyloid plaques in the brain (47).

Insulin signaling is important to neurite growth, myelinated fiber regeneration and neural plasticity (48). Thus it is expected that disruption in insulin signal transduction might lead to cognitive deficit. Several other mechanisms linked to insulin resistance might participate in the neurodegenerative processes of $\mathrm{AD}$ as well. Insulin binds to is receptor on the cell surface which induces phosphorylation of tyrosine residues in the intracellular moiety of the insulin receptor (IR) as well as the docking and phosphorylation of tyrosine residues of insulin receptor substrate 1 (IRS1). The most important consequence of IRS1 phosphorylation is the activation of the phosphatidylinositol 3-kinase (PI3K)/Protein kinase B (Akt/PKB) pathway (49). PI3K activates Akt through phosphorylation of its serine $473 \mathrm{e}$ threonine 308. Then, Akt phosphorylates many substrates, activating anti-apoptotic factors and inactivating pro-apoptotic factors in the neuron (50), increasing glucose metabolism, adenosine triphosphate (ATP) production, insulin degrading enzyme (IDE) activity and decreasing glycogen synthase kinase 3 (GSK3) activity (51). Additionally, PI3K/Akt pathway mediates glucose translocation from the extracellular to the intracellular space via translocation of glucose transporter 4 (GLUT4) to the cell surface and the inhibition of liver 
gluconeogenesis via phosphorylation and inhibition of transcription factor Forkhead box class $\mathrm{O}(\mathrm{FoxO}) 1(49)$.

One of the consequences of insulin resistance is the disruption of the PI3K/Akt pathway (52). Disruption in this pathway affects all ATP-dependent cellular processes and increases GSK3 activity (53). GSK3 is a serine-threonine kinase that has many substrate molecules, including glycogen synthase, tau protein, IRS1 and $\gamma$-secretase (54). GSK3 negatively regulates glycogen synthesis (51) and insulin signaling (54), increases tau protein phosphorylation leading to destabilization of axonal microtubules and NFT formation (53) and induces $A \beta_{1-42}$ accumulation as a consequence of increased $\gamma$-secretase activity (52). Increased activity of GSK3 is also implicated in neuronal death (55). Therefore, the PI3K/Akt pathway disruption might promote the accumulation of amyloid plaques and NFTs.

The role of insulin resistance in the AD pathogenesis is not limited to its potential involvement in the promotion of aggregation of $A \beta_{1-42}$ and NFTs. Insulin as well as IGF-1 protect neurons from the synaptotoxic effects of soluble $\mathrm{A} \beta$ oligomers, also known as amyloid beta-derived diffusible ligands (ADDLs) (56). ADDLs are capable of binding to sites located at specific synapses. Once bound, ADDL inhibits long term potentiation (a classical paradigm of synaptic mechanisms related to memory), induces hyperphosphorylation of tau, oxidative stress, deterioration of synapses, loss of synaptic spines and loss of IR in the neuron surface (57). The protective action of insulin against ADDL effects requires an intact IR tyrosine kinase activity (57). As expected, this protective effect is diminished in both insulin and IGF-1 resistance (56).

In addition to the negative impact of insulin resistance in the integrity and function of neurons, cognitive decline in MetS could result from the low grade chronic inflammation that accompanies central obesity (58). Activation of inflammatory signaling by tumor necrosis factor alpha (TNF $\alpha)$ results in phosphorylation of serines 636 and 639 of IRS-1 by both c-Jun 
$\mathrm{N}$-terminal kinase (JNK) and inhibitor of NF- $\mathrm{B}$ kinase (IKK) (59) - a phenomenon typically associated with peripheral insulin resistance (60). Increased levels of TNF $\alpha$ are also directly correlated to cognitive decline $(61,62)$, probably due to JNK induced neuronal apoptosis $(63,64)$.

\subsection{Skeletal Muscle and Metabolic Syndrome}

The skeletal muscle has a major role in both metabolic health and the genesis of Metabolic Syndrome. Rodents fed with a sucrose and lipid-rich diet present insulin resistance in skeletal muscle before presenting increased body adiposity or increased adipocyte size in abdominal fat (65). Additionally, skeletal muscle insulin resistance is a characteristic feature in DM2 patients (65). The association between skeletal muscle insulin sensitivity and metabolic health is not a coincidence. Skeletal muscle is the major site of glucose uptake in the organism (66). The skeletal muscle represents about $40 \%$ of body mass in a healthy adult, is responsible for approximately $30 \%$ of resting metabolic rate and $80 \%$ of insulinstimulated glucose uptake. These figures show the critical role of the skeletal muscle in the regulation of glucose and metabolic homeostasis (67).

Skeletal muscle is unique among insulin-sensitive organs as it can improve its insulin sensitivity through voluntary contraction (physical exercise) - its typical function. Indeed, both animal and human studies show that exercise improves insulin sensitivity (68). Beyond that, there is a well-documented inverse relationship between physical activity and risk of developing chronic diseases, including obesity, MetS and DM2 $(69,70)$. For this reason, the study of the contraction-dependent molecular and cellular alterations in the regulation of skeletal muscle insulin sensitivity is fundamental to understanding MetS and DM2 pathophysiology. 
The bulk of knowledge about the link of exercise and insulin sensitivity comes from acute exercise in animal models. Acute exercise increases insulin sensitivity, induces IR and IRS1 tyrosine phosphorylation and decreases protein tyrosine phosphatase 1B (PTP1B) activity, IRS1 serine phosphorylation and inflammatory signalization in skeletal muscle of diet-induced obese rats (71). The benefits of acute exercise only last 48 hours (72). Additionally, protein post-translational modifications and changes in abundance derived from acute exercise may cease with repeated physical activity despite persisting insulin sensitivity (72). Chronic exercise training promotes mitochondrial biogenesis, angiogenesis, muscle fiber-type switch and improves insulin sensitivity $(73,74)$ through the activation of PGC1 $\alpha$ and several transcription factors, including Erra, PPAR $\delta$, NR4A3 and FoxO3A (75) (Fig 1). These alterations improve metabolic homeostasis and therefore are considered the mediators of exercise training benefits.

Exercise also activates autophagy in several tissues. Autophagy is a self-degradative process activated in response to an energy stress or during critical moments in the development to provide cells with an alternative energy source. Autophagy has also a role in removal of misfolded or aggregated proteins, damaged organelles and intracellular pathogens (76). The term autophagy comprises three different processes all of which involve sequestration and proteolytic degradation of cytoplasmic components at lysosomes: macroautophagy, micro-autophagy and chaperone-mediated autophagy. Macro-autophagy is the most well-known form of autophagy and involves the formation of a double membrane vesicle containing the structure targeted to degradation and the fusion of this vesicle to the lysosome, while in micro-autophagy and in chaperone-mediated autophagy the material that will undergo proteolytic degradation is- respectively, delivered directly to the lysosome by lysosomal invagination or by mechanism that involves chaperone proteins (76). Autophagy 


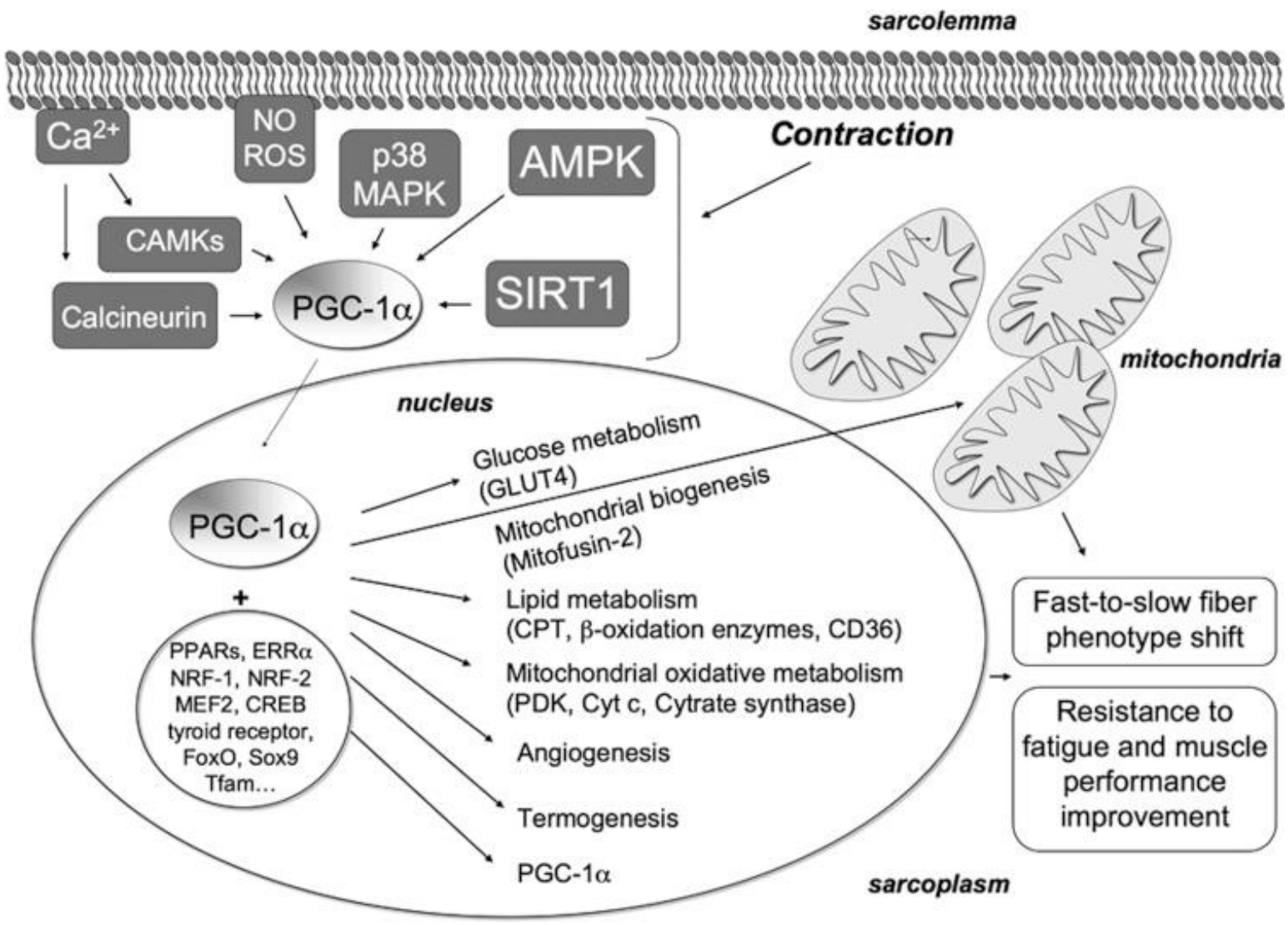

Figure 1. Signaling pathways activated by muscle contraction. Instracellular sensors transduce the mechanical, energetic and oxidative stresses generated by muscle contraction and induce transcription of PGC1 $\alpha$. PGC1 $\alpha$ then co-activates several transcription factors including Err $\alpha$, PPAR $\delta$, NR4A3 and FoxO3A. This results in adaptive resposes which include enhanced glucose and lipid metabolism, mitochondrial biogenesis and muscle fiber switch. Figure from Ferraro et al, 2004 (75).

is frequently used as synonym for macro-autophagy (as we will do throughout in this thesis). Autophagy can be induced in in skeletal and cardiac muscles (77), liver, pancreatic $\beta$ cells, adipose tissue and brain (78) in response to acute exercise. Autophagy can also occur independently of exercise induction, (basal autophagy) and functions as a housekeeping mechanism cleaning celss of dysfunctional molecules and organelles, maintaining cell homeostasis. More than 30 autophagy-related genes (Atg) have been described. The proteins encoded by Atg genes form different complexes during the various steps of the autophagy 
process (75), which include the formation of the autophagosome (autophagic vacuole) - a double membrane vesicle that engulfs the structure targeted to degradation - which will then fuse to lysosomes, allowing defective organelles and proteins to be digested by lysosomal hydrolases (75) (Fig 2). Autophagy also enhances survival during nutritional stress imposed by decreased nutrients, therefore turning the degraded intracellular material an alternative source of energy (75). Defective autophagic response to exercise results in defective translocation of GLUT4 in skeletal muscle, decreased muscle 5' adenosine monophosphateactivated protein kinase (AMPK) activation, glucose uptake and insulin sensitivity (77). Mice with defective acute autophagic response to exercise are glucose intolerant - an alteration that is not corrected by exercise training (77). Voluntary chronic exercise training increases basal autophagy in skeletal muscle and the integrity of this response is required for exercise training-induced muscle remodeling (79). The maintenance of skeletal muscle mass and the preservation of myofiber integrity depend on the balance between protein synthesis and protein degradation. Along with autophagy, the ubiquitin-proteasome activity is another proteolytic process that mediates protein degradation in cells. Activation of mTORC2 during exercise prevents protein degradation by phosphorylating and inhibiting fokhead box (FoxO) class of transcription factors which, in turn, prevents activation of both muscle ring finger protein - 1 (Murf-1) and atrogin/muscle atrophy f-box (MAFBx), two E3 ubiquitin ligases, which promote the ubiquitination and the proteasome-mediated degradation of critical sarcomeric proteins (75). Dephosphorylated FoxOs migrate into the nucleus and activate transcription of genes that control muscle mass and autophagy including Murf-1, MAFBx, beclin, LC3 and Atg 12, creating a fine balance between protein synthesis and protein degradation (75) (Fig 2). 
The data presented above show the importance of skeletal muscle adaptation to exercise training in metabolic health and suggest that interference in the muscle remodeling response to exercise training may be a mechanism through which metabolic diseases emerge.

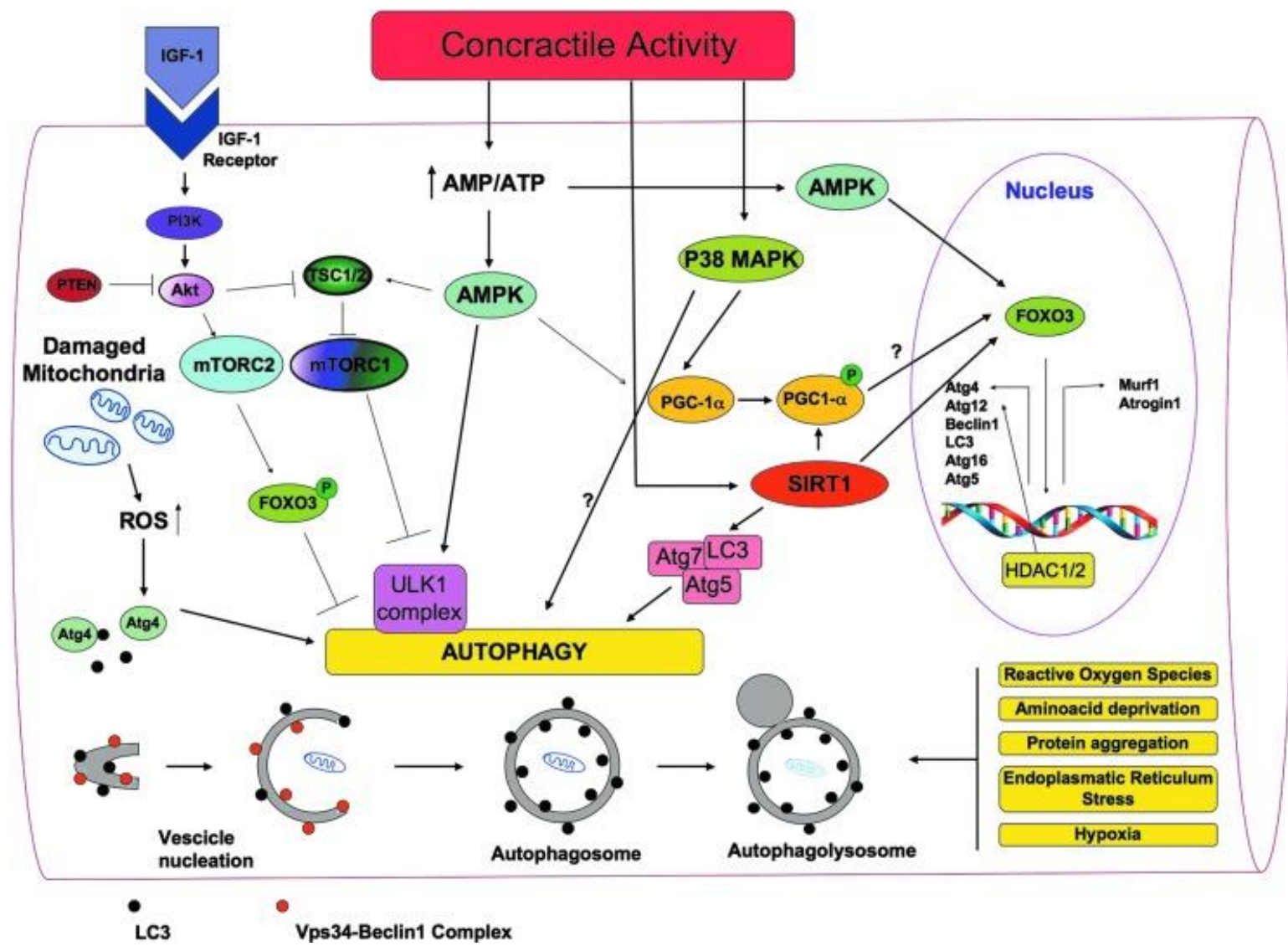

Figure 2. Exercise-induced activation of autophagy. Autophagy is a multi-step process in which damaged proteins and organelles are enveloped into autophagosomes. The autophagosome formation requires interaction of several proteins, including beclin, Atg5, Atg7, Atg9, Atg12 and LC3. The autophagosome is then fused with the lysosome, becoming autophagolysosome. The sequestered organelles and proteins are then digested by lysosomal hydrolases. Damaged proteins are also recycled via the ubiquitin-proteasome activity. Activation FoxO3 leads to increased activity of E3 ligases Murf-1 and MAFBx (Atrogin-1), which in turn promote the ubiquitination and proteasome-mediated degradation of damaged sarcomeric proteins. On the other hand, exercise-induced activation of mTORC2 inhibits cytoplasmic FoxO, and consequently Murf-1 and MAFBx, preventing excessive degradation of proteins, keeping the fine balance between protein synthesis and protein degradation. Figure from Ferraro et al, 2004 (75). 


\subsection{Fructose metabolism and Metabolic Syndrome}

In Western society, the rise in MetS frequency was paralleled by a rise in consumption of a high fructose diet $(80,81)$. Excess fructose in the diet has long been known to induce MetS in rodents, causing metabolic changes including insulin resistance $(82,83)$, hepatic stress response and dyslipidemia (83-85). Notably these alterations are also observed in humans exposed to high fructose beverages, such as soft drinks (86, 87). Additionally, long-term fructose feeding decreases leptin levels and the adipose tissue lipid storing capacity (88) and even impairs the ability of the muscle to restore glycogen reserve after fasting or exercise (89).

To understand the origin of such alterations, one must first understand how fructose is metabolized. The liver is the major site of fructose metabolism which breaks fructose down into

metabolic intermediates that enter promptly the triose pool in a process that bypasses the phosphofructokinase rate-limiting step in glycolysis. The expansion of triose phosphate pool is responsible for metabolic adaptations to acute fructose load while the responses to long-term load will depend on enzymatic adaptation (90).

The metabolic consequences of fructose loading depends on the feeding status. In the liver of fructose-fed animals, the increase in the flux through glycolytic pathway leads to lactate production, activation of pyruvate dehydrogenase and enhancement of oxidative pathway with carbon dioxide and ketone body production (90). This metabolic environment also favors esterification of non-esterified fatty acids (NEFAs) augmenting the liver production and secretion of very low density lipoprotein (VLDL) (90) (Fig. 3). In starved animals, activation of gluconeogenesis enzymes leads to formation of glucose from fructose (90). Long-term load of fructose causes the liver to form more glucose and glycogen from fructose and respond more intensely to the actions of fructose in promoting VLDL output. 
In adipose tissue, fructose impairs both glucose utilization and esterification of fatty acids. This raises NEFAs concentration and increases VLDL production. Increased concentration of triglyceride and NEFAs impair glucose utilization in skeletal muscle (90). The consequence is increased insulin resistance, hyperinsulinemia and formation of a vicious cycle in which insulin resistance will stimulate the already increased VLDL production by the liver. Thus chronic fructose feeding will produce metabolic derangement similar to that found in MetS. 


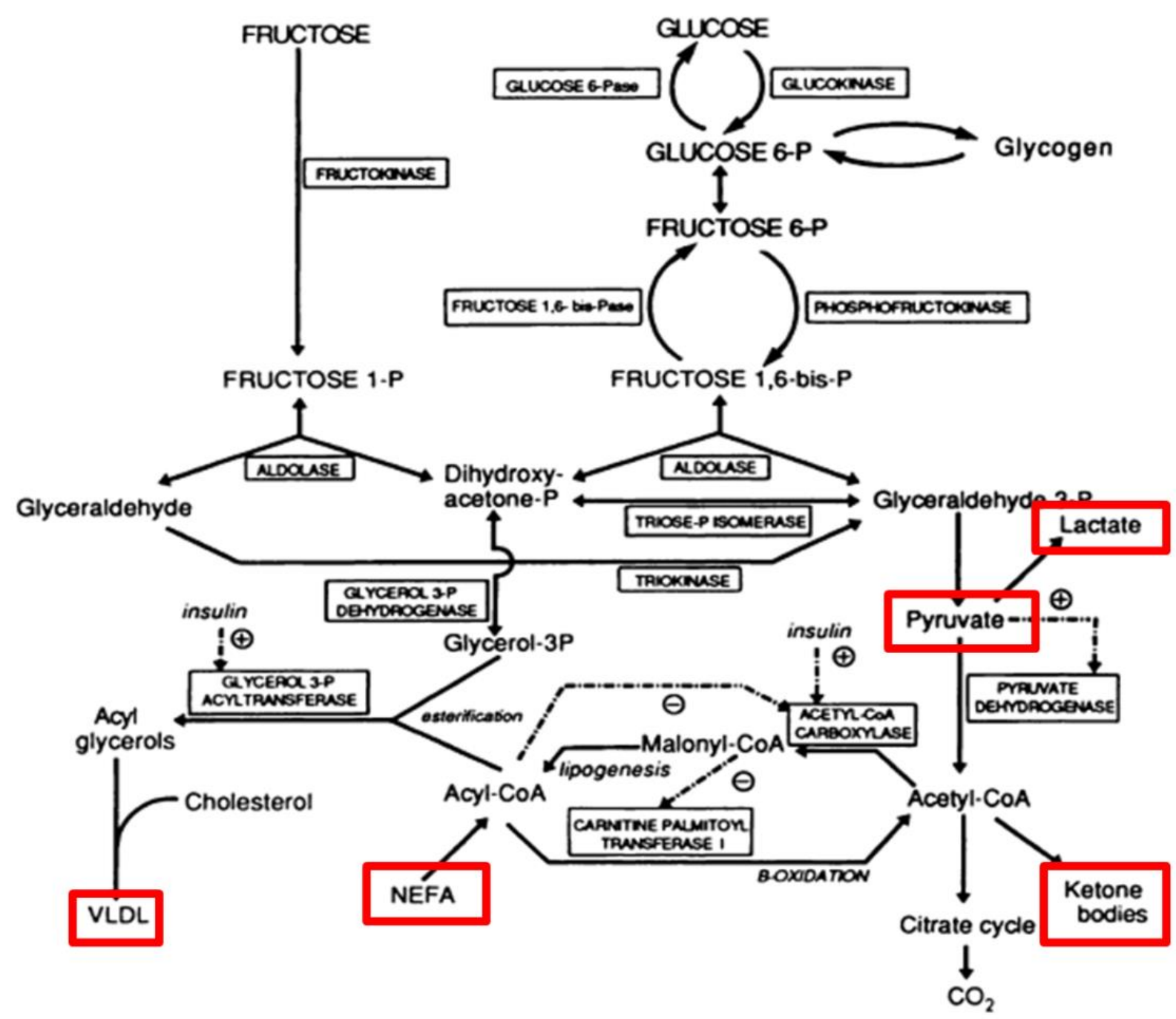

Figure 3. Fructose and glucose metabolism. The liver is the major site of fructose metabolism which breaks fructose down into metabolic intermediates that enter promptly the triose pool in a process that bypasses the phosphofructokinase rate-limiting step in glycolysis. This leads to enhanced production of lactate and pyruvate and the activations of oxidative pathway with the formation of ketone bodies. This metabolic environment also favors the production of non-esterified fatty acids (NEFAs) and the production and secretion of very low density lipoprotein. Modified from Mayes, PA, 1993 (90). 


\subsection{Role of fructose in cognitive decline}

Several lines of evidence have shown that the negative effects of fructose load are not limited to peripheral tissues, but also occur in the central nervous system (CNS), being a risk factor to cognitive decline and dementia (91).

Based on existing evidence, the pathophysiology underlining the cognitive decline linked to a fructose-rich diet can be summarized into two general pathways:

1. Insulin resistance. The brain was once considered an insulin-insensitive organ, but it is now estabilished that insulin plays an important role in several areas of the brain, including the hippocampus. Insulin action is required neuronal survival, synaptic plasticity, learning and memory (92) (Fig. 4). Nutritionally induced insulin resistance significantly affects the neural insulin signaling pathway (44), decreasing brain-derived neurotrophic factor (BDNF) protein expression and dendritic spine density (93), which is accompanied by decreased phosphorylation of cAMP response element-binding protein (CREB) and synapsin and synaptophysin levels in fructose-fed rats (94). In this model, improvement of insulin resistance by dietary supplementation of $n-3$ fatty acid is paralleled by amelioration of deficiency in BDNF, synapsis and synaptophysin concentrations and in CREB phosphorylation (94), suggesting that brain insulin resistance may contribute to cognitive impairment.

2. Hypertriglyceridemia. The n-methyl-d-aspartate (NMDA) receptor is the predominant receptor for controlling synaptic plasticity and memory function (95). For the receptor to be activated, both glutamate and glycine must bind to it, which in turn, opens the ionic channel and allow the entry of $\mathrm{Na}+$ and $\mathrm{Ca} 2+$ ions to enter the post-synaptic neuron. This, in turn, results in depolarization of the neuron (96) which is important for various forms of synaptic plasticity, including long-term potentiation and for hippocampal-dependent spatial learning 
and memory (97) (Fig 4). High levels of triglyceride induced by excess of fructose in the diet impair NMDA-mediated maintenance of hippocampal long-term synaptic potentiation and induces oxidative stress in the brain (98), causing cognitive decline in both humans (99) and rodents (98). Lowering triglycerides can reverse the cognitive impairment in the brain by also reducing oxidative stress (98).

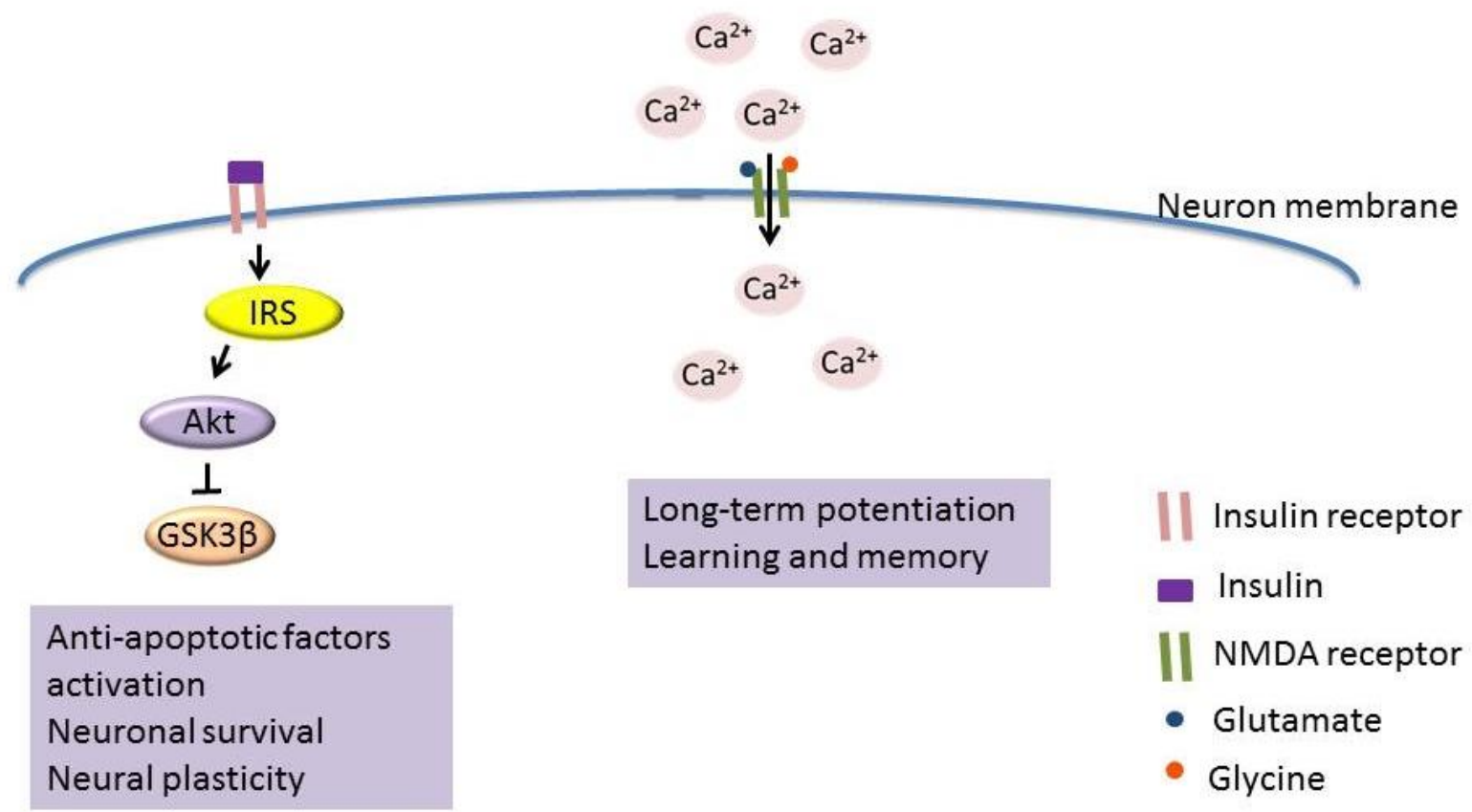

Figure 4. Insulin- and NMDA-signaling in the neuron. Insulin binds to its cognate receptor on the neuron cell surface, leading to the activation of IRS and the PI3K-Akt pathway. This in turn, promotes neuronal survival, activates anti-apoptotic factors and inactivates GSK3 $\beta$, preventing the phosphorylation and destabilization of microtulubes. Glutamate and glycine bind to the NMDA receptor, opening the ionic channel and allowing the entry of positive ions in the neuron. This leads to long-term potentiation and learning and memory. Figure by Natalia Gomes Gonçalves.

Exercise has the ability to improve multiple aspects of MetS (100-102) and to reduce high fat diet-induced cognitive decline (103), but its effects in fructose-induced cognitive decline are not known. Given that athletes and the general public often consume energy 
drinks and other beverages that contain substantial amounts of fructose (104-106), it is important to investigate this issue. Therefore we designed this study to investigate if ingestion of fructose can impair working memory and the mechanisms by which this might occur and if exercise can prevent these effects. 
2 Aims and Objectives 


\section{Aims and Objectives}

In view of the known positive effects of exercise in memory, learning, insulin sensitivity and metabolic syndrome, the objectives of this study are:

1. To evaluate if physical training is can reverse experimental insulin resistance caused by fructose ingestion associated cognitive decline;

2. To verify if the improvement of cognitive function is a result of enhanced insulin sensitivity, diminished inflammation activity or another mechanism.

In order to achieve these aims, rats were be submitted to a protocol of inductions of metabolic syndrome. Animals' memory was be evaluated with cognitive testing in the Barnes Maze and intracellular signaling molecules from hippocampus were be assessed for insulin resistance and inflammatory pathways by Western Blot and Real Time PCR, as discussed in the next session. 
3 Methods 


\section{Methods}

\subsection{Animals}

Eight week old male Wistar rats were used in this study. They were kept in cages with 4-5 animals under a 12h light/dark cycle. Animals were randomly assigned into the following groups:

1. Control (C) - rats did not undergo exercise training, fructose feeding or metformin treatment

2. Exercise (E) - rats underwent exercise training, but not fructose feeding or metformin treatment

3. Frutose (F) - rats were given standard chow $(2990 \mathrm{kcal} / \mathrm{kg})$ as a solid diet and a $15 \%$ fructose solution was given as drinking solution but did not undergo exercise training or metformin treatment.

4. Fructose+Exercise (FE) - rats were given standard chow $(2990 \mathrm{kcal} / \mathrm{kg})$ as a solid diet and a $15 \%$ fructose solution was given as drinking solution. Additionally they underwent exercise training but not metformin treatment.

5. Fructose+Metformin (FM) - rats were given standard chow $(2990 \mathrm{kcal} / \mathrm{kg})$ as a solid diet and a $15 \%$ fructose solution was given as drinking solution. They also received metformin in the drinking water $(500 \mathrm{mg} / \mathrm{kg} /$ day) $(107)$. These rats did not undergo exercise training.

All animals underwent 8 weeks of experimental treatment. Animals in the exercise/fructose protocol were trained in the Barnes maze for 5 days after the 8 weeks of the protocol. The test in the maze occurred $48 \mathrm{~h}$ after the last training session. Twenty-four hours after the test their tissues were harvested (Fig.5A). Animals in the metformin/fructose protocol were trained in the Barnes maze for 5 days in the week before the beginning of the 
experimental protocol. In the first day of experimental protocol animals were tested in the Barnes Maze which was followed by the beginning of the metformin/fructose treatment. Animals were tested in the maze every 2 weeks during treatment until 8 weeks of treatment, after which there was tissue collection (Fig.5B).

This study was approved by the Ethics Committee of University of São Paulo School of Medicine under the number 073/13 and all animal experiments were performed according to procedures approved at our institution.

\subsection{Treadmill exercise protocol}

Rats were initially adapted to the treadmill (KT 400, Imbramed, RS, Brasil, Fig. 6) for 3 days $(10 \mathrm{~min} /$ day, $0,3 \mathrm{~km} / \mathrm{h})$. After that, a maximal exercise capacity test was performed with an initial velocity of $0,3 \mathrm{~km} / \mathrm{h}$ for 5 minutes followed by an increase of $0,1 \mathrm{~km} / \mathrm{h}$ every 1,5min until animal exhaustion. Total test time, velocity and distance were recorded for each rat. Rats were trained at moderate intensity (60\% of maximal velocity) for $60 \mathrm{~min} /$ day, 5 days a week for 8 weeks. After 8 weeks, the maximal exercise capacity test was repeated. Aerobic training began the same day as the beginning of the fructose diet (Fig. 6). No electrical shock was applied to the animals during all the protocol.

\subsection{Barnes Maze}

All animals were trained in the Barnes Maze (108) with Poucet's modification (109) in order to evaluate working memory (110).

The apparatus consisted of a circular platform, $115 \mathrm{~cm}$ diameter with 18 equallyspaced circular holes $8 \mathrm{~cm}$ in diameter. A dark escape box was located beneath one of the holes. The start box was an open-ended cylinder $30 \mathrm{~cm}$ in diameter located in the center of the 
platform. Extra-maze clues were placed around the room (Fig. 7). A video camera was positioned $1,60 \mathrm{~m}$ above the maze.

A

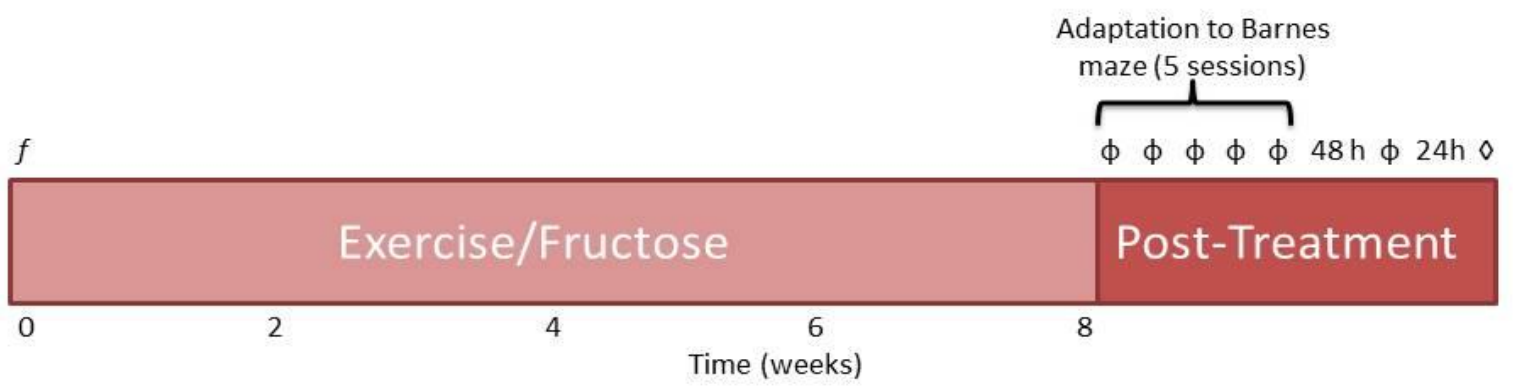

B

Adaptation to Barnes

maze ( 5 sessions)

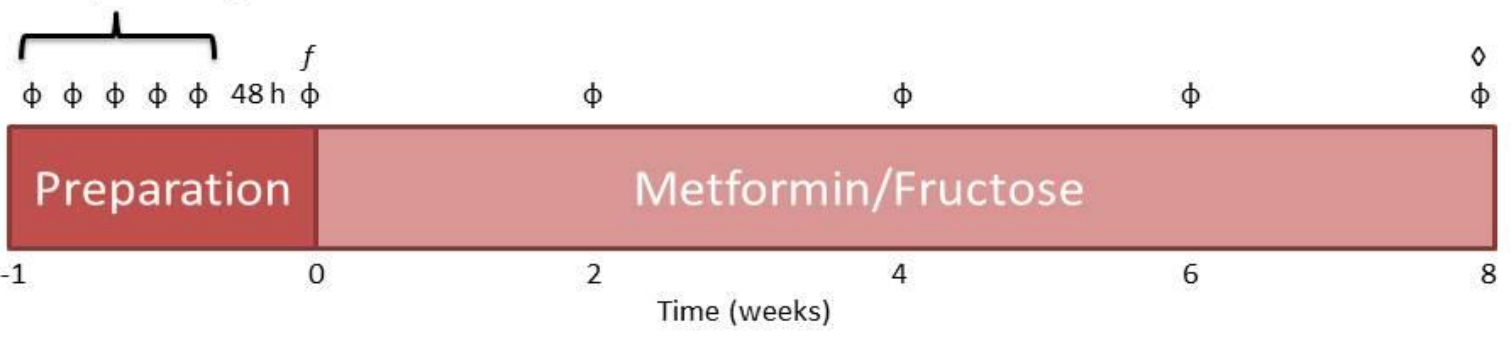

$\phi:$ Barnes maze

$f:$ First day of treatment

$\diamond:$ Tissue collection for molecular studies

Figure 5. Overview of the experimental protocol. A. Animals were trained in the Barnes maze for 5 days after the 8 weeks of exercise/fructose protocol and $48 \mathrm{~h}$ after the last training session. $24 \mathrm{~h}$ after the test there was tissue collection. B. Animals were trained in the Barnes maze for 5 days in the week before the beginning of the experimental protocol. In the first day of experimental protocol animals were tested in the Barnes Maze which was followed by the beginning of the metformin/fructose treatment. Animals were tested in the maze every 2 weeks during treatment until 8 weeks of treatment, after which there was tissue collection. Figure by Camila Vega and Chin Jia Lin. 


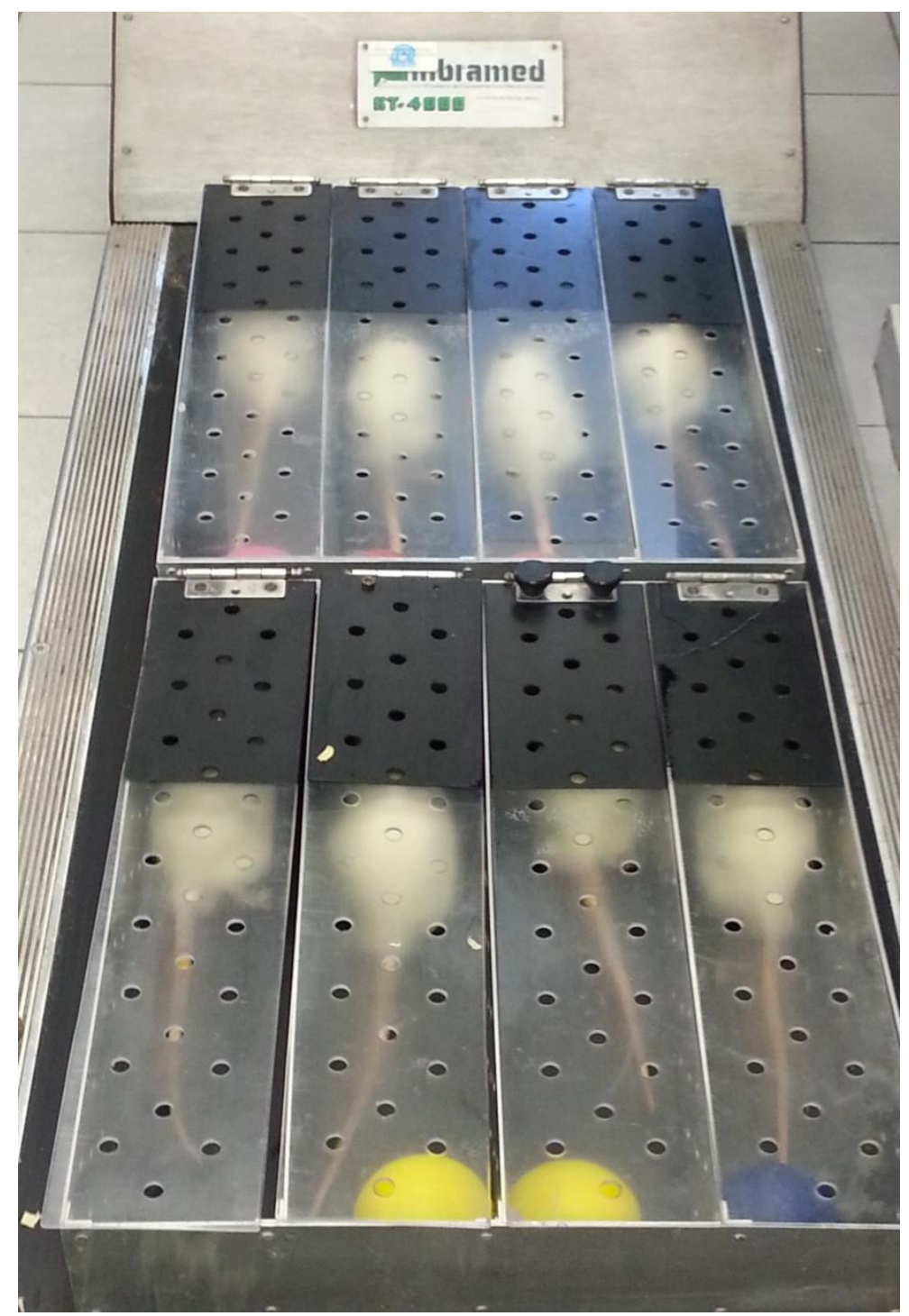

Figure 6. Treadmill exercise training. Picture: Natalia Gomes Gonçalves.

For the behavioral procedures, animals were trained to locate the escape box for 5 days after 8 weeks of the exercise/fructose protocol (Fig. 5A) or animals were trained to locate the escape box for 5 days in the week before the beginning of the metformin/fructose protocol and every 2 weeks during the experimental protocol until 8 weeks of treatment (Fig. 5B). The location of the escape box was arbitrarily chosen for the first day of trial. Afterward, before the trials of subsequent days, the escape box was randomly relocated to a new position which was used in all trials of that day. On the first day of the maze, the rats were free to explore the maze for 4 minutes and then they were put inside the escape box for $1 \mathrm{~min}$. No 
data were collected in the first day. On the other 5 days animals were given 2 trials a day with $1 \mathrm{~h}$ interval between trials. In the first trial (acquisition) the animal learned the location of the escape box that day. The second trial (test) was given 1 hour after the first to evaluate the retention of the memory. In both acquisition and test, the trial began with positioning the animal inside the start box which was placed at the center of the maze. After 30s the animal was released and allowed to explore the maze to look for the escape box. An aversive noise was played during the time the animal was exploring the maze and was turned off as soon as the trial ended. The trial ended when the animal found the escape box or if the animal did not find the box after a pre-determined time ( $3 \mathrm{~min})$. The parameters used to evaluate retention of memory were number of errors (number of nose pokes in holes that did not contain the escape box), distance and time to locate the escape box. Image analysis was performed with Tracker, version 4.8 (111).

\subsection{Tissue collection and Biochemical analysis}

After 8 weeks, 7 or 8 rats of each group were fasted overnight and anaesthetised $(75 \mathrm{mg} / \mathrm{km}$ ketamine $+10 \mathrm{mg} / \mathrm{kg}$ xilazine, i.p.). Blood was collected by cardiac puncture and centrifuged at $5000 \mathrm{rpm}$ at $4{ }^{\circ} \mathrm{C}$ to obtain serum samples. After the blood collection, the rats were decapitated and hippocampus and quadriceps muscle were dissected, preserved in RNAlater (Ambion) and stored at $-80^{\circ} \mathrm{C}$ until use.

Serum insulin levels were measured with an ELISA kit (Millipore) as per manufacturer's instructions. Serum triglyceride and glucose levels were measured by enzymatic colorimetric assay in the Cobas c111 analyzer (Roche). 


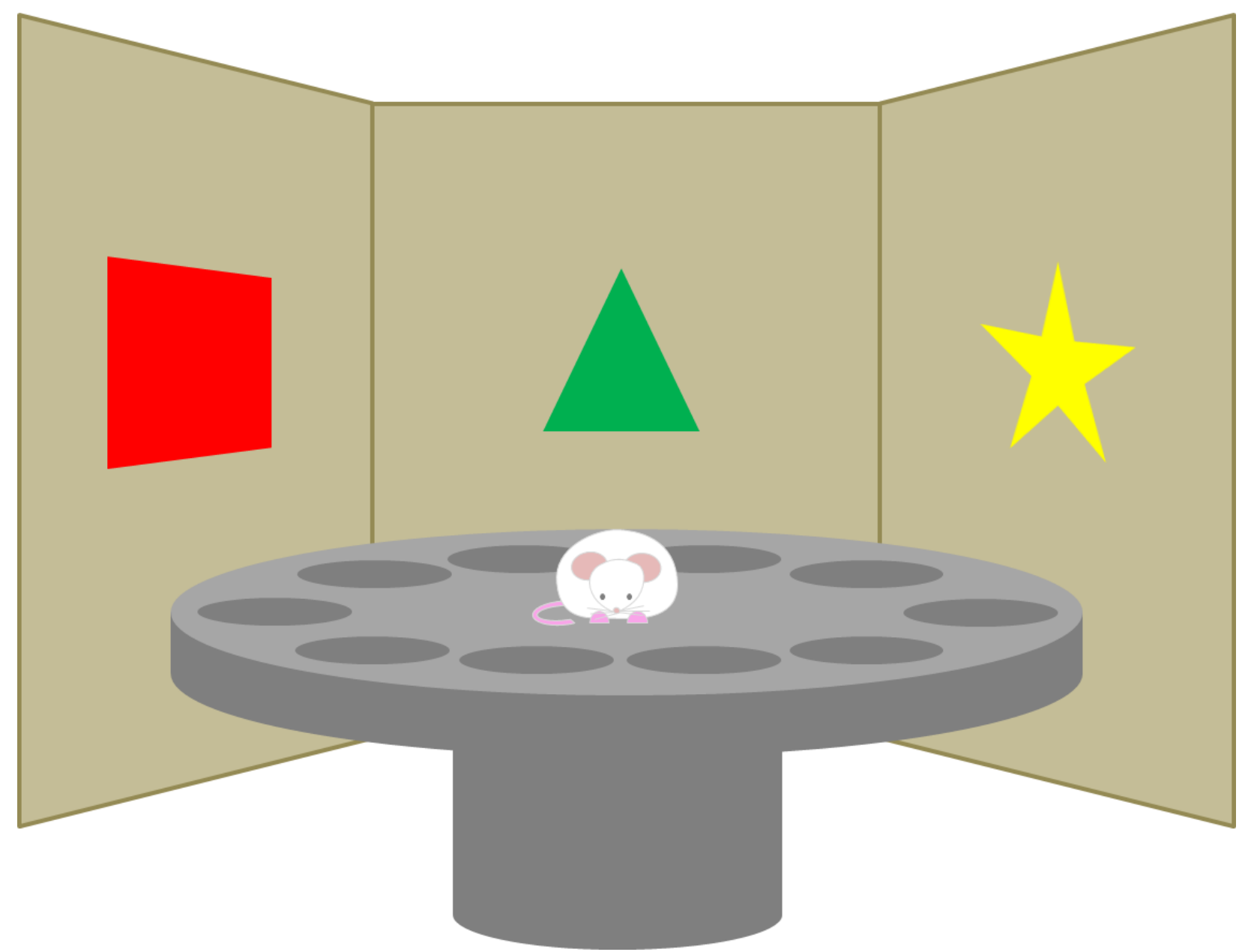

Figure 7. Barnes Maze. The apparatus consisted of a circular platform, $115 \mathrm{~cm}$ diameter with 18 equally-spaced circular holes $8 \mathrm{~cm}$ in diameter. A dark escape box was located beneath one of the holes (its position was arbitrarily chosen for the day). Animals were given 2 trials a day with $1 \mathrm{~h}$ interval between trials. In the first trial (acquisition) the animal learned the location of the escape box that day. The second trial (test) was given 1 hour after the first to evaluate the retention of the memory. In both acquisition and test, the trial began with positioning the animal inside the start box which was placed at the center of the maze. After 30s the animal was released and allowed to explore the maze to look for the escape box. An aversive noise was played during the time the animal was exploring the maze and was turned off as soon as the trial ended. The trial ended when the animal found the escape box or if the animal did not find the box after a pre-determined time ( 3 min). Figure by Larissa Langhi. 
We used the HOMA2 model $(112,113)$ to evaluate insulin resistance (HOMA-IR), pancreatic beta cell reserve (HOMA-\%B) and insulin sensitivity (HOMA-\%S). The indexes were calculated with the Oxford HOMA calculator (114).

\subsection{RNA extraction and gene expression analysis}

Total RNA from hippocampus and quadriceps was obtained with Tri Reagent (Invitrogen) as per manufacturer's instructions. RNA was then treated with DNaseI for 20-30 min at $37^{\circ} \mathrm{C}$ for genomic DNA removal. RNA was reversely transcribed into DNA with a commercial kit (High Capacity cDNA Reverse Transcription Kit, ABI) as per manufacturer's instructions. Gene expression analysis was performed using Quantitative Real Time Polimerase Chain Reaction in assay buffer which contains EvaGreen fluorescent dye (Solis BioDyne, Tartu, Estonia) using the primers listed in Table 2. Relative gene expression was calculated using procedures reported previously (115). A sample collected from an untreated control was used as a calibrator in all Real Time PCR quantification experiments.

\subsection{Protein extraction and Western Blot}

After 8 weeks, 5 rats of each group were anaesthesised and the abdominal cavity was opened. Insulin $\left(10^{-6} \mathrm{~mol} / \mathrm{L}\right.$ in saline $)$ was injected in the portal vein and after $90 \mathrm{~s}$ rats were decapitated and hippocampus was collected for Western Blot analysis. Hippocampus was homogenized with ceramic beads in the Precellys homogenizer (Bertin) in RIPA buffer (150mM NaCl, 50mM Tris- $\mathrm{HCl} \mathrm{pH} 8.0,1 \% \mathrm{NP}-40,0,5 \%$ sodium deoxicholate, $0,1 \% \mathrm{SDS}$ ) containing protease and phosphatase inhibitors (Protease Inhibitor Cocktail Tablets and PhosSTOP Phosphate Inhibitor Cocktail Tablets, Roche) at $4^{\circ} \mathrm{C}$. The resulting solution was then centrifuged at $12000 \mathrm{rpm}$ for $20 \mathrm{~min}$ at $4^{\circ} \mathrm{C}$. Supernatant was used for protein quantification with a colorimetric method (660nm Protein Assay Reagent, Pierce). Proteins were denatured 
in Laemmli buffer, run on SDS-PAGE and transferred to PVDF membranes. PVDF membranes were blocked for $1 \mathrm{~h}$ in $5 \%$ BSA, probed in primary antibody overnight and secondary antibody for $2 \mathrm{~h}$. Blots were revealed by chemiluminescence (ECL reagent, Pierce) in the GE ImageQuant equipment. Antibodies used to probe the membranes were: $\alpha$-tubulin, IRS-1 pS ${ }^{616}$, IRS-1 $\mathrm{pS}^{312}$ from Invitrogen; BDNF, insulin-receptor $\beta$, IRS-1, GSK-3 $\beta$, GSK$3 \beta \mathrm{pY}^{216}$ from Santa Cruz; synaptophysin from Millipore; Akt and pAkt from Cell Signaling. Secondary antibodies used were anti-mouse (Invitrogen) and anti-rabbit (Pierce).

\subsection{Statistical analysis}

All data are presented as mean \pm standard error of the mean (SEM). Normality of samples was assessed with Shapiro-Wilk test. Homocesdasticity (homogeneity of variances) was assessed with Fligner-Killeen test. Since there was no violation of normality or homogeneity of variances, no transformation of original data was necessary. Multi-group comparisons were performed using two-way ANOVA for the Barnes Maze test or ANOVA with Tukey post hoc test for the other experiments. $\mathrm{p}<0.05$ was considered statistically significant. 
Table 2. Primer pairs used in Real Time PCR experiments

\begin{tabular}{|c|c|c|c|c|c|}
\hline & Forward & $\mathbf{T m}^{\circ}$ & Reverse & $\mathbf{T m}^{\circ}$ & NCBI Reference Sequence \\
\hline Atg7 & GCTCCTCACTTTTTGCCAACA & 60.6 & GGAGCCACCACATCATTGC & 62.3 & NM_001012097.1 \\
\hline Atg9 & AATGTGGTGCCAAGGTGATTT & 58.7 & CAGTTTGACACTGAATACCAGCG & 62.8 & NM_001014218.1 \\
\hline $\operatorname{Atg} 12$ & CACCACTGCACCTGCCTCCATTTTTAACTC & 67.5 & ATGGCACACATGGCTGAGGACTACTCTG & 69 & NM_001038495.1 \\
\hline BDNF & TGGCCCTGCGGAGGCTAAGT & 72.1 & AGGGTGCTTCCGAGCCTTCCT & 71.3 & NM_001270638.1 \\
\hline Beclin & TGAATGAGGGCGACAGTGAACA & 62.7 & GCATCTGGTTCTCTACACTCTTG & 62.8 & NM_053739.2 \\
\hline Bnip3 & TTCCACTAGTACCTTTTGATGA & 57.1 & GAACACCGCATTTACAAAACAA & 57.1 & NM_053420.3 \\
\hline CAMK IV & AGGAGACCTCCAGTATGGTGC & 64.5 & CTCCTCAGTCATGGGGTCCAT & 64.5 & NM_012727.3 \\
\hline CPT1a & TCTTGCAGTCGACTCACCTT & 60.4 & TCCACAGGACACATAGTCAGG & 62.6 & NM_031559.2 \\
\hline $\mathrm{CS}$ & GATTGTGCCCAATGTCCTCT & 60.4 & TTCATCTCCGTCATGCCATA & 58.4 & NM_130755.1 \\
\hline Ctsl & CTATCGCCACCAGAAGCACA & 62.4 & AACCACACTGGCCCTGATTC & 62.4 & NM_013156.2 \\
\hline CypA & CTTCTTGCTGGTCTTGCCATTCC & 64.6 & TATCTGCACTGCCAAGACTGAGTG & 64.6 & NM_017101.1 \\
\hline ERR $\alpha$ & GCAGGGCAGTGGGAAGCTA & 64.5 & ССТCTTGAAGAAGGCTTTGCA & 60.6 & NM_001008511.2 \\
\hline FNDC5 & ATGAAGGAGATGGGGAGGAA & 60.4 & GCGGCAGAAGAGAGCTATGACA & 64.5 & NM_001270981.1 \\
\hline FoxO3A & GCAAGCCGTGTACCGTGGA & 64.5 & CGGGAGCGCGATGTTATCT & 62.3 & NM_001106395.1 \\
\hline GLUT4 & GCAGCGAGTGACTGGAACA & 62.3 & CCAGCCACGTTGCATTGTAG & 62.4 & NM_012751.1 \\
\hline Lamp2 & CATATAAGAACTTCCCAGAGGAGCAT & 63 & TGGCTCAGCTTTCCTTGTTTC & 60.6 & NM_017068.2 \\
\hline LC3 & AGTGCTGTCCCGAATGTCTC & 62.4 & CGTCCTGGACAAGACCAAGT & 62.4 & NM_022867.2 \\
\hline MAFBx & TGGGTGTATCGAATGGAGAC & 60.4 & TCAGCCTCTGCATGATGTTC & 60.4 & NM_133521.1 \\
\hline Murf-1 & CTTCGTGTTCCTTGCACATC & 60.4 & ACCTGCTGGTGGAGAACATC & 62.4 & NM_080903.1 \\
\hline NR4A3 & TCAGCCTTTTTGGAGCTGTT & 58.4 & TGAAGTCGATGCAGGACAAG & 60.4 & NM_031628.1 \\
\hline PGC1 $1 \alpha 1$ & GGACATGTGCAGCCAAGACTCT & 64.5 & CACTTCAATCCACCCAGAAAGCT & 62.8 & NM_031347.1 \\
\hline PPAR $\delta$ & CTCCTGCTCACTGACAGATG & 62.4 & TCTCCTCCTGTGGCTGTTC & 62.3 & NM_013141.2 \\
\hline
\end{tabular}


4 Results 


\section{Results}

\subsection{Body weight and metabolic profile}

The animals were weighted before the exercise/metformin/fructose protocols started (week 0) and after 8 weeks of the protocols. There was no statistical difference among groups in pre-treatment weight $\left(\mathrm{F}_{3,72}=0.54, \mathrm{p}=0.658\right)$. In the $8^{\text {th }}$ week, there was a statistically significant difference in group $\mathrm{E}$ compared to groups $\mathrm{C}$ and $\mathrm{FE}\left(\mathrm{F}_{3,37}=5.24, \mathrm{p}=0.005\right)$ (Table $3)$.

There was a slight increase in serum triglyceride levels in the F and FE groups, but that did not reach significance $\left(\mathrm{F}_{3,22}=2.040, \mathrm{p}=0.135\right)$. There were also no differences among groups in glucose $\left(\mathrm{F}_{3,22}=1.000 \mathrm{p}=0.411\right)$ and insulin $\left(\mathrm{F}_{3,22}=0.290, \mathrm{p}=0.835\right)$ serum levels. Also, there were no significant differences in HOMA-IR $\left(\mathrm{F}_{3,22}=0.940, \mathrm{p}=0.436\right)$, HOMA-\%S $\left(\mathrm{F}_{3,22}=0.650, \mathrm{p}=0.588\right)$ and HOMA-\% $\mathrm{B}\left(\mathrm{F}_{3,22}=0.000, \mathrm{p}=1.000\right)($ Table 3$)$.

Table 3. Metabolic profile of animals 8 weeks after experimental treatment

\begin{tabular}{|c|c|c|c|c|c|c|c|}
\hline & $\begin{array}{l}\text { \%Body } \\
\text { weight } \\
\text { gain }\end{array}$ & $\begin{array}{l}\text { Glucose } \\
(\mathrm{mg} / \mathrm{dL})\end{array}$ & $\begin{array}{l}\text { Triglyceride } \\
(\mathrm{mg} / \mathrm{dL})\end{array}$ & $\begin{array}{l}\text { Insulin } \\
(\mathrm{mUI} / \mathrm{mL})\end{array}$ & HOMA2-IR & HOMA2-\%B & HOMA2-\%S \\
\hline C (7) & $\begin{array}{l}74.35 \quad \pm \\
5.23\end{array}$ & $\begin{array}{l}168.43 \pm \\
8.06\end{array}$ & $46.01 \pm 6.42$ & $17.13 \pm 0.44$ & $2.51 \pm 0.06$ & $53.19 \pm 4.02$ & $40.17 \pm 1.07$ \\
\hline E (8) & $\begin{array}{l}58.55 \pm \\
5.54^{*}\end{array}$ & $\begin{array}{l}160.29 \pm \\
5.93\end{array}$ & $41.05 \pm 1.49$ & $17.31 \pm 0.49$ & $2.54 \pm 0.09$ & $52.75 \pm 2.80$ & $39.8 \pm 1.47$ \\
\hline F (7) & $\begin{array}{l}82.89 \pm \\
4.75\end{array}$ & $\begin{array}{l}191.14 \quad \pm \\
19.49\end{array}$ & $52.3 \pm 6.45$ & $18.13 \pm 0.77$ & $2.82 \pm 0.17$ & $53.28 \pm 8.77$ & $36.68 \pm 2.33$ \\
\hline $\begin{array}{l}\text { FE } \\
\text { (7) }\end{array}$ & $\begin{array}{l}111.90 \pm \\
6.85\end{array}$ & $\begin{array}{l}166.86 \pm \\
5.87\end{array}$ & $62.76 \pm 5.40$ & $17.36 \pm 0.92$ & $2.54 \pm 0.13$ & $53.20 \pm 2.32$ & $40.33 \pm 2.06$ \\
\hline
\end{tabular}

Animals in group E gained significantly less weight than the other groups. There was no significant difference among groups in the other parameters. Results are presented as mean \pm SEM. The numbers in parenthesis represent the number of animals included in the experiment. $* \mathrm{p}<0.010$ 


\subsection{Effect of Exercise in Physical Fitness}

In the initial maximal exercise capacity test, there was no statistical difference in velocity between groups $\left(\mathrm{F}_{3,59}=1.47, \mathrm{p}=0.234\right)$. After 8 weeks of treadmill training, groups $\mathrm{E}$ and FE were both able to run significantly faster than the non-trained groups $\mathrm{C}$ and $\mathrm{F}$ $(\mathrm{F} 3,24=37.24, \mathrm{p}<0.001)$ and to reach higher velocities than they did during the initial test $(\mathrm{E}$ : $\mathrm{p}=0.047$; FE: $\mathrm{p}=0.001$ ). Interestingly, non-trained animals performed poorer in the final test relative to the initial test $(\mathrm{C}: \mathrm{p}=0.001 ; \mathrm{F}: \mathrm{p}=0.035$, Fig. $8 \mathrm{~A})$.

The same trend is seen both in duration and distance. For duration, there was no difference among groups in the initial test $(\mathrm{F} 3,24=0.59, \mathrm{p}=0.660)$. After 8 weeks of treadmill training, groups $\mathrm{E}$ and $\mathrm{FE}$ were capable of running at maximal velocity for longer time than the non-trained groups $\mathrm{C}$ and $\mathrm{F}(\mathrm{F} 3,24=58.66, \mathrm{p}<0.001)$ and also than themselves at their own initial test (E: $\mathrm{p}<0.001 ; \mathrm{FE}: \mathrm{p}=0.001)$. Non-trained animals performed poorer in the final test relative to the initial test $(\mathrm{C}: \mathrm{p}=0.003 ; \mathrm{F}: \mathrm{p}=0.008$, Fig. $8 \mathrm{~B})$. For distance, there was no statistical difference among groups in the initial test $(\mathrm{F} 3,24=2.28, \mathrm{p}=0.090)$. After 8 weeks of treadmill training, the distance groups $\mathrm{E}$ and FE were capable of running at maximal velocity was significantly longer than the non-trained groups $C$ and $F(F 3,24=42.34, p<0.001)$ and also than their own initial test $(E: p<0.001 ; F E: p<0.001)$. Again, non-trained animals performed poorer in the final test relative to the initial test $(\mathrm{C}: \mathrm{p}=0.005 ; \mathrm{F}: \mathrm{p}=0.009$, Fig. 8C). 

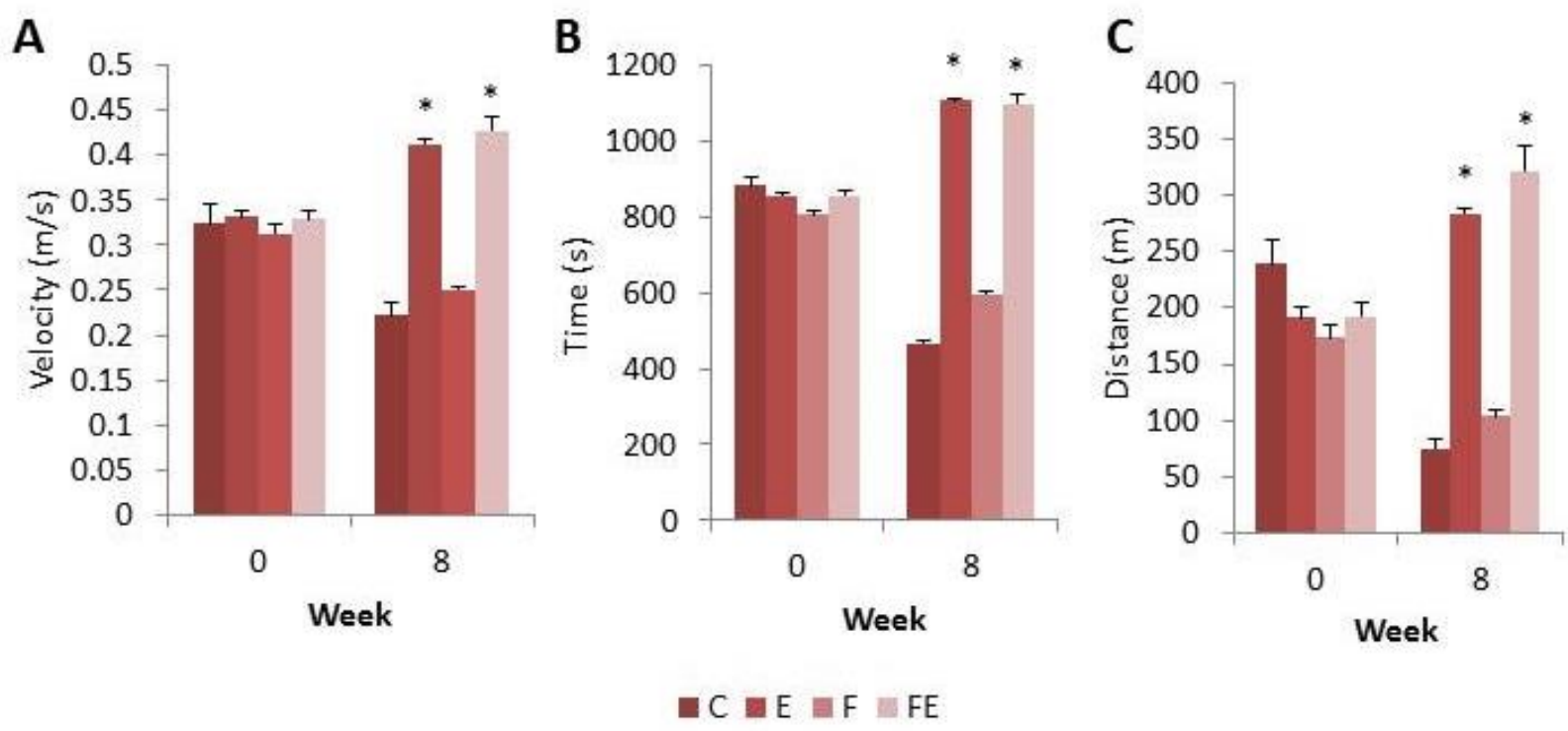

Figure 8. Maximal exercise capacity test. A. Velocity. After 8 weeks of treadmill training, both group E and FE were able to run significantly faster than the untrained groups C and F. B. Time. After 8 weeks of treadmill training, groups $\mathrm{E}$ and $\mathrm{FE}$ were capable of running at maximal velocity for longer time than the untrained littermates (groups C and F, respectively). C. Distance. After 8 weeks of treadmill training, the distance groups E and FE were capable of running at maximal velocity was significantly longer than their untrained counterparts (groups $\mathrm{C}$ and F). Groups: C - control, E - exercise, F - fructose, FE - fructose+exercise Results are presented as mean \pm SEM.. $* \mathrm{p}<0.001$.

\subsection{Barnes Maze}

Animals were subjected to the Barnes Maze to assess the working memory performance. Testing took place for 5 days after the 8 weeks of exercise/fructose protocol each animal was tested twice on the same day with an interval of $1 \mathrm{~h}$ between trials. The escape box was placed in a different location each day. Number of errors an animal made before entering the box, distance it traveled and time it took to locate the escape box were recorded.

Figure 9 shows that there was no difference among groups before the exercise/fructose protocol (day 1; latency: $\mathrm{F}_{3,31}=1.70, \mathrm{p}=0.190 ;$ distance: $\mathrm{F}_{2,53}=1.650$, $\mathrm{p}=0.200$; number of errors $\mathrm{F}_{2,53}=2.160 \mathrm{p}=0.115$ ), but along the weeks the $\mathrm{F}$ and $\mathrm{FE}$ groups 
performed poorer than the $\mathrm{C}$ and $\mathrm{E}$ groups. Indeed, two-way ANOVA showed an effect of day and group in latency to find the escape box (day: $p<0.001$, group: $p<0.001$ ) and post-hoc test showed that $\mathrm{F}$ and $\mathrm{FE}$ groups performance was significantly worse than the $\mathrm{C}$ and $\mathrm{E}$ groups in day $4(\mathrm{p}=0.006)$ and the $\mathrm{F}$ group performed significantly poorer than the other three groups in day $5(\mathrm{p}<0.001)$ (Fig. 9A). The two other tested parameters followed a similar trend with two-way ANOVA indicating an effect of day and group in distance (day: $p=0.028$, group: $\mathrm{p}<0.001$ ) and number of errors (day: $\mathrm{p}=0.006$, group: $\mathrm{p}<0.001$ ). Post-hoc test showed $\mathrm{F}$ and $\mathrm{FE}$ groups traveled significantly longer distances than the $\mathrm{C}$ and $\mathrm{E}$ groups in days 4 $(\mathrm{p}=0.014)$ and $5(\mathrm{p}=0.006)$ (Fig. 9B). The $\mathrm{F}$ and FE groups also had significantly higher number of errors than $\mathrm{C}$ and $\mathrm{E}$ groups in day $4(\mathrm{p}=0.008)$ and the $\mathrm{F}$ group had significantly higher number of errors than the other groups in day $5(\mathrm{p}<0.001)$ (Fig. 9C). These results suggest that fructose induces cognitive decline in working memory and that it is not prevented by exercise.

\subsection{Fructose does not impair insulin signaling in the hippocampus}

Brain insulin resistance has often been reported to be the cause of cognitive decline observed in Alzheimer`s and metabolic diseases (44, 46, 57, 116). Therefore, we investigated the effect of fructose in the insulin pathway in the hippocampus. There was no significant inter-group difference in $\operatorname{IR}\left(\mathrm{F}_{3,13}=1.04, \mathrm{p}=0.419\right), \operatorname{IRS}-1\left(\mathrm{~F}_{3,15}=2.22, \mathrm{p}=0.144\right)$, IRS-1 $\mathrm{p}^{\mathrm{S} 312}$ $\left(\mathrm{F}_{3,14}=0.74, \mathrm{p}=0.550, \operatorname{IRS}-1 \mathrm{p}^{\mathrm{S} 616}\left(\mathrm{~F}_{3,15}=1.54, \mathrm{p}=0.260\right)(\right.$ Fig. 10$)$, Akt $\left(\mathrm{F}_{3,15}=0.99, \mathrm{p}=0.435\right)$, Akt $\mathrm{p}^{\mathrm{S} 473}\left(\mathrm{~F}_{3,12}=0.93, \mathrm{p}=0.470\right)$, GSK3 $\beta\left(\mathrm{F}_{3,17}=2.68, \mathrm{p}=0.090\right)$ and $\mathrm{GSK} 3 \beta \mathrm{p}^{\mathrm{S} 216}\left(\mathrm{~F}_{3,18}=1.39\right.$, $\mathrm{p}=0.287$ ) (Fig. 11), suggesting that the fructose load did not cause deficiency in insulin signaling. 

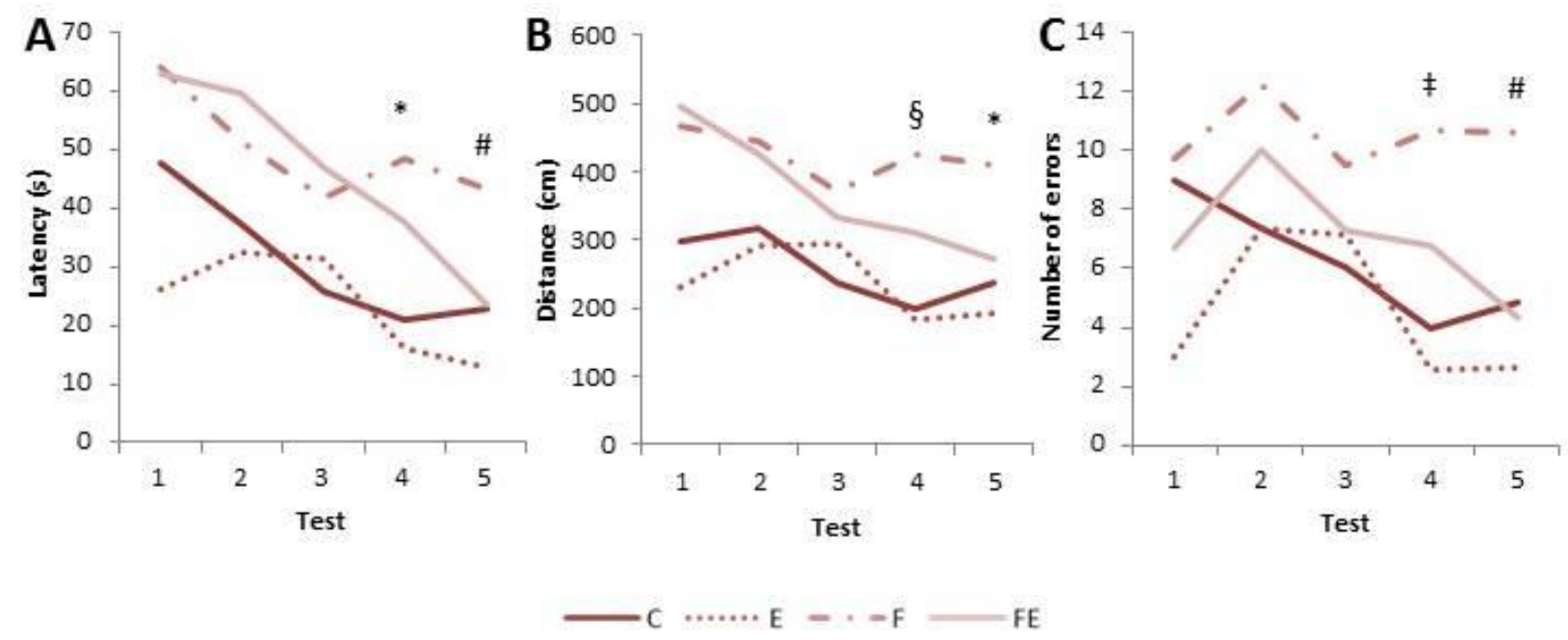

Figure 9. Evaluation of working memory in the Barnes Maze test. A. Latency. F and FE groups took longer to find the escape box than the $\mathrm{C}$ and $\mathrm{E}$ groups in day 4 and the $\mathrm{F}$ group performed significantly poorer than the other three groups in day 5. B. Traveled distance before entering the escape box. F and FE groups traveled significantly longer distances than the $\mathrm{C}$ and $\mathrm{E}$ groups in days 4 and 5. C. Number of errors before entering the escape box. F and FE groups had significantly higher number of errors than $\mathrm{C}$ and $\mathrm{E}$ groups in day 4 and the F group had significantly higher number of errors than the other groups in day 5. Groups: $\mathrm{C}-$ control, $\mathrm{E}-$ exercise, F - fructose, FE - fructose+exercise. The symbols above the curves indicate statistical significance; *: $p=0.006, F+F E \times C+E ; \#: p<0.001, F \times F+C+E ; \S: p<0,02, F+F E \times C+E ;+: p=0.008, F+F E \times C+E$.

\subsection{Effect of fructose in accumulation of markers of brain plasticity}

BDNF is induced in many parts of the brain with exercise, more vigorously in the hippocampus (117). BDNF promotes neurogenesis, synaptogenesis and plasticity, which are critical to learning and memory $(48,118,119)$. We sought to investigate how fructose affects protein expression of BDNF and synaptophysin, a marker of synapse growth. There was a slight increase in both BDNF and synaptophysin in the exercise group compared to the other groups, but that did not reach statistical significance. It is also worthy of note that both the levels of BDNF and synaptophysin remain as low in the fructose+exercise group as in the untrained groups (BDNF: $F_{3,18}=0.86, p=0.485$; synaptophysin: $F_{3,17}=0.78, p=0.527$ ) (Fig. 12). 

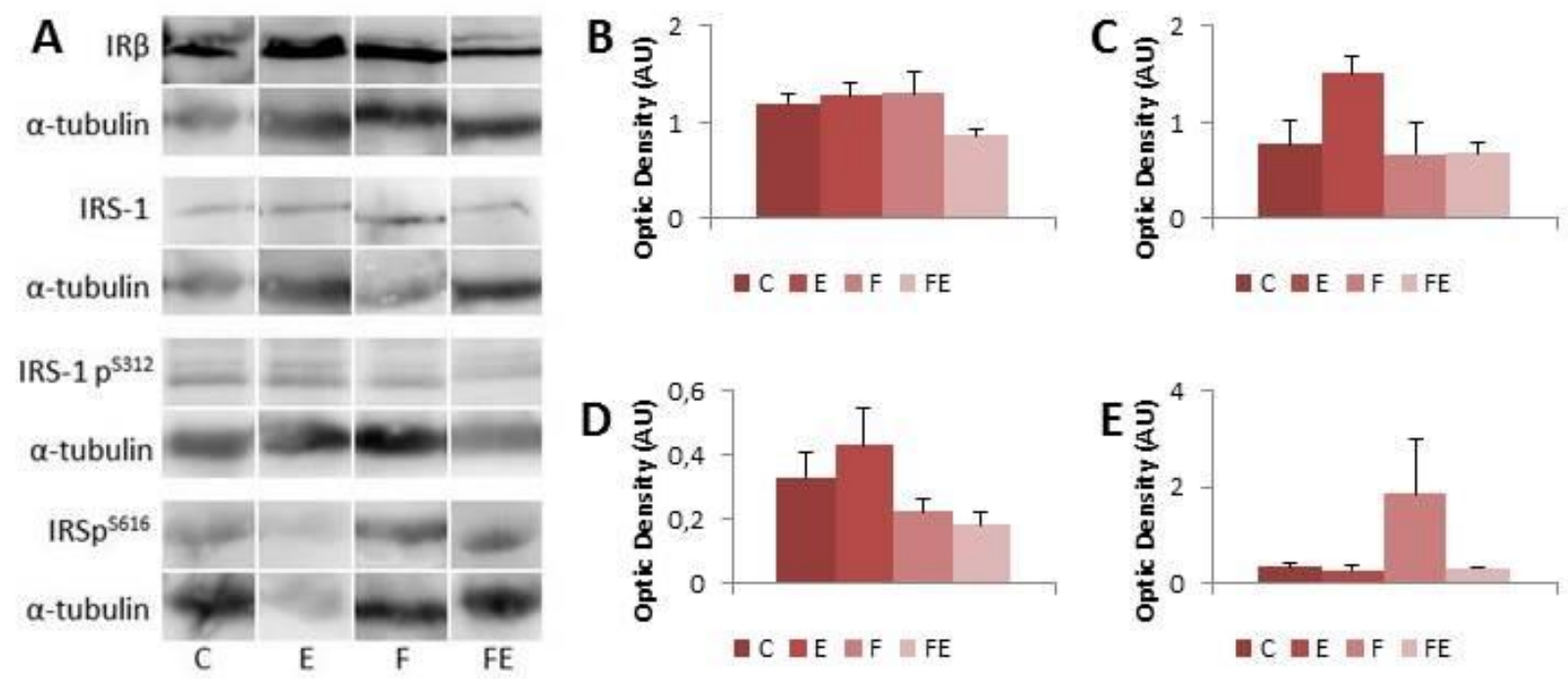

Figure 10. Effect of fructose on accumulation of IR and IRS protein in hippocampus. A. Representative

Western Blots. B. IR protein levels. C. IRS protein levels. D. IRS-1 $\mathrm{p}^{\mathrm{S312}}$ protein levels. E. IRS-1 $\mathrm{p}^{\mathrm{S616}}$ protein levels. Groups: C - control, E - exercise, F - fructose, FE - fructose+exercise. Results are presented as mean \pm SEM. There was no significant difference among groups.
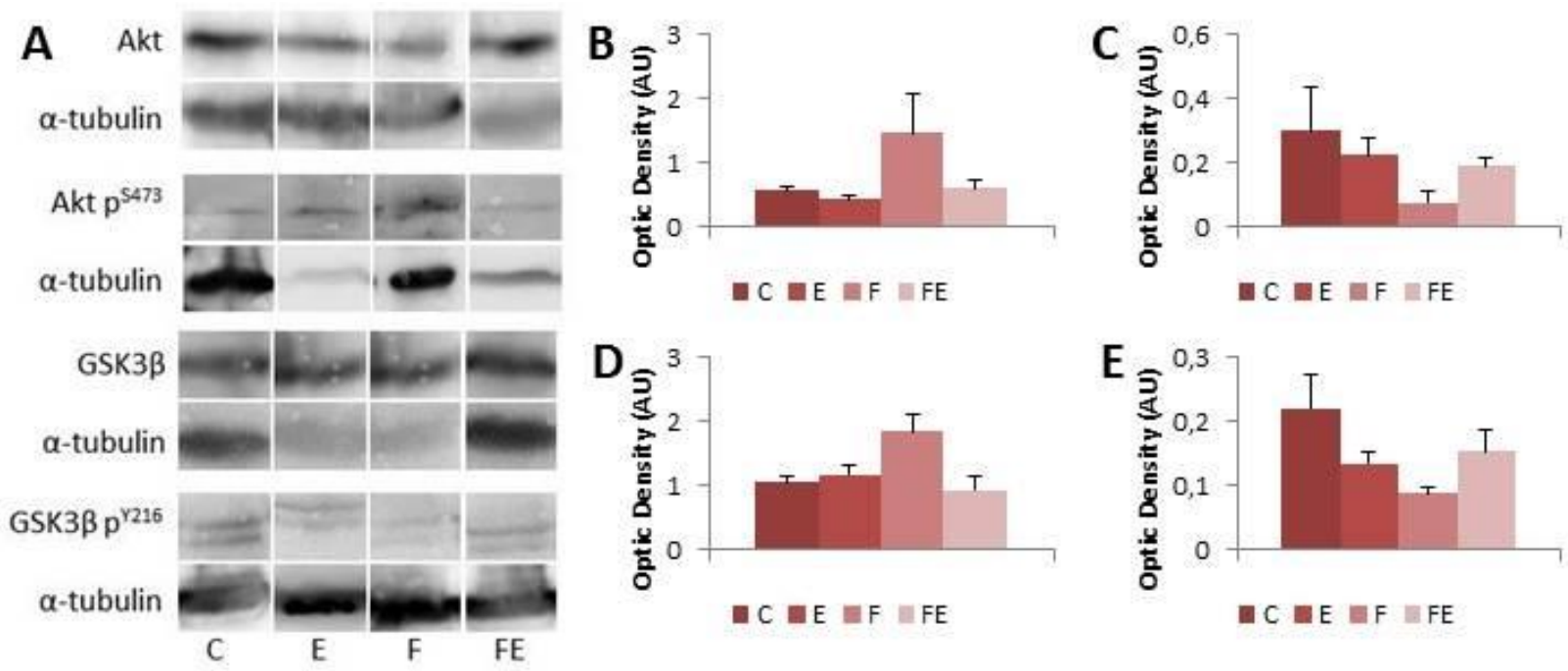

Figure 11. Effect of fructose on Akt and GSK3ß protein concentration in hippocampus. A. Representative

Western Blots. B. Akt protein levels. C. Akt $\mathrm{p}^{\text {S473 }}$ protein levels. D. GSK3 $\beta$ protein levels. E. GSK3 $\beta$ p ${ }^{\text {S216 }}$ protein levels. Groups: C - control, E - exercise, F - fructose, FE - fructose+exercise. Results are presented as mean \pm SEM. There was no significant difference among groups. 

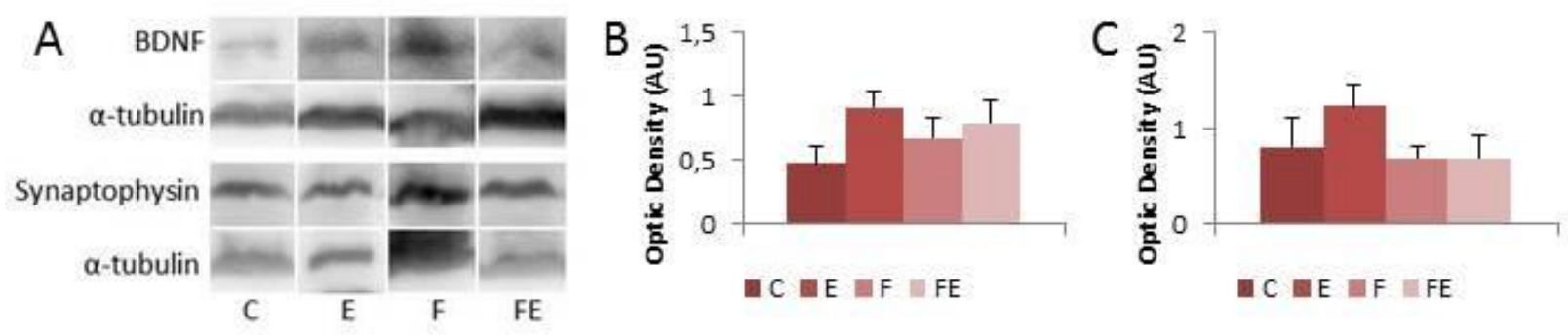

Figure 12. Effect of fructose on BDNF and synaptophysin protein content in hippocampus. A. Representative Western Blots. B. BDNF protein levels. C. Synaptophysin protein levels. Groups: C - control, E - exercise, $\mathrm{F}$ - fructose, $\mathrm{FE}$ - fructose+exercise. Results are presented as mean $\pm \mathrm{SEM}$. There was no significant difference among groups.

\subsection{Fructose attenuates expression of PGC1 $\alpha$ and FNDC5}

Exercise is known to increase expression of peroxisome proliferator-activated receptor gamma (PPAR $\gamma)$ coactivator 1 alpha (PGC1 $\alpha)$ and fibronectin type III domaincontaining protein 5 (FNDC5). The latter is exported into the blood stream as irisin (120). Irisin is the hormone responsible for the increase in neuronal BDNF (121). As we found no evidence of increase in BDNF in the fructose+exercise group, we decided to study the expression of transcript 1 PGC1 $\alpha$ and FNDC5 in both the muscle and the hippocampus.

Figure 13 shows that exercise was not able to increase the expression of PGC1 $1 \alpha 1$ and FNDC5 when accompanied by ingestion of fructose. Indeed, factorial ANOVA showed that fructose was the only variable to affect expression of PGC1 $\alpha 1$ and FNDC5 both in the muscle (PGC1 1 1 $\mathrm{p}=0.004$; FNDC5 $\mathrm{p}=0.01$ ) and in the hippocampus (PGC1 $1 \mathrm{p}=0.066$; FNDC5 $\mathrm{p}=0.024)$.

Quantitative real-time PCR experiments showed that groups F and FE have a $67 \%$ decrease in the expression of PGC1 $1 \alpha 1(\mathrm{p}=0.006)$ and a $63 \%$ decrease in the expression of FNDC5 ( $\mathrm{p}=0.011)$ in striated muscle compared to groups $\mathrm{C}$ and E (Fig. 13A and 13C). A similar trend was found in the hippocampus, where groups $\mathrm{F}$ and $\mathrm{FE}$ have a $80 \%$ decrease in 
the expression of PGC1 $1 \alpha 1(\mathrm{p}=0.016)$ and a $64 \%$ decrease in the expression of FNDC5 $(\mathrm{p}=0.008)$ compared to groups $\mathrm{C}$ and $\mathrm{E}$ (Fig. 13B and 13D).
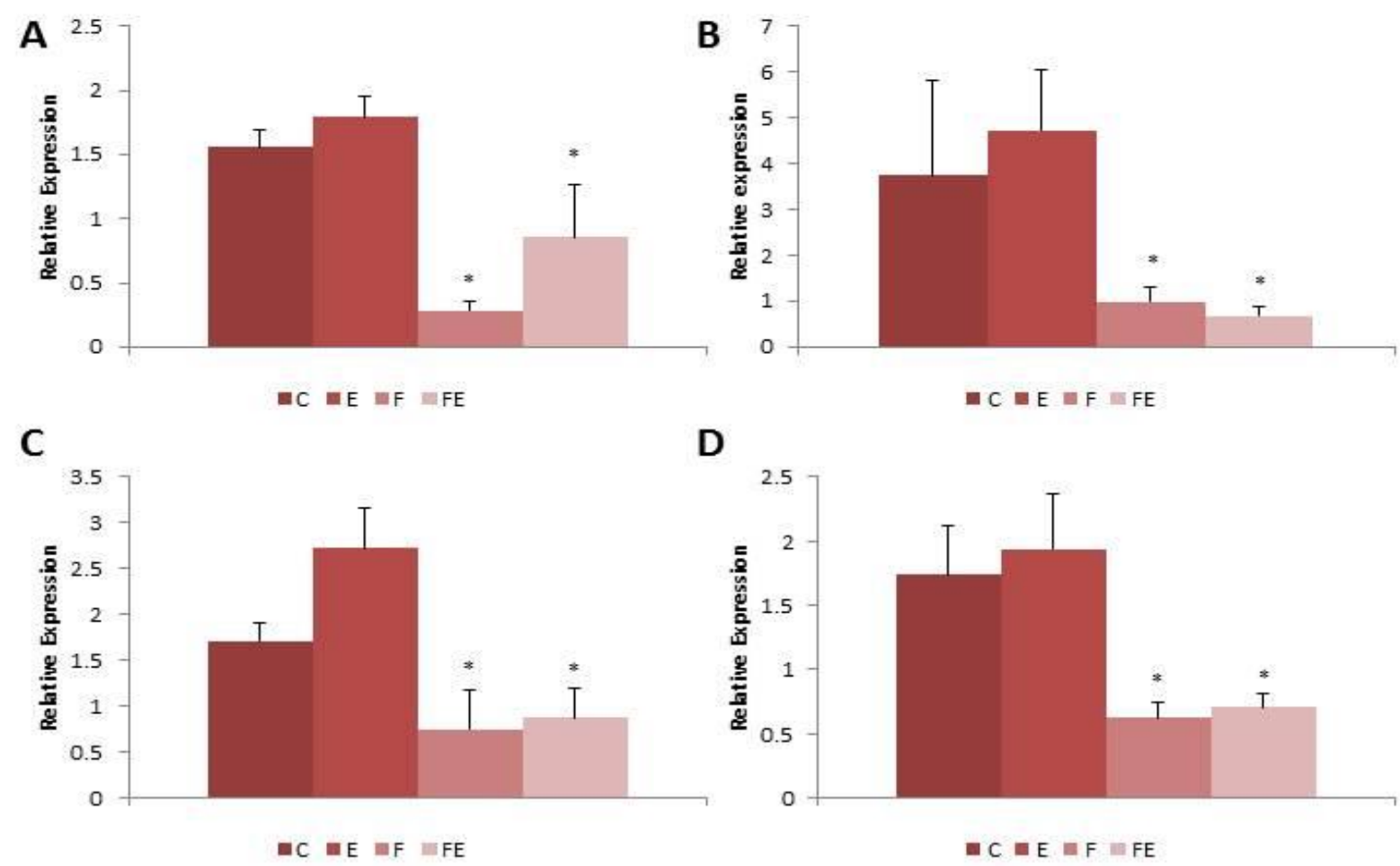

Figure 13. Ingestion of fructose blunted the expression of PGC1a1 and FNDC5 in both skeletal muscle and hippocampus. A. PGC1a1 expression in muscle. Groups F and FE showed $67 \%$ decrease in the expression of PGC1 11 compared to groups $\mathrm{C}$ and E. B. PGC1 1 expression in hippocampus. Groups F and FE have an 80\% decrease in the expression of PGC1 $\alpha 1$ compared to groups $\mathrm{C}$ and E. C. FNDC5 expression in muscle. Groups F and FE have a 63\% decrease in the expression of FNDC5 compared to groups C and E. D. FNDC5 expression in hippocampus. Groups F and FE have a 64\% decrease in the expression of FNDC5 compared to groups $\mathrm{C}$ and $\mathrm{E}$. Groups: $\mathrm{C}$ - control, E - exercise, F - fructose, FE - fructose+exercise. Results are presented as mean \pm SEM. $* \mathrm{p}<0.020$.

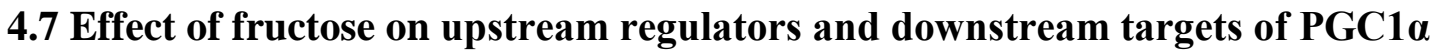

PGC1 $\alpha$ is a transcriptional coactivator and is involved in pathways related to energy and nutrient homeostasis (122), thus we investigated some of its upstream regulators and downstream targets. Figure 14 shows that along with downregulation of PGC1 $\alpha$, its downstream targets are also downregulated in muscle of rats exposed to fructose. Factorial 
ANOVA shows that fructose was the only variable to affect expression of nuclear receptor subfamily 4 group A member 3 (NR4A3) ( $\mathrm{p}=0.024)$. Groupwise comparison of expression indicated that $\mathrm{F}$ and $\mathrm{FE}$ groups have an $80 \%$ decrease in the expression of NR4A3 compared to groups $\mathrm{C}$ and $\mathrm{E}(\mathrm{p}=0.027)$. Expression of GLUT4 followed a similar trend, as factorial ANOVA showed that fructose was the only factor affecting its expression $(p=0.038)$, which was $78 \%$ decreased in the $\mathrm{F}$ and $\mathrm{FE}$ groups compared to $\mathrm{C}$ and $\mathrm{E}$ groups $(\mathrm{p}=0.022)$. By contrast, exercise was the only variable to affect expression of FoxO3A gene $(p=0.029)$, as exercise partially reverses the downregulation of FoxO3A induced by fructose $(\mathrm{E}+\mathrm{FE} \times \mathrm{C}+\mathrm{F}$, $\mathrm{p}=0.038)$. Expression of both estrogen-related receptor alpha (Err $\alpha)$ and peroxisome proliferator-activated receptor delta (PPAR $\delta$ ) was increased in the exercise group $(66 \%$ and $79 \%$, respectively) compared to all other groups (Erra: $F_{3,15}=31.54, p<0.001$; PPAR $\delta$ : $\left.\mathrm{F}_{3,14}=18.08, \mathrm{p}<0.001\right)$. Taken together, these results suggest that fructose feeding might induce a decrease in fatty acid oxidation and glucose transport in the skeletal muscle and that exercise is not able to reverse these alterations.

We also investigated the expression of calcium/calmodulin-dependent protein kinase type IV (CAMK IV), a transcription activator of PGC1 $\alpha$ (123). We found no significant difference in the expression of CAMK IV $\left(\mathrm{F}_{3,15}=0.82, \mathrm{p}=0.510\right)$ (Fig. 14), which suggests that the decrease in PGC1 $\alpha$ expression is not caused by a decrease in CAMK IV expression. 


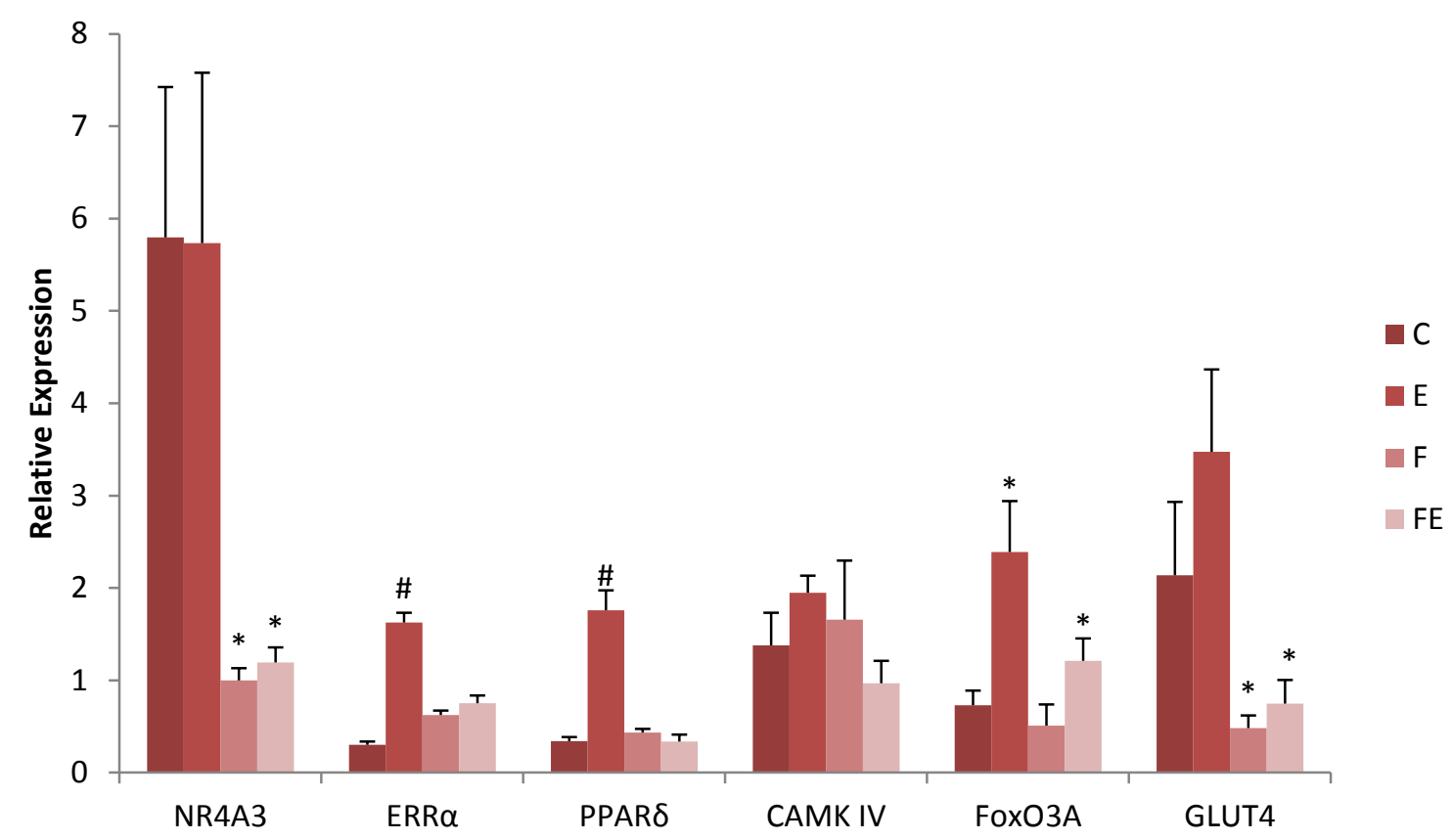

Figure 14. Fructose ingestion negatively affected the expression of regulators and downstream targets of PGC1a1 in skeletal muscle. Groups F and FE groups have an 80\% decrease in the expression of NR4A3 and 78\% decrease in expression of GLUT4 compared to groups C and E. Group E has an increase of $66 \%$ in the expression of Err $\alpha$ and an increase of $79 \%$ in the expression of PPAR $\delta$ compared to the other groups. There was no significant difference among groups in the expression of CAMK IV. Groups E and FE have increased expression of FoxO3A compared to groups $\mathrm{C}$ and F. Groups: C - control, E - exercise, F - fructose, FE fructose+exercise. Results are presented as mean \pm SEM.* $\mathrm{p}<0.040$; \# $\mathrm{p}<0.001$.

\subsection{Effect of fructose in muscle autophagy}

To investigate the effect of fructose and exercise in autophagy, we performed qRTPCR analysis in quadriceps muscle. We first investigated expression of genes involved in autophagosome formation (beclin 1 and autophagy-related proteins (Atg) 7, 9 and 12). Expression of beclin and Atg7 in groups E and FE was significantly higher than in groups C and $F(A \operatorname{tg} 6: F 3,15=7.95, p=0.004$; Atg7: F3, 23=10.97, p=0.001, Fig. 15). In contrast, groups $\mathrm{F}$ and $\mathrm{FE}$ showed decreased expression of $\operatorname{Atg} 9(\mathrm{~F} 3,18=11.26, \mathrm{p}=0.001$, Fig. 15). Atg9 expression was lowest in FE group although the rats in group E showed highest expression of Atg9 (Fig. 15). Groups E and FE showed a trend for a more intense expression 
of Atg12 than groups $\mathrm{C}$ and $\mathrm{F}$ did $(\mathrm{F} 3,19=2.91, \mathrm{p}=0.069$, Fig. 15). These results indicate that exercise induces expression of genes involved in autophagosome formation and that fructose attenuates the effects of exercise on expression of Atg9. The final steps of autophagy were assessed by analyzing expression of microtubule-associated proteins $1 \mathrm{~A} / 1 \mathrm{~B}$ light chain 3B (LC3) - a marker of autophagosome accumulation - and of lysosome-associated membrane protein 2 (Lamp-2). We found no significant difference in LC3 expression $(\mathrm{F} 3,24=0.62$, $\mathrm{p}=0.610$, Fig. 16A). In contrast, expression of Lamp-2 in group $\mathrm{E}$ was higher than in group FE (F3, 24=3.44, p=0.040, Fig. 16A). The expression of lysosomal cathepsin L (Ctsl) in skeletal muscle was also investigated. Animals from group E showed a more intense expression of Ctsl than animals from other groups but this was not statistically significant (F3, 18=3.10, p=0.061, Fig. 16B).

We also evaluated the effect of fructose on ubiquitin-proteasome by studying the expression of E3 ubiquitin ligases muscle atrophy F-box (MAFBx) and muscle ring finger-1 (Murf-1). There was no difference in MAFBx expression across the groups (F3, $21=1.66$, $\mathrm{p}=0.213$, Fig. 17). However, group E showed a significantly higher expression of MurF-1 when compared to group FE (F3, 23=5.56, p=0.007, Fig. 17). Finally, we assessed the expression of BCL2 interacting protein 3 (Bnip3) - a marker of mitochondrial autophagy and no statistically significant difference in Bnip3 expression was detected across the experimental groups $(\mathrm{F} 3,15=2.06, \mathrm{p}=0.164$, Fig. 18). 


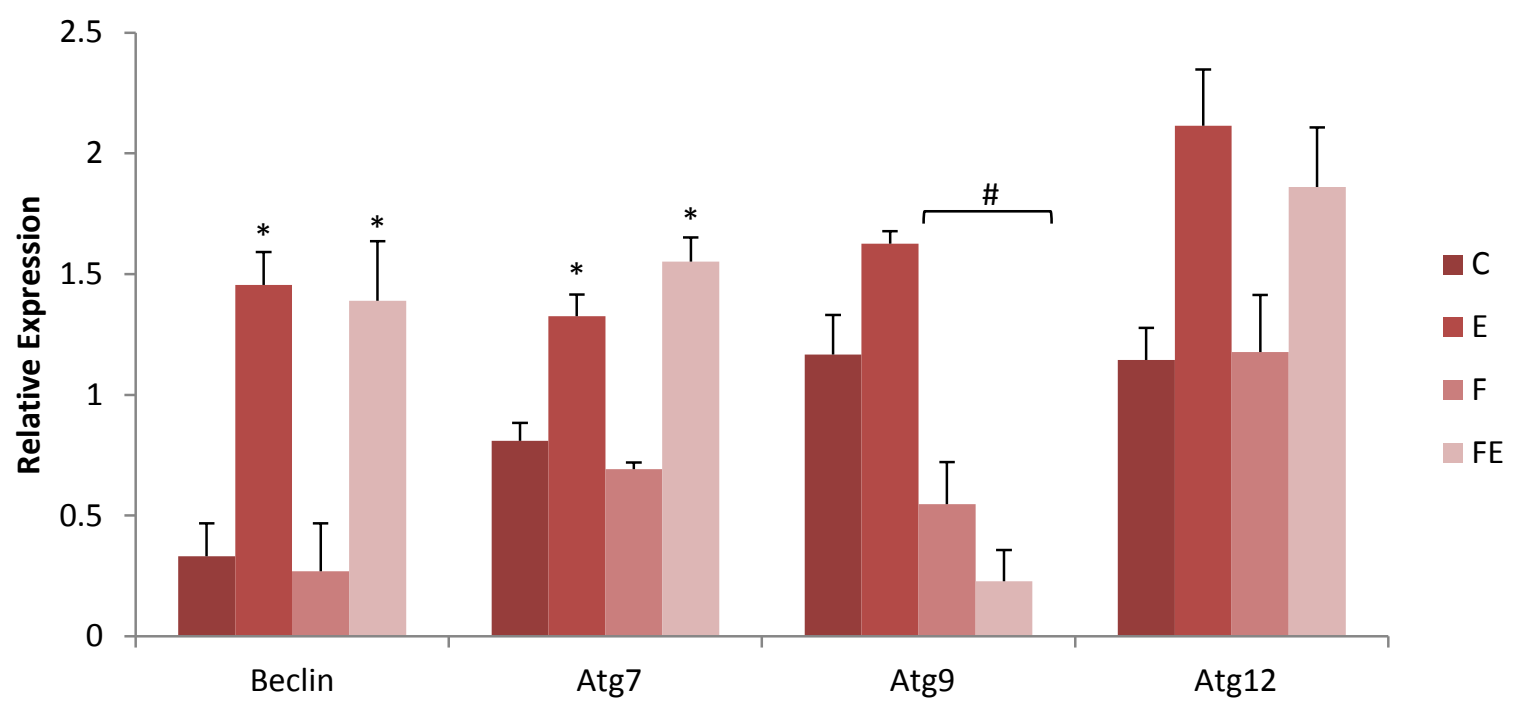

Figure 15. Effects of fructose and exercise training on expression of the Atg family genes. Expression of beclin and Atg7 in groups $\mathrm{E}$ and FE was significantly higher than in groups $\mathrm{C}$ and F. Expression of Atg9 was significantly lower in the FE group compared to the $\mathrm{E}$ group. There was no significant difference among groups in the expression of Atg12. Groups: C - control, E - exercise, F - fructose, FE - fructose+exercise. Results are presented as mean \pm SEM. $* \mathrm{p}<0.005, \# \mathrm{p}=0.001$.
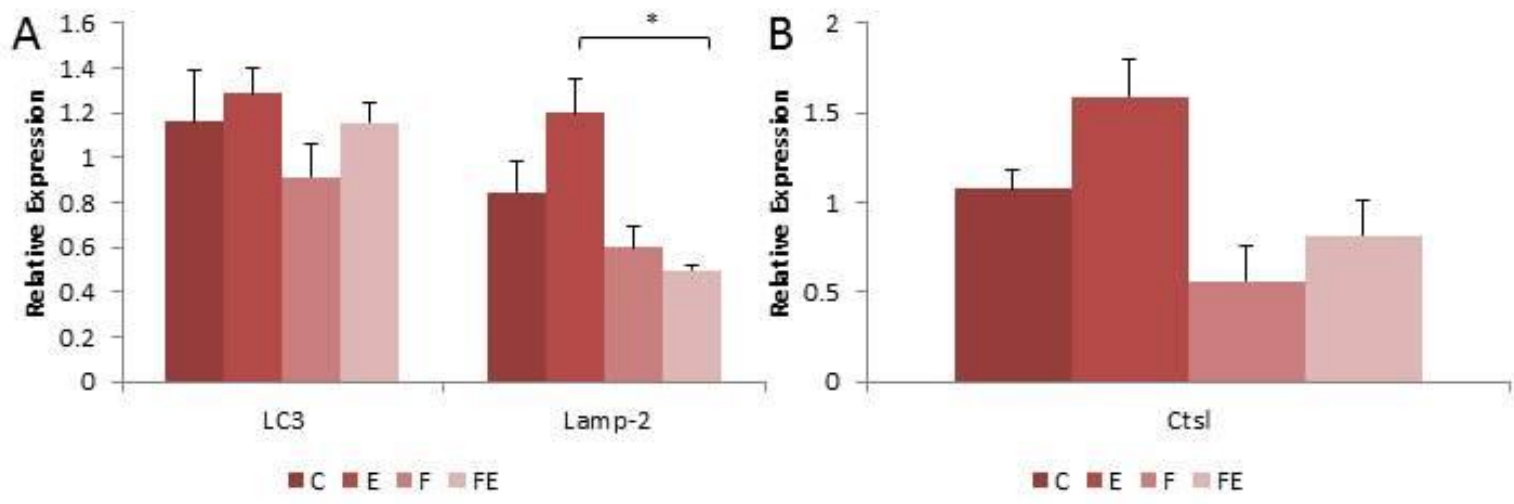

Figure 16. Expression of genes involved in the final steps of autophagy pathway under the effects of fructose feeding and exercise training A. Autophagy marker LC3 and lysosomal marker Lamp-2. There was no differenc in expression of LC3 among groups. Expression of Lamp-2 in group E was significantly higher than in group FE B. Lisosomal enzyme Ctsl. There was no significant difference in expression of Ctsl among groups. Groups: $\mathrm{C}$ - control, $\mathrm{E}$ - exercise, $\mathrm{F}$ - fructose, FE - fructose+exercise. Results are presented as mean \pm SEM. $* \mathrm{p}=0.040$. 


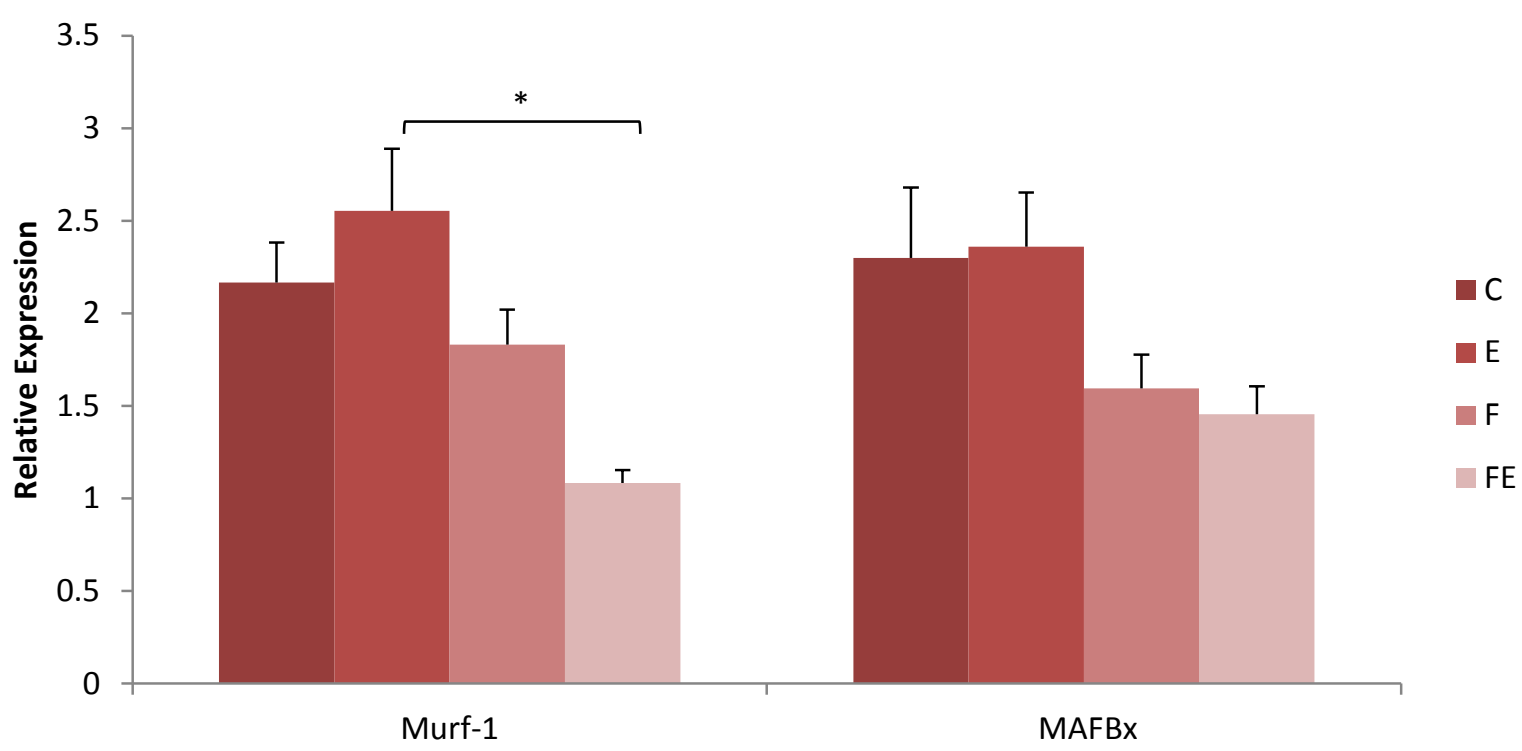

Figure 17. Expression of ubiquitin ligases Murf-1 and MAFBx in the context of fructose loading and chronic aerobic exercise. Group E showed a significantly higher expression of MurF-1 when compared to group FE. There was no significant difference in expression of MAFBx among groups. Results are presented as mean \pm SEM. Groups: $\mathrm{C}$ - control, $\mathrm{E}$ - exercise, $\mathrm{F}$ - fructose, $\mathrm{FE}-$ fructose+exercise. ${ }^{*} \mathrm{p}=0.007$

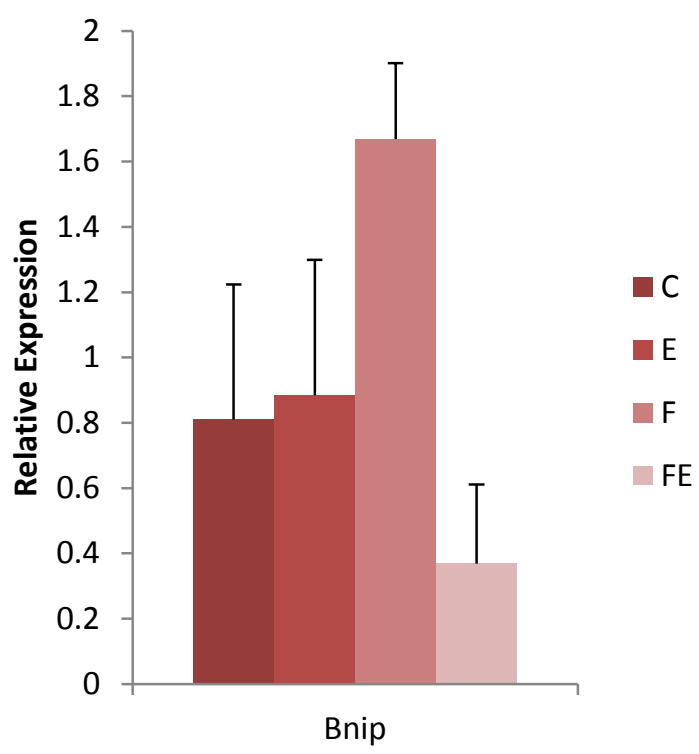

Figure 18. Effects of chronic fructose ingestion and aerobic training on expression of mitochondrial function regulator Bnip3. There was no significant difference in expression of Bnip3 among groups. Groups: $\mathrm{C}$ - control, E- exercise, $\mathrm{F}$ - fructose, FE - fructose+exercise. Results are presented as mean $\pm \mathrm{SEM}$. There was no significant difference among groups 


\subsection{Effect of fructose and metformin in the working memory}

AMPK activation reportedly enhances expression of several glucose and lipid metabolism genes $(124,125)$, including FNDC5 (126), therefore we tested the effects of the AMPK activator metformin in working memory and genes involved in muscle metabolism. Animals were subjected to the Barnes Maze in order to assess the working memory performance. Figure 19 shows that there was no difference among groups before the fructose/metformin protocol (week 0; latency: $F_{2,53}=1.11 \mathrm{p}=0.337$; distance: $\mathrm{F}_{2,53}=0.46$, $\mathrm{p}=0.663$; number of errors $\mathrm{F}_{2,53}=0.02 \mathrm{p}=0.981$ ), but along the weeks the $\mathrm{F}$ group performed poorer than the C and FM groups. Indeed, two-way ANOVA showed an effect of time and group in latency to find the escape box (time: $\mathrm{p}=0.005$, group: $\mathrm{p}=0.014$ ) and post-hoc test showed that $\mathrm{F}$ group performance was worse than the $\mathrm{C}$ and $\mathrm{FM}$ groups ( $\mathrm{F}-\mathrm{C} \mathrm{p}=0.036, \mathrm{~F}-\mathrm{FM}$ $\mathrm{p}=0.026$, FM-C p=0.991) (Fig. 19A). The two other tested parameters followed a similar trend with two-way ANOVA indicating an effect of time and group in distance (time: 0.005, group: 0.019) and number of errors (time: 0.008, group: 0.023). Post-hoc test showed a difference in group for both distance (F-C 0.035, F-FM 0.041, FM-C p = 0.998) (Fig. 19B) and number of errors (F-C 0.048, F-FM 0.043, FM-C p =0.998) (Fig. 19C). These results suggest that metformin was able to prevent the decline in working memory induced by fructose loading. 

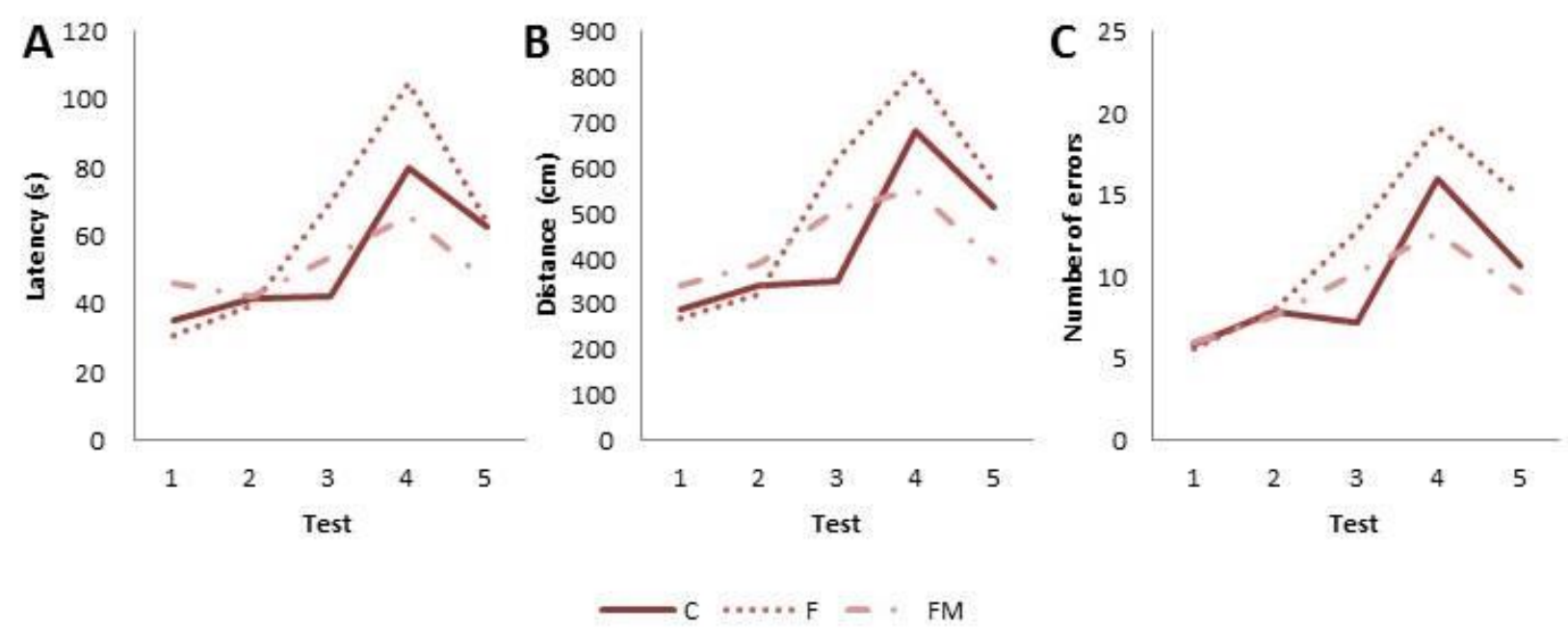

Figure 19. Effect of fructose and metformin in the working memory. The working memory was tested once every two weeks during the experimental protocol as described in Methods. There was no significant difference among groups before the fructose/metformin protocol in any of the three tested parameters. Along the weeks the F group performed poorer than the $\mathrm{C}$ and FM groups in all of the tested parameters. A. Latency. F-C $\mathrm{p}=0.036$, F-FM $\mathrm{p}=0.026$, FM-C $\mathrm{p}=0.991$. B. Traveled distance before entering the escape box. $\mathrm{F}-\mathrm{C} 0.035$, FFM 0.041, FM-C p = 0.998. C. Number of errors before entering the escape box. F-C 0.048, F-FM 0.043, FM-C $\mathrm{p}=0$.998. Groups $\mathrm{C}$ - control, $\mathrm{F}$ - fructose, $\mathrm{FM}-$ fructose+metformin

\subsection{Effect of fructose and metformin in muscle metabolism}

We assessed how fructose and metformin might affect the metabolism of striated muscle through comparison of the expression of PGC1 $\alpha$, FNDC5, GLUT4 and beta oxidation pathway genes carnitine palmitoyltransferase 1A (CPT1a) and citrate synthase (CS). Figure 20 shows that fructose negatively affects PGC1 $\alpha$ expression in the quadriceps femori, which is prevented by metformin $\left(\mathrm{F}_{2,9}=21.75 \mathrm{p}=0.002\right)$. There was no significant difference among groups in the expression of GLUT4 $\left(\mathrm{F}_{2,10}=1.17, \mathrm{p}=0.364\right)$, FNDC5 $\left(\mathrm{F}_{2,10}=1.14, \mathrm{p}=0.365\right)$, CPT1a $\left(\mathrm{F}_{2,10}=0.58, \mathrm{p}=0.587\right)$ and $\mathrm{CS}\left(\mathrm{F}_{2,10}=2.19, \mathrm{p}=0.183\right)$. 


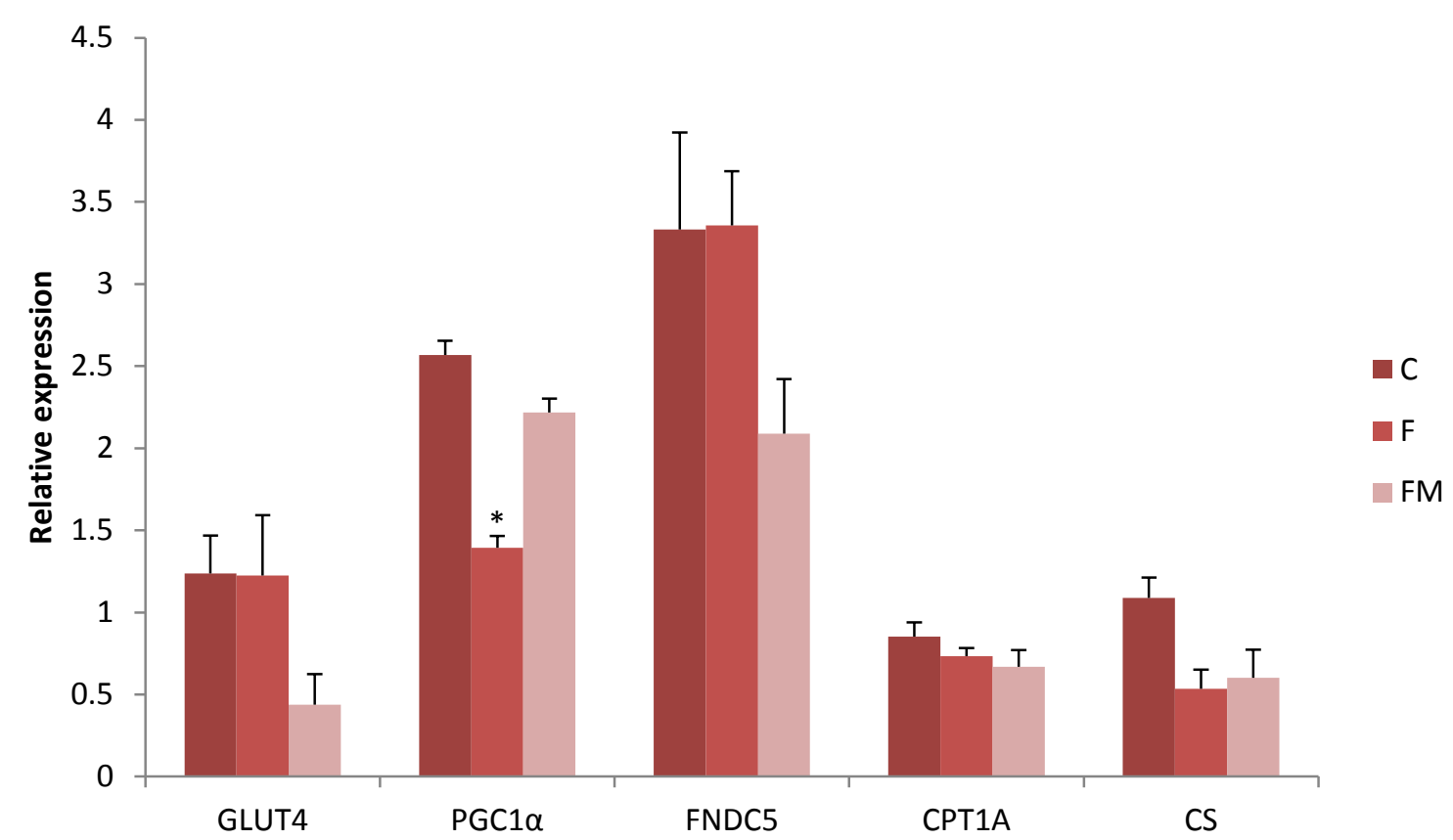

Figure 20. Effect of fructose and metformin on expression of GLUT4, PGC1 $\alpha$, FNDC5, CPT1a and CS in skeletal muscle. Group F showed decrease in PGC1 $\alpha$ expression compared to groups $\mathrm{C}$ and FM. There was no significant difference among groups in the expression of GLUT4, FNDC5, CPT1a and CS. Groups C - control, $\mathrm{F}-$ fructose, $\mathrm{FM}-$ fructose+metformin. Results are presented as mean $\pm \mathrm{SEM} . * \mathrm{p}=0.002$

\subsection{Effect of fructose and metformin in the brain}

The effect of fructose and metformin in the brain was assessed through comparison of expression of PGC1 $\alpha$, FNDC5 and BDNF in the hippocampus. Figure 21 shows that fructose negatively affects expression of PGC1 $\alpha$, FNDC5 and BDNF in the hippocampus, all of which are prevented by metformin. Indeed metformin induces a massive increase in the expression of both FNDC5 $\left(\mathrm{F}_{2,10}=9.38, \mathrm{p}=0.010\right)$ and $\operatorname{BDNF}\left(\mathrm{F}_{2,10}=6.60, \mathrm{p}=0.020\right)$, although no effect in the expression of PGC1 $\alpha$ was observed $\left(\mathrm{F}_{2,10}=9.69, \mathrm{p}=0.010\right)$. 


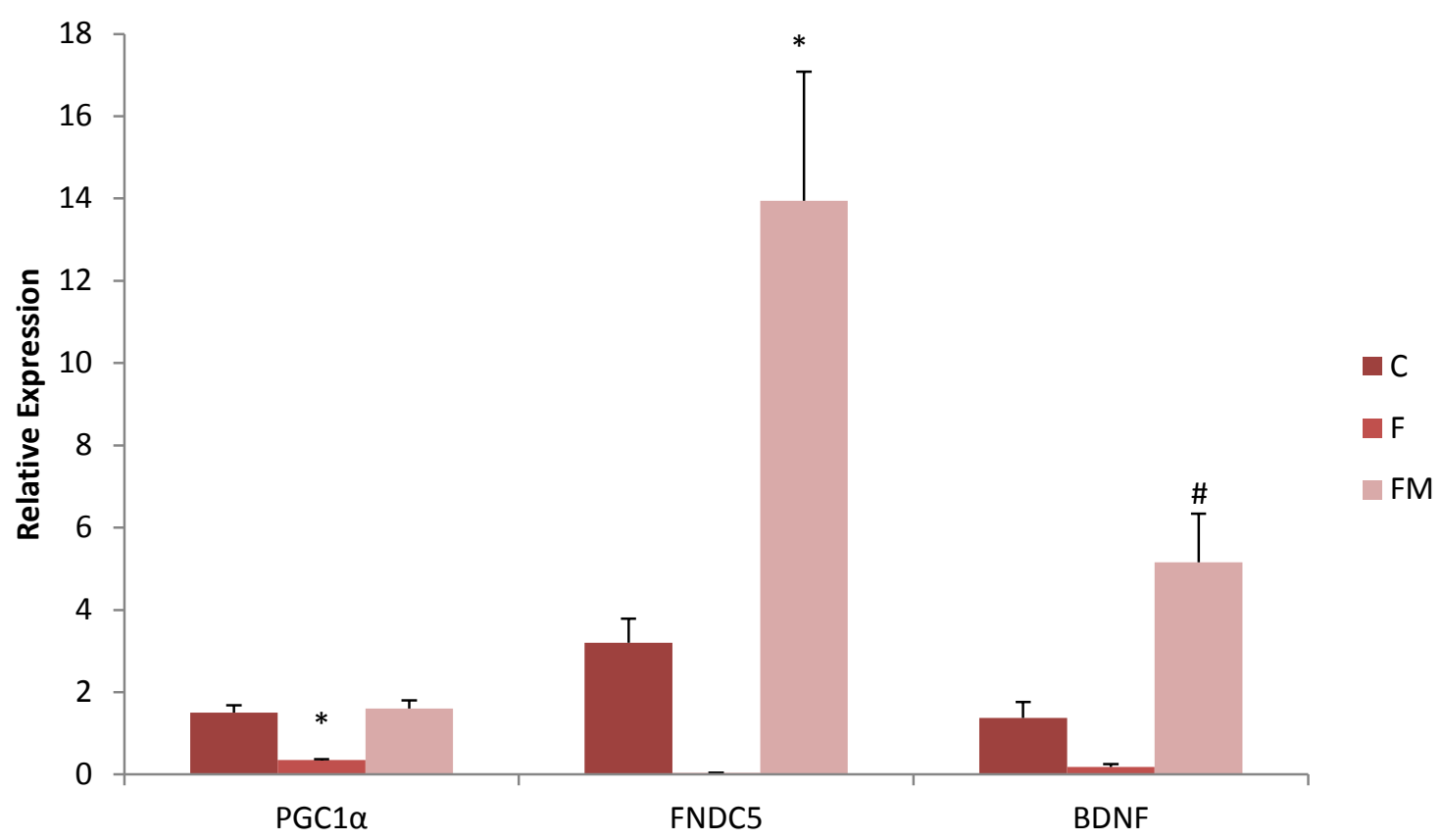

Figure 21. Effect of fructose and metformin in PGC1 $\alpha$, FNDC5 and BDNF expression levels in the hippocampus. Group F showed decrease in PGC1 $\alpha$ expression compared to groups C and FM. Group FM showed massive increase in the expression of both FNDC5 and BDNF compared to groups C anf F. Groups $\mathrm{C}-$ control, $\mathrm{F}-$ fructose, $\mathrm{FM}-$ fructose+metformin. Results are presented as mean $\pm \mathrm{SEM} .{ }^{*} \mathrm{p}=0.010 ; \quad \# \mathrm{p}=$ 0.020 
5 Discussion 


\section{Discussion}

The benefits of exercise in health are undeniable. It has been reported to reduce the risk of cardiovascular diseases, diabetes mellitus type 2 and some types of cancers (127). Physical training has also benn shown to improve learning and memory (117). In this study we showed that substituting drinking water with a $15 \%$ fructose solution caused cognitive decline in rats, an alteration that was not ameliorated by exercise due to the negative effects of fructose in muscle metabolism. The lack of effect of physical training on cognitive decline paralleled the impaired expression of PGC1 $\alpha$ and FNDC5 in both the brain and the skeletal muscle. This association between cognitive decline and impairement of expression of PGC1 $\alpha$ and FNDC5 by fructose ingestion suggests that blunting the responde of PGC1 $\alpha$ pathway is probably the mechanism by which ingestion of fructose causes cognitive deficit. We also showed that fructose attenuates expression of genes downstream of PGC1 $\alpha$ that are important to the adaptation of skeletal muscle to physical training NR4A3, FoxO3A, Erra, PPAR $\delta$ and GLUT4. Therefore, our results suggest that excessive ingestion of a macronutrient might be able to attenuate the benefits of aerobic exercise - a phenomenon that needs to be investigates in greater detail given is self-evident importance in the management of lifestyle-related diseases.

In this study, animals that underwent 8 weeks of fructose treatment - both sedentary and exercised - showed an increase in body weight compared to control groups. However, except for a slight, but not significant, increase in serum triglyceride in the fructose and fructose+exercise groups, there were no detectable metabolic changes. This contrasts with other studies that used fructose (83-85), as they found evidence of insulin resistance and hypertriglyceridemia, but these differences might be due to different concentration of fructose in the diet. This fact also suggests that clinical relevant effects of fructose loading might 
manifest before laboratorial evidences of insulin resistance and other metabolic abnormalities can be detected.

In addition to metabolic changes, fructose consumption has been linked to cognitive decline $(91,116)$. Indeed, we found that substituting drinking water with a $15 \%$ fructose solution induced cognitive decline. Compared to the control group, fructose-fed animals showed decreased performance in the task when tested in the working memory version of the Barnes Maze. Surprisingly, exercise did not seem to counteract the negative effect of fructose in the working memory, as animals of the fructose+exercise group also performed pooly in the task compared to control groups. This effect seems to be linked solely to the consumption of fructose, as cognitive decline induced by high fat diet and drug-induced diabetes (streptozotocin or alloxan) is reversed by exercise $(103,128,129)$. Brain insulin resistance has often been reported to be associated with cognitive decline linked to Alzheimer`s and metabolic diseases $(44,46,57,116)$. Here we show that although there was a clear loss of memory function, there was no change in the insulin signaling in the hippocampus, as assessed by IR, IRS-1, IRS-1 $\mathrm{p}^{\mathrm{S} 312}$, IRS-1 $\mathrm{p}^{\mathrm{S} 616}$, Akt, Akt $\mathrm{p}^{\mathrm{S} 473}$, GSK3 $\beta$ and GSK3 $\beta \mathrm{p}^{\mathrm{S} 216}$. In contrast to the seemingly intact insulin signaling pathway, we found no exercise-dependent induction of BDNF and synaptophysin - markers of brain plasticity - in the hippocampus of animals assigned to the fructose+exercise group - a finding that could explain why this group showed no improvement in the Barnes Maze test.

Unexpectedly, the expression of PGC1 $1 \alpha 1$ and FNDC5 remains low in the fructose+exercise group in both the muscle and the hippocampus, contrary to what is observed in the exercise group. PGC1 $\alpha$ induces mitochondrial oxidative metabolism and GLUT4 translocation to the cell membrane (130) thereby increasing muscle glucose uptake. PGC1 $\alpha$ also redirects glucose towards oxidative instead of glycolytic metabolism and activates molecular programs specific of slow-twitch muscle fiber (131). Fiber type switch is 
an important change associated with tolerance to endurance exercise, as studies show that muscle cells lacking PGC1 $\alpha$ are prone to contraction-induced fatigue and PGC1 $\alpha$ knockout mice are exercise intolerant (132). Fiber switch also brings benefits to energy metabolism. Increased content of fast-twitch fibers relative to the slow-twitch ones is associated with insulin resistance, DM2 and obesity $(133,134)$. Conversely, subjects with slow-twitch enriched skeletal muscle present a greater insulin-stimulated glucose transport (135-137). Finally, the slow- to fast-twitch shift in fiber distribution that occurs in aging and physical inactivity is accompanied by a decrease in muscle oxidative capacity and insulin sensitivity (138). Therefore, although after eight weeks of treatment there was no evidence of exercise intolerance in the fructose+exercise group in the maximal exercise capacity test, animals assigned to this group might still present disturbances in muscle metabolism (as discussed below). Furthermore, the fructose-induced reduction of FNDC5 expression in both the muscle and the hippocampus might result in a more deficient response to exercise since both mucle-derived irisin and FNDC5 expressed in the central nervous system are reported to stimulate BDNF expression in the brain (121) .

Analysis of expression of NR4A3, a regulator of lipid and carbohydrate metabolism and fiber-type switch in the skeletal muscle $(139,140)$, showed that fructose induces a decrease in its expression and that exercise is unable to reverse the alteration. The same is true for $\operatorname{PPAR} \delta$, a fatty acid catabolism regulator (141) whose expression is significantly increased with exercise alone, but not when exercise is combined with fructose feeding. PGC1 $\alpha$ also promotes the expression of transcription factors with which it interacts. One of such factors is Erra (142). Erro is a transcription factor that interacts with PGC1 $\alpha$ in order to regulate mitochondrial biogenesis (143) and glucose (144) and fatty acid metabolism (145). Erra expression is upregulated with exercise alone, but not when exercise is combined with fructose feeding. Err $\alpha$ and PGC1 $\alpha$ interact with each other in order to increase expression of 
pyruvate dehydrogenase lipoamine kinase isozyme 4 (PDK4) which decreases glucose oxidation and increase alternate mitochondrial oxidative pathways (144), such as fatty acid oxidation. The downregulation of Erra along with the downregulation of NR4A3 and PPAR $\delta$ suggest that fructose feeding impairs the ability of muscle to adapt to the metabolic demands of exercise, as there is no decrease in glucose oxidation or increase in fatty acid oxidation. Additionally, expression of the glucose receptor GLUT4 is decreased in the fructose-fed animals, agreeing with previous find by Goyaram et al (146). This suggests a decrease in glucose transport in the muscle as GLUT4 expression is correlated with glucose transport in the muscle cell (130).

Muscle contraction-dependent calcium signaling stimulates PGC1 $\alpha$ transcription via calcineurin and CAMK IV (147). Constitutively expressed CAMK IV induces increased mitochondrial biogenesis and fatty acid metabolism through activation of PGC1 $\alpha$ transcription (123). Our expression analysis of CAMK IV did not show any differences among groups, suggesting that the decrease in PGC1 $\alpha$ expression in fructose-fed animals is not caused by a decrease in the expression of CAMK IV.

Fructose can also impact negatively muscle metabolism by attenuating the exerciseinduced basal autophagy in skeletal muscle. We showed that, compared to sedentary rats, treadmill training induced basal expression of autophagy genes (beclin, Atg7, and Atg12) in quadriceps femori. These results are in agreement with observations that aerobic training increases both accumulation of autophagy proteins and autophagy flux (79) and with report of increased expression of Atg7 and Lamp-2 in vastus lateralis of elderly women that underwent caloric restriction and aerobic exercise (148). We also showed that fructose ingestion attenuated expression of Atg9 and Lamp-2 in skeletal muscle of treadmill-trained rats. Atg9 is a multispanning membrane protein that is a key regulator of autophagy induction (149) and Lamp-2 is a lysosomal glycoprotein responsible for the fusion of autophagosome to 
lysosome (150). Therefore, it is possible to speculate that the exercise-induced increase in basal autophagy is impaired in the fructose-treated animals.

Intact responses of autophagy to aerobic exercise are a requirement for the role of skeletal muscle as a regulator of whole body metabolism $(77,79)$. Accordingly, in the present study, animals undergoing both treadmill training and fructose feeding exhibited worse metabolic parameters when compared to animals subjected to exercise only, albeit not as severe as sedentary, fructose-fed rats. Defective autophagy could be an innate functional defect of skeletal muscle, as suggested by the report that protein degradation via autophagy is impaired in starved cultured myotubes from patients with severe obesity (151), or a result of exposure to an exogenous factor as our results might imply. Therefore, targeting autophagy in skeletal muscle might be an interesting approach to treat obesity and MetS patients, especially those presenting sarcopenia.

In this study, both exercise-only and fructose-fed exercise-trained rats showed improvement in physical conditioning and they performed similarly in maximal exercise capacity test. This seems to contradict what is known about the effect of PGC1 $\alpha$ in mitochondrial biology and energy metabolism $(74,122,132,152-154)$ and about its effect in autophagy and in maintenance of muscle mass and function as muscle-specific deficiency of Atg7 resulted in muscle atrophy and decreased muscle strength (155) and mice with haploinsufficiency of beclin were more intolerant to aerobic exercise than their wild-type counterparts (79). Possible explanations include the existence of redundancy in transcriptional co-activators as indicated by the overlapping of functions in the PGC1 family of coactivators (156) and that PGC1 $\alpha$ might not be mandatory for some of the adaptations induced by exercise, as indicated by some loss-of-function studies (157-159). Another possible explanation is that the length of fructose treatment in this study did not afford enough time for the fructose-fed rats to exhibit the consequences of impaired muscle 
metabolism and autophagy in full extent. This might also be caused by our experimental protocol as aerobic training and fructose feeding were concomitantly administered throughout the experimental period.

Our study did not address directly the mechanism behind the attenuation of exercisestimulated expression of autophagy-related genes in fructose-fed rats. However, there are some clues about the regulatory molecules that might be involved. Both the FoxO3A transcription factor and the transcription co-activator PCG1 $\alpha$ participate in the regulation of autophagy in skeletal muscle. FoxO3A coordinates both ubiquitin-proteasome and autophagy pathway in skeletal muscle $(160,161)$ while induction of PCG1 $\alpha$ by exercise training is required for exercise-dependent increase in basal autophagy (79). Consonant with these observations from experimental models, increased expression of autophagy genes in muscle of elderly women that underwent caloric restriction and aerobic training was paralleled by an increase in expression of both FoxO3A and PCG1 $\alpha$. (148). Here we have found that expression of both PCG1 $\alpha$ and FoxO3A in exercised skeletal muscle was attenuated by fructose administration. These evidences support the notion that fructose impairs the exercise-induced basal expression of autophagy-related genes by affecting negatively the expression of PCG1 $\alpha$ and FoxO3.

The observed effects of fructose in the defective induction of genes related to skeletal muscle response to exercise training are probably mediated by a transcriptional mechanism as the affected genes participate in multiple cellular processes. Fructose-induced inflammation might lead to impaired activation of $\mathrm{PGC} 1 \alpha$ and other transcriptional regulators of skeletal muscle adaptation to aerobic training (162), as well as cyclooxygenase 2-mediated insulin resistance in rats $(163,164)$, however this hypothesis contradicts evidence of antiinflammatory properties of exercise training in rodent models of diabetes and tobacco smoking (165-167). Fructose might also affect glycogen content in skeletal muscle. Exercise- 
trained rats that ingest fructose have higher content of both liver and muscle glycogen than exercised rats that ingest control diet (168). As activation of PPAR $\delta$ varies inversely with the glycogen content of muscle fiber (169), it is possible that fructose impairs the transcription of PGC1 $\alpha$, which is dependent on the activity of PPAR $\delta$ in myotubes (170), by enhancing the accumulation of glycogen in skeletal muscle. A third hypothesis is the negative effect of fructose on gene expression in skeletal muscle be mediated by accumulation of lactate and lipids. Lactate is the major byproduct of fructose metabolization exported by the liver, being responsible for the date of almost a quarter of ingested fructose (171). Despite its abundance, lactate has been reported to enhance PGC1 $\alpha$ expression in both animal and cultured cell models $(172,173)$. Therefore it seems highly unlikely that excess lactate is the culprit. Fructose also increases plasma triglyceride and NEFAs by both increasing lipid synthesis and decreasing lipid clearance $(90,171)$. Exposure of skeletal muscle to lipids results in muscle insulin resistance and accumulation of fatty acids (174), which in turn burdens mitochondria and might impair expression of exercise-induced genes in muscle.

Some studies have reported a direct effect of metformin in the brain, for example, metformin induces autophagy and protects against focal cerebral ischaemia $(175,176)$ and increased hippocampal neurogenesis through an atypical PKC-CBP pathway (177). We found that fructose feeding induced a decrease in the hippocampal expression of PGC1 $\alpha$, FNDC5 and BDNF. Metformin not only prevented the decrease in the expression of the three genes in fructose-fed rats, but induced a massive increase in the expression of FNDC5 and BDNF. This was accompanied by an improvement in the performance in the working memory version of the Barnes maze in the fructose+metformin group compared to the fructose group. As metformin prevented the fructose feeding-induced decrease on the expression of PGC1 $\alpha$ in quadriceps femori, but not on the expression of FNDC5, CPT1A, CS and GLUT4, we 
might speculate that the mechanism by which metformin acted was by a direct effect in the brain, bypassing the negative effects of fructose in the muscle.

In summary, our results show that ingestion of fructose may lead to severe alteration in the muscle response to exercise: glucose oxidation remains high, fatty acid oxidation remains low, expression of GLUT4 is decreased, basal autophagy is diminished and transcription activation of irisin is blunted. This muscle metabolic mal-adaptation leads to attenuation of exercise beneficial effects in other organs, more specifically, the brain, impairing neuronal plasticity and learning and memory. Surprisingly we found that metformin prevents fructose-induced cognitive decline by directly acting in the central nervous system, as it induces an increase in hippocampal expression of PGC1 $\alpha$, FNDC5 and BDNF even without evidence of enhanced muscle metabolism.

Our study shows that there is a hierarchy of lifestyles with respect to metabolism health as excessive ingestion of a macronutrient - in this case fructose - is able to profoundly affect the ability of muscle to adapt to exercise training. Our findings might change both the nutritional recommendations to athletes and the strategy to manage chronic noncommunicable diseases. 
6 Conclusion 


\section{Conclusion}

We did not achieve our initial aims as we found no evidence of insulin resistance in the hippocampus and exercise was not able to reverse the cognitive decline presented by the animals. The following conclusions are based in our concrete findings.

1. Substituting drinking water with a $15 \%$ fructose solution causes deterioration of working memory even though no evidence for brain insulin resistance was found;

2. Physical training is not able to reverse the fructose-induced cognitive deterioration;

3. Fructose ingestion blunts the exercise-dependent induction of BDNF and synaptophysin in the hippocampus. This is a possible reason why aerobic training is not effective in correcting the cognitive deficit caused by fructose;

4. In the skeletal muscle, fructose ingestion impais several exercise-induced physiological processes that are required for beneficial effects of physical training;

5. Metformin can directly induce expression of BDNF in the hippocampus thereby attenuating the deterioration of working memory induced by fructose ingestion. 
7 References 


\section{References}

1. Mathers CD, Loncar D. Projections of global mortality and burden of disease from 2002 to 2030. Plos Medicine. 2006;3(11).

2. Abegunde DO, Mathers CD, Adam T, Ortegon M, Strong K. Chronic diseases 1 - The burden and costs of chronic diseases in low-income and middle-income countries. Lancet. 2007;370(9603):1929-38.

3. IDF. The IDF consensus worldwide definition of the metabolic syndrome 2006 [Available from: http://www.idf.org/metabolic-syndrome.

4. Ford ES, Giles WH. A comparison of the prevalence of the metabolic syndrome using two proposed definitions. Diabetes Care. 2003;26(3):575-81.

5. Dutra ES, Baiocchi de Carvalho KM, Miyazaki E, Merchan-Hamann E, Ito MK. Metabolic syndrome in central Brazil: prevalence and correlates in the adult population. Diabetology \& Metabolic Syndrome. 2012;4.

6. Silva KF, Prata A, da Cunha DF. Frequency of metabolic syndrome and the food intake patterns in adults living in a rural area of Brazil. Revista Da Sociedade Brasileira De Medicina Tropical. 2011;44(4):425-9.

7. Gronner MF, Bosi PL, Carvalho AM, Casale G, Contrera D, Pereira MA, et al. Prevalence of metabolic syndrome and its association with educational inequalities among Brazilian adults: a population-based study. Brazilian Journal of Medical and Biological Research. 2011;44(7):713-9.

8. Rodrigues SL, Baldo MP, Mill JG. Association of Waist-Stature Ratio with Hypertension and Metabolic Syndrome: Population-Based Study. Arquivos Brasileiros De Cardiologia. 2010;95(2):186-91.

9. Cavagioni LC, Bensenor IM, Halpern A, Pierin AMG. Metabolic Syndrome in professional truck drivers who work on Highway BR-116 within the area of Sao Paulo city Regis Bittencourt. Arquivos Brasileiros De Endocrinologia E Metabologia. 2008;52(6):101523.

10. Marquezine GF, Oliveira CM, Pereira AC, Krieger JE, Mill JG. Metabolic syndrome determinants in an urban population from Brazil: Social class and gender-specific interaction. International Journal of Cardiology. 2008;129(2):259-65.

11. Nakazone MA, Pinheiro A, Vauria Braga Braile MC, De Souza Pinhel MA, De Sousa GF, Pinheiro S, Jr., et al. Prevalence of metabolic syndrome using NCEP-ATPIII and IDF definitions in Brazilian individuals. Revista Da Associacao Medica Brasileira. 2007;53(5):407-13.

12. Velasquez-Melendez G, Gazzinelli A, Correa-Oliveira R, Pimenta AM, Kac G. Prevalence of metabolic syndrome in a rural area of Brazil. Sao Paulo Medical Journal. 2007;125(3):155-62.

13. Barbosa P, Lessa I, de Almeida Filho N, Magalhães L, Araújo J. Criteria for central obesity in a Brazilian population: impact on the metabolic syndrome. Arq Bras Cardiol. 2006;87(4):407-14.

14. Leitão MP, Martins IS. [Prevalence and factors associated with metabolic syndrome in users of primary healthcare units in São Paulo--SP, Brazil]. Rev Assoc Med Bras. 2012;58(1):60-9.

15. Pearson-Leary J, McNay EC. Intrahippocampal administration of amyloid- $\beta(1-42)$ oligomers acutely impairs spatial working memory, insulin signaling, and hippocampal metabolism. J Alzheimers Dis. 2012;30(2):413-22.

16. Gami AS, Witt BJ, Howard DE, Erwin PJ, Gami LA, Somers VK, et al. Metabolic syndrome and risk of incident cardiovascular events and death - A systematic review and meta-analysis of longitudinal studies. Journal of the American College of Cardiology. 2007;49(4):403-14.

17. Huang PL. A comprehensive definition for metabolic syndrome. Disease Models \& Mechanisms. 2009;2(5-6):231-7. 
18. Caballeria L, Pera G, Rodriguez L, Antonia Auladell M, Bernad J, Canut S, et al. Metabolic syndrome and nonalcoholic fatty liver disease in a Spanish population: influence of the diagnostic criteria used. European Journal of Gastroenterology \& Hepatology. 2012;24(9):1007-11.

19. Mendez-Sanchez N, Chavez-Tapia NC, Motola-Kuba D, Sanchez-Lara K, PoncianoRodriguez G, Baptista $\mathrm{H}$, et al. Metabolic syndrome as a risk factor for gallstone disease. World Journal of Gastroenterology. 2005;11(11):1653-7.

20. Drager LF, Queiroz EL, Lopes HF, Genta PR, Krieger EM, Lorenzi-Filho G. Obstructive sleep apnea is highly prevalent and correlates with impaired glycemic control in consecutive patients with the metabolic syndrome. J Cardiometab Syndr. 2009;4(2):89-95.

21. Rosato V, Bosetti C, Talamini R, Levi F, Montella M, Giacosa A, et al. Metabolic syndrome and the risk of breast cancer in postmenopausal women. Annals of Oncology. $2011 ; 22(12): 2687-92$.

22. Pelucchi C, Serraino D, Negri E, Montella M, Dellanoce C, Talamini R, et al. The Metabolic Syndrome and Risk of Prostate Cancer in Italy. Annals of Epidemiology. 2011;21(11):835-41.

23. Rosato V, Tavani A, Bosetti C, Pelucchi C, Talamini R, Polesel J, et al. Metabolic syndrome and pancreatic cancer risk: a case-control study in Italy and meta-analysis. Metabolism-Clinical and Experimental. 2011;60(10):1372-8.

24. Kandaraki E, Christakou C, Diamanti-Kandarakis E. Metabolic syndrome and polycystic ovary syndrome ... and vice versa. Arquivos Brasileiros De Endocrinologia E Metabologia. 2009;53(2):227-37.

25. Kato-Narita EM, Nitrini R, Radanovic M. Assessment of balance in mild and moderate stages of Alzheimer's disease Implications on falls and functional capacity. Arquivos De Neuro-Psiquiatria. 2011;69(2A):202-7.

26. Novelli $M$, Nitrini $R$, Caramelli $P$. Validation of the Brazilian version of the quality of life scale for patients with Alzheimer's disease and their caregivers (QOL-AD). Aging \& Mental Health. 2010;14(5):624-31.

27. Smid J, Nitrini R. Distúrbios Cognitivos e Neurodegenerativos na Síndrome Metabólica. In: Gicacaglia LR, Silva MER, Santos RF, editors. Tratado de Síndrome Metabólica. São Paulo: Roca; 2010. p. 479-83.

28. Herrera E, Caramelli P, Silveira ASB, Nitrini R. Epidemiologic survey of dementia in a community-dwelling Brazilian population. Alzheimer Disease \& Associated Disorders. 2002;16(2):103-8.

29. Hampel H, Prvulovic D, Teipel S, Jessen F, Luckhaus C, Froliche L, et al. The future of Alzheimer's disease: The next 10 years. Progress in Neurobiology. 2011;95(4):718-28.

30. Reitz C. Dyslipidemia and Dementia: Current Epidemiology, Genetic Evidence, and Mechanisms Behind the Associations. Journal of Alzheimers Disease. 2012;30:S127-S45.

31. Yaffe K. Metabolic syndrome and cognitive disorders - Is the sum greater than its parts? Alzheimer Disease \& Associated Disorders. 2007;21(2):167-71.

32. Ford ES, Giles WH, Dietz WH. Prevalence of the metabolic syndrome among US adults - Findings from the Third National Health and Nutrition Examination Survey. JamaJournal of the American Medical Association. 2002;287(3):356-9.

33. Launer LJ, Masaki K, Petrovitch H, Foley D, Havlik RJ. THE ASSOCIATION BETWEEN MIDLIFE BLOOD-PRESSURE LEVELS AND LATE-LIFE COGNITIVE FUNCTION - THE HONOLULU-ASIA AGING STUDY. Jama-Journal of the American Medical Association. 1995;274(23):1846-51.

34. Qiu CX, Winblad B, Fratiglioni L. The age-dependent relation of blood pressure to cognitive function and dementia. Lancet Neurology. 2005;4(8):487-99.

35. Kanaya AM, Barrett-Connor E, Gildengorin G, Yaffe K. Change in cognitive function by glucose tolerance status in older adults - A 4-year prospective study of the Rancho Bernardo Study Cohort. Archives of Internal Medicine. 2004;164(12):1327-33.

36. Yaffe K, Kanaya A, Lindquist K, Simonsick EM, Harris T, Shorr RI, et al. The metabolic syndrome, inflammation, and risk of cognitive decline. Jama-Journal of the American Medical Association. 2004;292(18):2237-42. 
37. Whitmer RA, Gunderson EP, Barrett-Connor E, Quesenberry CP, Yaffe K. Obesity in middle age and future risk of dementia: a 27 year longitudinal population based study. British Medical Journal. 2005;330(7504):1360-2B.

38. Whitmer RA, Gustafson DR, Barrett-Connor E, Haan MN, Gunderson EP, Yaffe K. Central obesity and increased risk of dementia more than three decades later. Neurology. 2008;71(14):1057-64.

39. Yaffe K, Haan M, Blackwell T, Cherkasova E, Whitmer R, West N. Metabolic syndrome and cognitive decline in elderly latinos: Findings from the SALSA study. Neurology. 2007;68(12):A83-A.

40. Selkoe DJ. Amyloid beta-protein and the genetics of Alzheimer's disease. Journal of Biological Chemistry. 1996;271(31).

41. Pimplikar SW. Reassessing the amyloid cascade hypothesis of Alzheimer's disease. International Journal of Biochemistry \& Cell Biology. 2009;41(6):1261-8.

42. Li L, Hoelscher C. Common pathological processes in Alzheimer disease and type 2 diabetes: A review. Brain Research Reviews. 2007;56(2):384-402.

43. Janson J, Laedtke T, Parisi JE, O'Brien P, Petersen RC, Butler PC. Increased risk of type 2 diabetes in Alzheimer disease. Diabetes. 2004;53(2):474-81.

44. Mielke JG, Taghibiglou C, Liu L, Zhang Y, Jia Z, Adeli K, et al. A biochemical and functional characterization of diet-induced brain insulin resistance. $J$ Neurochem. 2005;93(6):1568-78.

45. Pratchayasakul W, Kerdphoo S, Petsophonsakul P, Pongchaidecha A, Chattipakorn $\mathrm{N}$, Chattipakorn SC. Effects of high-fat diet on insulin receptor function in rat hippocampus and the level of neuronal corticosterone. Life Sci. 2011;88(13-14):619-27.

46. Talbot K, Wang HY, Kazi H, Han LY, Bakshi KP, Stucky A, et al. Demonstrated brain insulin resistance in Alzheimer's disease patients is associated with IGF-1 resistance, IRS-1 dysregulation, and cognitive decline. J Clin Invest. 2012;122(4):1316-38.

47. Matsuzaki T, Sasaki K, Tanizaki Y, Hata J, Fujimi K, Matsui Y, et al. Insulin resistance is associated with the pathology of Alzheimer disease: the Hisayama study. Neurology. 2010;75(9):764-70.

48. Park H, Poo MM. Neurotrophin regulation of neural circuit development and function. Nat Rev Neurosci. 2013;14(1):7-23.

49. Mori MAdS, Anhê GF, Machado UF. Bases biomoleculares da resistência à insulina. In: Giacaglia LR, da Silva MER, dos Santos RF, editors. Tratado de Síndrome Metabólica. São Paulo: Editora Roca; 2010. p. 19-34.

50. Brunet A, Datta SR, Greenberg ME. Transcription-dependent and -independent control of neuronal survival by the PI3K-Akt signaling pathway. Current Opinion in Neurobiology. 2001;11(3).

51. Rayasam GV, Tulasi VK, Sodhi R, Davis JA, Ray A. Glycogen synthase kinase 3: more than a namesake. British Journal of Pharmacology. 2009;156(6).

52. Zhao WQ, Townsend $M$. Insulin resistance and amyloidogenesis as common molecular foundation for type 2 diabetes and Alzheimer's disease. Biochimica Et Biophysica Acta-Molecular Basis of Disease. 2009;1792(5):482-96.

53. Salkovic-Petrisic M, Osmanovic J, Grunblatt E, Riederer P, Hoyer S. Modeling Sporadic Alzheimer's Disease: The Insulin Resistant Brain State Generates Multiple LongTerm Morphobiological Abnormalities Including Hyperphosphorylated Tau Protein and Amyloid-beta. Journal of Alzheimers Disease. 2009;18(4):729-50.

54. Liberman Z, Eldar-Finkelman H. Serine 332 phosphorylation of insulin receptor substrate- 1 by glycogen synthase kinase-3 attenuates insulin signaling. Journal of Biological Chemistry. 2005;280(6).

55. Cross DAE, Culbert AA, Chalmers KA, Facci L, Skaper SD, Reith AD. Selective small-molecule inhibitors of glycogen synthase kinase-3 activity protect primary neurones from death. Journal of Neurochemistry. 2001;77(1).

56. Zhao WQ, Lacor PN, Chen H, Lambert MP, Quon MJ, Krafft GA, et al. Insulin Receptor Dysfunction Impairs Cellular Clearance of Neurotoxic Oligomeric A beta. Journal of Biological Chemistry. 2009;284(28):18742-53. 
57. Gupta A, Bisht B, Dey CS. Peripheral insulin-sensitizer drug metformin ameliorates neuronal insulin resistance and Alzheimer's-like changes. Neuropharmacology. $2011 ; 60(6): 910-20$.

58. Gutierrez DA, Puglisi MJ, Hasty AH. Impact of increased adipose tissue mass on inflammation, insulin resistance, and dyslipidemia. Curr Diab Rep. 2009;9(1):26-32.

59. Bomfim TR, Forny-Germano L, Sathler LB, Brito-Moreira J, Houzel J-C, Decker H, et al. An anti-diabetes agent protects the mouse brain from defective insulin signaling caused by Alzheimer's disease-associated A beta oligomers. Journal of Clinical Investigation. 2012;122(4).

60. White MF. IRS proteins and the common path to diabetes. American Journal of Physiology-Endocrinology and Metabolism. 2002;283(3).

61. Holmes C, Cunningham C, Zotova E, Woolford J, Dean C, Kerr S, et al. Systemic inflammation and disease progression in Alzheimer disease. Neurology. 2009;73(10).

62. Marioni RE, Strachan MWJ, Reynolds RM, Lowe GDO, Mitchell RJ, Fowkes FGR, et al. Association Between Raised Inflammatory Markers and Cognitive Decline in Elderly People With Type 2 Diabetes The Edinburgh Type 2 Diabetes Study. Diabetes. 2010;59(3).

63. Beeler N, Riederer BM, Waeber G, Abderrahmani A. Role of the JNK-interacting protein 1/islet brain 1 in cell degeneration in Alzheimer disease and diabetes. Brain Research Bulletin. 2009;80(4-5).

64. Morishima Y, Gotoh Y, Zieg J, Barrett T, Takano H, Flavell R, et al. beta-amyloid induces neuronal apoptosis via a mechanism that involves the c-Jun $\mathrm{N}$-terminal kinase pathway and the induction of Fas ligand. Journal of Neuroscience. 2001;21(19).

65. Roberts CK, Hevener AL, Barnard RJ. Metabolic syndrome and insulin resistance: underlying causes and modification by exercise training. Compr Physiol. 2013;3(1):1-58.

66. DeFronzo RA, Tripathy D. Skeletal muscle insulin resistance is the primary defect in type 2 diabetes. Diabetes Care. 2009;32 Suppl 2:S157-63.

67. Egan B, Zierath JR. Exercise metabolism and the molecular regulation of skeletal muscle adaptation. Cell Metab. 2013;17(2):162-84.

68. Conn VS, Koopman RJ, Ruppar TM, Phillips LJ, Mehr DR, Hafdahl AR. Insulin Sensitivity Following Exercise Interventions: Systematic Review and Meta-Analysis of Outcomes Among Healthy Adults. J Prim Care Community Health. 2014;5(3):211-22.

69. Booth FW, Roberts CK, Laye MJ. Lack of exercise is a major cause of chronic diseases. Compr Physiol. 2012;2(2):1143-211.

70. Gennuso KP, Gangnon RE, Thraen-Borowski KM, Colbert LH. Dose-response relationships between sedentary behaviour and the metabolic syndrome and its components. Diabetologia. 2015;58(3):485-92.

71. Da Silva AS, Pauli JR, Ropelle ER, Oliveira AG, Cintra DE, De Souza CT, et al. Exercise intensity, inflammatory signaling, and insulin resistance in obese rats. Med Sci Sports Exerc. 2010;42(12):2180-8.

72. Hawley JA, Lessard SJ. Exercise training-induced improvements in insulin action. Acta Physiol (Oxf). 2008;192(1):127-35.

73. Yan Z, Okutsu M, Akhtar YN, Lira VA. Regulation of exercise-induced fiber type transformation, mitochondrial biogenesis, and angiogenesis in skeletal muscle. J Appl Physiol (1985). 2011;110(1):264-74.

74. Lira VA, Benton CR, Yan Z, Bonen A. PGC-1alpha regulation by exercise training and its influences on muscle function and insulin sensitivity. Am J Physiol Endocrinol Metab. 2010;299(2):E145-61.

75. Ferraro E, Giammarioli AM, Chiandotto S, Spoletini I, Rosano G. Exercise-induced skeletal muscle remodeling and metabolic adaptation: redox signaling and role of autophagy. Antioxid Redox Signal. 2014;21(1):154-76.

76. Glick D, Barth S, Macleod KF. Autophagy: cellular and molecular mechanisms. J Pathol. 2010;221(1):3-12.

77. He C, Bassik MC, Moresi V, Sun K, Wei Y, Zou Z, et al. Exercise-induced BCL2regulated autophagy is required for muscle glucose homeostasis. Nature. 2012;481(7382):511-5. 
78. He C, Sumpter R, Levine B. Exercise induces autophagy in peripheral tissues and in the brain. Autophagy. 2012;8(10):1548-51.

79. Lira VA, Okutsu M, Zhang M, Greene NP, Laker RC, Breen DS, et al. Autophagy is required for exercise training-induced skeletal muscle adaptation and improvement of physical performance. Faseb j. 2013;27(10):4184-93.

80. Mozumdar A, Liguori G. Persistent increase of prevalence of metabolic syndrome among U.S. adults: NHANES III to NHANES 1999-2006. Diabetes Care. 2011;34(1):216-9.

81. Cordain L, Eaton SB, Sebastian A, Mann N, Lindeberg S, Watkins BA, et al. Origins and evolution of the Western diet: health implications for the 21 st century. Am J Clin Nutr. 2005;81(2):341-54.

82. Zavaroni I, Sander S, Scott S, Reaven GM. Effect of fructose feeding on insulin secretion and insulin action in the rat. Metabolism. 1980;29(10):970-3.

83. Thorburn AW, Storlien LH, Jenkins AB, Khouri S, Kraegen EW. Fructose-induced in vivo insulin resistance and elevated plasma triglyceride levels in rats. Am $\mathrm{J}$ Clin Nutr. 1989;49(6):1155-63.

84. Kelley GL, Allan G, Azhar S. High dietary fructose induces a hepatic stress response resulting in cholesterol and lipid dysregulation. Endocrinology. 2004;145(2).

85. Taghibiglou C, Carpentier A, Van Iderstine SC, Chen B, Rudy D, Aiton A, et al. Mechanisms of hepatic very low density lipoprotein overproduction in insulin resistance. Evidence for enhanced lipoprotein assembly, reduced intracellular ApoB degradation, and increased microsomal triglyceride transfer protein in a fructose-fed hamster model. $\mathrm{J}$ Biol Chem. 2000;275(12):8416-25.

86. Bray GA. Potential health risks from beverages containing fructose found in sugar or high-fructose corn syrup. Diabetes Care. 2013;36(1):11-2.

87. Aeberli I, Hochuli M, Gerber PA, Sze L, Murer SB, Tappy L, et al. Moderate amounts of fructose consumption impair insulin sensitivity in healthy young men: a randomized controlled trial. Diabetes Care. 2013;36(1):150-6.

88. Aijälä M, Malo E, Ukkola O, Bloigu R, Lehenkari $\mathrm{P}$, Autio-Harmainen $\mathrm{H}$, et al. Longterm fructose feeding changes the expression of leptin receptors and autophagy genes in the adipose tissue and liver of male rats: a possible link to elevated triglycerides. Genes Nutr. 2013;8(6):623-35.

89. Conlee RK, Lawler RM, Ross PE. Effects of glucose or fructose feeding on glycogen repletion in muscle and liver after exercise or fasting. Ann Nutr Metab. 1987;31(2):126-32.

90. Mayes PA. Intermediary metabolism of fructose. Am J Clin Nutr. 1993;58(5 Suppl):754S-65S.

91. Stephan BC, Wells JC, Brayne C, Albanese E, Siervo M. Increased fructose intake as a risk factor for dementia. J Gerontol A Biol Sci Med Sci. 2010;65(8):809-14.

92. De Felice FG, Lourenco MV, Ferreira ST. How does brain insulin resistance develop in Alzheimer's disease? Alzheimers Dement. 2014;10(1 Suppl):S26-32.

93. Stranahan AM, Norman ED, Lee K, Cutler RG, Telljohann RS, Egan JM, et al. Dietinduced insulin resistance impairs hippocampal synaptic plasticity and cognition in middleaged rats. Hippocampus. 2008;18(11):1085-8.

94. Agrawal R, Gomez-Pinilla F. 'Metabolic syndrome' in the brain: deficiency in omega-3 fatty acid exacerbates dysfunctions in insulin receptor signalling and cognition. J Physiol. 2012;590(Pt 10):2485-99.

95. Tsien JZ. Building a brainier mouse. Sci Am. 2000;282(4):62-8.

96. Li F, Tsien JZ. Memory and the NMDA receptors. N Engl J Med. 2009;361(3):302-3.

97. Ng D, Pitcher GM, Szilard RK, Sertié A, Kanisek M, Clapcote SJ, et al. Neto1 is a novel CUB-domain NMDA receptor-interacting protein required for synaptic plasticity and learning. PLoS Biol. 2009;7(2):e41.

98. Farr SA, Yamada KA, Butterfield DA, Abdul HM, Xu L, Miller NE, et al. Obesity and hypertriglyceridemia produce cognitive impairment. Endocrinology. 2008;149(5):2628-36.

99. Perlmuter LC, Nathan DM, Goldfinger SH, Russo PA, Yates J, Larkin M. Triglyceride levels affect cognitive function in noninsulin-dependent diabetics. J Diabet Complications. 1988;2(4):210-3. 
100. Mackenzie R, Maxwell N, Castle P, Elliott B, Brickley G, Watt P. Intermittent Exercise with and without Hypoxia Improves Insulin Sensitivity in Individuals with Type 2 Diabetes. Journal of Clinical Endocrinology \& Metabolism. 2012;97(4):E546-E55.

101. Frisbee JC, Samora JB, Peterson J, Bryner R. Exercise training blunts microvascular rarefaction in the metabolic syndrome. American Journal of Physiology-Heart and Circulatory Physiology. 2006;291(5):H2483-H92.

102. Lesniewski LA, Durrant JR, Connell ML, Henson GD, Black AD, Donato AJ, et al. Aerobic exercise reverses arterial inflammation with aging in mice. Am J Physiol Heart Circ Physiol. 2011;301(3):H1025-32.

103. Noble EE, Mavanji V, Little MR, Billington CJ, Kotz CM, Wang C. Exercise reduces diet-induced cognitive decline and increases hippocampal brain-derived neurotrophic factor in CA3 neurons. Neurobiol Learn Mem. 2014;114:40-50.

104. Johnson RJ, Murray R. Fructose, exercise, and health. Curr Sports Med Rep. 2010;9(4):253-8.

105. Da Silva-Grigoletto ME, Fernández JM, de Sá CA, Gómez-Puerto JR, Vaamonde D, Pérez-Jiménez $\mathrm{F}$. Fructose addition to a glucose supplement modifies perceived exertion during strength and endurance exercise. J Strength Cond Res. 2010;24(12):3334-42.

106. Bray GA. Energy and fructose from beverages sweetened with sugar or high-fructose corn syrup pose a health risk for some people. Adv Nutr. 2013;4(2):220-5.

107. Verma S, Bhanot S, McNeill JH. Antihypertensive effects of metformin in fructose-fed hyperinsulinemic, hypertensive rats. J Pharmacol Exp Ther. 1994;271(3):1334-7.

108. Barnes CA. Memory deficits associated with senescence: a neurophysiological and behavioral study in the rat. J Comp Physiol Psychol. 1979;93(1):74-104.

109. Poucet B, Herrmann T, Buhot MC. Effects of short-lasting inactivations of the ventral hippocampus and medial septum on long-term and short-term acquisition of spatial information in rats. Behav Brain Res. 1991;44(1):53-65.

110. Samson ML, Kajitani K, Robertson GS. Nitric-oxide synthase mediates the ability of darbepoetin alfa to attenuate pre-existing spatial working memory deficits in rats subjected to transient global ischemia. J Pharmacol Exp Ther. 2010;333(2):437-44.

111. Brown D. Tracker Video Analysis and Modeling Tool [Available from: https://www.cabrillo.edu/ dbrown/tracker/.

112. Levy JC, Matthews DR, Hermans MP. Correct homeostasis model assessment (HOMA) evaluation uses the computer program. Diabetes Care. 1998;21(12).

113. Wallace TM, Levy JC, Matthews DR. Use and abuse of HOMA modeling. Diabetes Care. $2004 ; 27(6)$.

114. Oxford HOMA Calculator [Available from: www.dtu.ox.ac.uk/homacalculator/download.php.

115. Livak KJ, Schmittgen TD. Analysis of relative gene expression data using real-time quantitative PCR and the 2(-Delta Delta C(T)) Method. Methods. 2001;25(4):402-8.

116. Agrawal R, Gomez-Pinilla F. Metabolic syndrome' in the brain: deficiency in omega-3 fatty acid exacerbates dysfunctions in insulin receptor signalling and cognition. Journal of Physiology-London. 2012;590(10).

117. Cotman CW, Berchtold NC. Physical activity and the maintenance of cognition: Learning from animal models. Alzheimers \& Dementia. 2007;3(2):S30-S7.

118. Greenberg ME, Xu B, Lu B, Hempstead BL. New insights in the biology of BDNF synthesis and release: implications in CNS function. J Neurosci. 2009;29(41):12764-7.

119. Kuipers SD, Bramham CR. Brain-derived neurotrophic factor mechanisms and function in adult synaptic plasticity: new insights and implications for therapy. Curr Opin Drug Discov Devel. 2006;9(5):580-6.

120. Bostrom P, Wu J, Jedrychowski MP, Korde A, Ye L, Lo JC, et al. A PGC1-alphadependent myokine that drives brown-fat-like development of white fat and thermogenesis. Nature. 2012;481(7382):463-U72.

121. Wrann CD, White JP, Salogiannnis J, Laznik-Bogoslavski D, Wu J, Ma D, et al. Exercise induces hippocampal BDNF through a PGC-1a/FNDC5 pathway. Cell Metab. 2013;18(5):649-59. 
122. Puigserver $\mathrm{P}$, Spiegelman BM. Peroxisome proliferator-activated receptor-gamma coactivator 1 alpha (PGC-1 alpha): transcriptional coactivator and metabolic regulator. Endocr Rev. 2003;24(1):78-90.

123. Wu H, Kanatous SB, Thurmond FA, Gallardo T, Isotani E, Bassel-Duby R, et al. Regulation of mitochondrial biogenesis in skeletal muscle by CaMK. Science. 2002;296(5566):349-52.

124. Long YC, Barnes BR, Mahlapuu M, Steiler TL, Martinsson S, Leng Y, et al. Role of AMP-activated protein kinase in the coordinated expression of genes controlling glucose and lipid metabolism in mouse white skeletal muscle. Diabetologia. 2005;48(11):2354-64.

125. Suwa M, Egashira T, Nakano H, Sasaki H, Kumagai S. Metformin increases the PGC-1alpha protein and oxidative enzyme activities possibly via AMPK phosphorylation in skeletal muscle in vivo. J Appl Physiol (1985). 2006;101(6):1685-92.

126. Li DJ, Huang F, Lu WJ, Jiang GJ, Deng YP, Shen FM. Metformin promotes irisin release from murine skeletal muscle independently of AMP-activated protein kinase activation. Acta Physiol (Oxf). 2015;213(3):711-21.

127. Malhotra A, Noakes T, Phinney S. It is time to bust the myth of physical inactivity and obesity: you cannot outrun a bad diet. Br J Sports Med. 2015.

128. Reisi P, Alaei H, Babri S, Sharifi MR, Mohaddes G. Effects of treadmill running on spatial learning and memory in streptozotocin-induced diabetic rats. Neurosci Lett. 2009;455(2):79-83.

129. Diegues JC, Pauli JR, Luciano E, de Almeida Leme JA, de Moura LP, Dalia RA, et al. Spatial memory in sedentary and trained diabetic rats: molecular mechanisms. Hippocampus. 2014;24(6):703-11.

130. Michael LF, Wu Z, Cheatham RB, Puigserver P, Adelmant G, Lehman JJ, et al. Restoration of insulin-sensitive glucose transporter (GLUT4) gene expression in muscle cells by the transcriptional coactivator PGC-1. Proc Natl Acad Sci U S A. 2001;98(7):3820-5.

131. Lin J, Wu H, Tarr PT, Zhang CY, Wu Z, Boss O, et al. Transcriptional co-activator PGC-1 alpha drives the formation of slow-twitch muscle fibres. Nature. 2002;418(6899):797801.

132. Leone TC, Lehman JJ, Finck BN, Schaeffer PJ, Wende AR, Boudina S, et al. PGC1 alpha deficiency causes multi-system energy metabolic derangements: muscle dysfunction, abnormal weight control and hepatic steatosis. PLoS Biol. 2005;3(4):e101.

133. Simoneau JA, Kelley DE. Altered glycolytic and oxidative capacities of skeletal muscle contribute to insulin resistance in NIDDM. J Appl Physiol (1985). 1997;83(1):166-71.

134. Simoneau JA, Colberg SR, Thaete FL, Kelley DE. Skeletal muscle glycolytic and oxidative enzyme capacities are determinants of insulin sensitivity and muscle composition in obese women. FASEB J. 1995;9(2):273-8.

135. Daugaard JR, Nielsen JN, Kristiansen S, Andersen JL, Hargreaves M, Richter EA. Fiber type-specific expression of GLUT4 in human skeletal muscle: influence of exercise training. Diabetes. 2000;49(7):1092-5.

136. Henriksen EJ, Bourey RE, Rodnick KJ, Koranyi L, Permutt MA, Holloszy JO. Glucose transporter protein content and glucose transport capacity in rat skeletal muscles. Am J Physiol. 1990;259(4 Pt 1):E593-8.

137. Song XM, Ryder JW, Kawano Y, Chibalin AV, Krook A, Zierath JR. Muscle fiber type specificity in insulin signal transduction. Am J Physiol. 1999;277(6 Pt 2):R1690-6.

138. Papa S. Mitochondrial oxidative phosphorylation changes in the life span. Molecular aspects and physiopathological implications. Biochim Biophys Acta. 1996;1276(2):87-105.

139. Pearen MA, Myers SA, Raichur S, Ryall JG, Lynch GS, Muscat GE. The orphan nuclear receptor, NOR-1, a target of beta-adrenergic signaling, regulates gene expression that controls oxidative metabolism in skeletal muscle. Endocrinology. 2008;149(6):2853-65.

140. Pearen MA, Eriksson NA, Fitzsimmons RL, Goode JM, Martel N, Andrikopoulos S, et al. The nuclear receptor, Nor-1, markedly increases type II oxidative muscle fibers and resistance to fatigue. Mol Endocrinol. 2012;26(3):372-84.

141. Desvergne B, Wahli W. Peroxisome proliferator-activated receptors: nuclear control of metabolism. Endocr Rev. 1999;20(5):649-88. 
142. Mootha VK, Handschin C, Arlow D, Xie X, St Pierre J, Sihag S, et al. Erralpha and Gabpa/b specify PGC-1alpha-dependent oxidative phosphorylation gene expression that is altered in diabetic muscle. Proc Natl Acad Sci U S A. 2004;101(17):6570-5.

143. Schreiber SN, Emter R, Hock MB, Knutti D, Cardenas J, Podvinec M, et al. The estrogen-related receptor alpha (ERRalpha) functions in PPARgamma coactivator 1alpha (PGC-1alpha)-induced mitochondrial biogenesis. Proc Natl Acad Sci U $S$ A. 2004;101(17):6472-7.

144. Wende AR, Huss JM, Schaeffer PJ, Giguère V, Kelly DP. PGC-1alpha coactivates PDK4 gene expression via the orphan nuclear receptor ERRalpha: a mechanism for transcriptional control of muscle glucose metabolism. Mol Cell Biol. 2005;25(24):10684-94.

145. Huss JM, Torra IP, Staels B, Giguère V, Kelly DP. Estrogen-related receptor alpha directs peroxisome proliferator-activated receptor alpha signaling in the transcriptional control of energy metabolism in cardiac and skeletal muscle. Mol Cell Biol. 2004;24(20):9079-91.

146. Goyaram V, Kohn TA, Ojuka EO. Suppression of the GLUT4 adaptive response to exercise in fructose-fed rats. Am J Physiol Endocrinol Metab. 2014;306(3):E275-83.

147. Handschin C, Rhee J, Lin J, Tarr PT, Spiegelman BM. An autoregulatory loop controls peroxisome proliferator-activated receptor gamma coactivator 1 alpha expression in muscle. Proc Natl Acad Sci U S A. 2003;100(12):7111-6.

148. Wohlgemuth SE, Lees HA, Marzetti E, Manini TM, Aranda JM, Daniels MJ, et al. An Exploratory Analysis of the Effects of a Weight Loss Plus Exercise Program on Cellular Quality Control Mechanisms in Older Overweight Women. Rejuvenation Research. 2011;14(3):315-24.

149. Reggiori F, Tooze SA. Autophagy regulation through Atg9 traffic. J Cell Biol. 2012;198(2):151-3.

150. Saftig P, Beertsen W, Eskelinen EL. LAMP-2: a control step for phagosome and autophagosome maturation. Autophagy. 2008;4(4):510-2.

151. Bollinger LM, Powell JJ, Houmard JA, Witczak CA, Brault JJ. Skeletal muscle myotubes in severe obesity exhibit altered ubiquitin-proteasome and autophagic/lysosomal proteolytic flux. Obesity (Silver Spring). 2015;23(6):1185-93.

152. Baar K, Wende AR, Jones TE, Marison M, Nolte LA, Chen M, et al. Adaptations of skeletal muscle to exercise: rapid increase in the transcriptional coactivator PGC-1. FASEB J. 2002;16(14):1879-86.

153. Wu Z, Puigserver P, Andersson U, Zhang C, Adelmant G, Mootha V, et al. Mechanisms controlling mitochondrial biogenesis and respiration through the thermogenic coactivator PGC-1. Cell. 1999;98(1):115-24.

154. Pacelli C, De Rasmo D, Signorile A, Grattagliano I, di Tullio G, D'Orazio A, et al. Mitochondrial defect and PGC-1a dysfunction in parkin-associated familial Parkinson's disease. Biochim Biophys Acta. 2011;1812(8):1041-53.

155. Masiero E, Agatea L, Mammucari C, Blaauw B, Loro E, Komatsu M, et al. Autophagy is required to maintain muscle mass. Cell Metab. 2009;10(6):507-15.

156. Lin J, Handschin C, Spiegelman BM. Metabolic control through the PGC-1 family of transcription coactivators. Cell Metab. 2005;1(6):361-70.

157. Geng T, Li P, Okutsu M, Yin X, Kwek J, Zhang M, et al. PGC-1alpha plays a functional role in exercise-induced mitochondrial biogenesis and angiogenesis but not fibertype transformation in mouse skeletal muscle. Am J Physiol Cell Physiol. 2010;298(3):C5729.

158. Leick L, Wojtaszewski JF, Johansen ST, Kiilerich K, Comes G, Hellsten Y, et al. PGC-1 alpha is not mandatory for exercise- and training-induced adaptive gene responses in mouse skeletal muscle. Am J Physiol Endocrinol Metab. 2008;294(2):E463-74.

159. Rowe GC, Patten IS, Zsengeller ZK, El-Khoury R, Okutsu M, Bampoh S, et al. Disconnecting mitochondrial content from respiratory chain capacity in PGC-1-deficient skeletal muscle. Cell Rep. 2013;3(5):1449-56. 
160. Zhao J, Brault JJ, Schild A, Cao P, Sandri M, Schiaffino S, et al. FoxO3 coordinately activates protein degradation by the autophagic/lysosomal and proteasomal pathways in atrophying muscle cells. Cell Metab. 2007;6(6):472-83.

161. Mammucari C, Milan G, Romanello V, Masiero E, Rudolf R, Del Piccolo P, et al. FoxO3 controls autophagy in skeletal muscle in vivo. Cell Metab. 2007;6(6):458-71.

162. Böhm A, Hoffmann C, Irmler M, Schneeweiss P, Schnauder G, Sailer C, et al. TGF- $\beta$ Contributes to Impaired Exercise Response by Suppression of Mitochondrial Key Regulators in Skeletal Muscle. Diabetes. 2016;65(10):2849-61.

163. Liu TT, Shih KC, Kao CC, Cheng WT, Hsieh PS. Importance of cyclooxygenase 2mediated low-grade inflammation in the development of fructose-induced insulin resistance in rats. Chin J Physiol. 2009;52(2):65-71.

164. Rutledge AC, Adeli K. Fructose and the metabolic syndrome: pathophysiology and molecular mechanisms. Nutr Rev. 2007;65(6 Pt 2):S13-23.

165. Teixeira de Lemos E, Pinto R, Oliveira J, Garrido P, Sereno J, Mascarenhas-Melo F, et al. Differential effects of acute (extenuating) and chronic (training) exercise on inflammation and oxidative stress status in an animal model of type 2 diabetes mellitus. Mediators Inflamm. 2011;2011:253061.

166. Codella R, Lanzoni G, Zoso A, Caumo A, Montesano A, Terruzzi IM, et al. Moderate Intensity Training Impact on the Inflammatory Status and Glycemic Profiles in NOD Mice. J Diabetes Res. 2015;2015:737586.

167. Toledo AC, Magalhaes RM, Hizume DC, Vieira RP, Biselli PJC, Moriya HT, et al. Aerobic exercise attenuates pulmonary injury induced by exposure to cigarette smoke. European Respiratory Journal. 2012;39(2):254-64.

168. Murakami T, Shimomura Y, Fujitsuka N, Sokabe M, Okamura K, Sakamoto S. Enlargement glycogen store in rat liver and muscle by fructose-diet intake and exercise training. J Appl Physiol (1985). 1997;82(3):772-5.

169. Philp A, MacKenzie MG, Belew MY, Towler MC, Corstorphine A, Papalamprou A, et al. Glycogen content regulates peroxisome proliferator activated receptor- $\partial$ (PPAR- $\partial$ ) activity in rat skeletal muscle. PLoS One. 2013;8(10):e77200.

170. Coen PM, Jubrias SA, Distefano G, Amati F, Mackey DC, Glynn NW, et al. Skeletal muscle mitochondrial energetics are associated with maximal aerobic capacity and walking speed in older adults. J Gerontol A Biol Sci Med Sci. 2013;68(4):447-55.

171. Sun SZ, Empie MW. Fructose metabolism in humans - what isotopic tracer studies tell us. Nutr Metab (Lond). 2012;9(1):89.

172. Kitaoka Y, Takeda K, Tamura Y, Hatta H. Lactate administration increases mRNA expression of PGC-1 $\alpha$ and UCP3 in mouse skeletal muscle. Appl Physiol Nutr Metab. 2016;41(6):695-8.

173. Hashimoto T, Hussien R, Oommen S, Gohil K, Brooks GA. Lactate sensitive transcription factor network in L6 cells: activation of MCT1 and mitochondrial biogenesis. FASEB J. 2007;21(10):2602-12.

174. Koves TR, Ussher JR, Noland RC, Slentz D, Mosedale M, Ilkayeva O, et al. Mitochondrial overload and incomplete fatty acid oxidation contribute to skeletal muscle insulin resistance. Cell Metab. 2008;7(1):45-56.

175. Jiang T, Yu JT, Zhu XC, Wang HF, Tan MS, Cao L, et al. Acute metformin preconditioning confers neuroprotection against focal cerebral ischaemia by pre-activation of AMPK-dependent autophagy. Br J Pharmacol. 2014;171(13):3146-57.

176. Li J, Benashski SE, Venna VR, McCullough LD. Effects of metformin in experimental stroke. Stroke. 2010;41(11):2645-52.

177. Wang J, Gallagher D, DeVito LM, Cancino GI, Tsui D, He L, et al. Metformin activates an atypical PKC-CBP pathway to promote neurogenesis and enhance spatial memory formation. Cell Stem Cell. 2012;11(1):23-35. 


\section{Published article}




\title{
Fructose ingestion impairs expression of genes involved in skeletal muscle's adaptive response to aerobic exercise
}

Natalia Gomes Gonçalves ${ }^{1}$, Stephanie Heffer Cavaletti ${ }^{1}$, Carlos Augusto Pasqualucci ${ }^{1}$, Milton Arruda Martins ${ }^{2}$ and Chin Jia Lin ${ }^{1 *}$

\begin{abstract}
Background: The inverse relationship between exercise capacity and its variation over time and both cardiovascular and all-cause mortality suggests the existence of an etiological nexus between cardiometabolic diseases and the molecular regulators of exercise capacity. Coordinated adaptive responses elicited by physical training enhance exercise performance and metabolic efficiency and possibly mediate the health benefits of physical exercise. In contrast, impaired expression of genes involved in mitochondrial biogenesis or protein turnover in skeletal muscle — key biological processes involved in adaptation to physical training - leads to insulin resistance and obesity. Ingestion of fructose has been shown to suppress the exercise-induced GLUT4 response in rat skeletal muscle. To evaluate in greater detail how fructose ingestion might blunt the benefits of physical training, we investigated the effects of fructose ingestion on exercise induction of genes that participate in regulation of mitochondrial biogenesis and protein turnover in rat's skeletal muscle.

Methods: Eight-week-old Wistar rats were randomly assigned to sedentary (C), exercise (treadmill running)-only (E), fructose-only (F), and fructose + exercise (FE) groups and treated accordingly for 8 weeks. Blood and quadriceps femoris were collected for biochemistry, serum insulin, and gene expression analysis. Expression of genes involved in regulation of mitochondrial biogenesis and autophagy, GLUT4, and ubiquitin E3 ligases MuRF-1, and MAFbx/Atrogin-1 were assayed with quantitative real-time polymerase chain reaction.

Results: Aerobic training improved exercise capacity in both $E$ and FE groups. A main effect of fructose ingestion on body weight and fasting serum triglyceride concentration was detected. Fructose ingestion impaired the expression of PGC-1a, FNDC5, NR4A3, GLUT4, Atg9, Lamp2, Ctsl, Murf-1, and MAFBx/Atrogin-1 in skeletal muscle of both sedentary and exercised animals while expression of Erra and Ppar反 was impaired only in exercised rats.

Conclusions: Our results show that fructose ingestion impairs the expression of genes involved in biological processes relevant to exercise-induced remodeling of skeletal muscle. This might provide novel insight on how a dietary factor contributes to the genesis of disorders of glucose metabolism.
\end{abstract}

Keywords: Fructose, Exercise training, Skeletal muscle, Protein turnover, PGC-1a, Rats

\footnotetext{
*Correspondence: cjlin@usp.br

'Department of Pathology, School of Medicine, University of São Paulo, São

Paulo, Brazil

Full list of author information is available at the end of the article
} 


\section{Background}

The importance of physical activity as an essential component of a healthy lifestyle cannot be overlooked. Regular physical exercise enhances health span [1] while lack of physical activity or decreased physical fitness confers increased risk for premature death and increased risk for several chronic, non-communicable diseases [2]. Physical fitness or exercise capacity is a better predictor of mortality than traditional cardiovascular risk factors [3], and changes in exercise capacity over time are strong and inversely associated with all-cause mortality in men [4]. Interestingly, rats selectively bred for low exercise capacity exhibited defects characteristic of metabolic syndrome such as elevated blood pressure, impaired glucose tolerance, visceral adiposity, and elevated circulating levels of triglycerides [5]. These observations suggest that cardiometabolic diseases and the molecular determinants of exercise capacity are etiologically connected.

Physical exercise produces mechanical, metabolic, nutritional, and oxidative stresses in engaged skeletal muscles. These stimuli trigger a set of coordinated adaptive responses which result in modification of volume, protein content, mechanical properties, and metabolic capacities [6]. These responses restore homeostasis and improve the performance of challenged muscle groups $[6,7]$. Contracting skeletal muscle can also modulate the function of metabolically relevant tissues with production and release of myokines [8]. The enhancement of muscle metabolic efficiency and crosstalk of muscle with other tissues constitute the fundamental ingredients by which physical exercise improves the health of whole organism [7]. One of the most relevant exercise-induced muscle remodeling responses, from the perspective of metabolic efficiency, is the increase in mitochondrial density and enzyme activity, termed mitochondrial biogenesis [6]. Mitochondrial biogenesis is a complex process that requires co-expression of genes from two distinct genomes (nuclear and mitochondrial) and is regulated by transcription factors and transcription co-activators [8].

Peroxisome proliferator receptor- $\gamma$ co-activator- $1 \alpha$ $(\mathrm{PGC}-1 \alpha)$ is an inducible transcription co-activator that interacts with many different transcription factors to activate distinct biological programs in a multitude of tissues. In skeletal muscle, PGC- $1 \alpha$ is readily induced by endurance exercise and regulates the coordinated expression of mitochondrial proteins encoded in both nuclear and mitochondrial genomes. Induction of PGC$1 \alpha$ in skeletal muscle leads to activation of genetic programs characteristic of slow-twitch (type I, predominantly oxidative) muscle fibers and phenotypical changes such as increase in functional mitochondria, improvement in whole-body $\mathrm{VO} 2_{\max }$, shift of fuel usage from carbohydrate to fat during submaximal exercise, and improved endurance performance [9]. Moreover, PGC- $1 \alpha$ mediates the exercise-dependent up-regulation of fibronectin type III domain-containing protein 5 (FNDC5) which is proteolytically cleaved to generate irisin-a myokine that enhances thermogenesis and promotes conversion of white adipose cell to brown adipose cell [10]. Therefore, exercise induction of PGC$1 \alpha$ seems to be an event that orchestrates adaptive responses of skeletal muscle to physical exercise although the results from loss-of-function studies suggest that PGC- $1 \alpha$ is probably not mandatory for some of the training-induced adaptive responses [11-13].

Protein turnover-proteolysis coupled with de novo protein synthesis-is another cellular process involved with exercise-induced muscle remodeling. Damaged proteins and organelles need to be removed by proteasome and autophagy proteolysis and replaced by newly synthesized ones in exercised muscles during the recovery [14]. Autophagy also plays an essential role in maintaining the mass of skeletal muscle and provides skeletal muscle cells with an alternative energy source during energy stress caused by physical training $[14,15]$. Interestingly, loss-of-function studies have shown that autophagy is required for exercise-dependent mitochondrial biogenesis and improvement of endurance capacity $[14,16]$.

Metabolic syndrome (MetS) and obesity have a longknown relationship with decreased muscle mass and strength. Morphological and functional alterations have been observed in skeletal muscle of obese or MetS subjects [17-19], and mice exposed to high-fat diet have decreased total muscle mass of hind limbs, muscle fiber diameter, muscle protein content, and grip strength [20]. Moreover, skeletal muscle myotubes from severely obese individuals are shown to have altered proteasome and autophagic proteolytic flux [21]. These findings suggest that MetS (or obesity) is associated with morphological and functional abnormalities of skeletal muscle which might be a consequence of MetS (or obesity) per se or caused, at least in part, by altered proteolytic pathways or other cellular processes due to dietary habits or physical inactivity.

Increased consumption of high-fructose corn syrup (HFCS) or sucrose via ingestion of ultra-processed food and sugar-sweetened beverages (SSB) has been linked to the obesity and diabetes epidemics in the USA [22]. Fructose is a major monosaccharide component of both HFCS and sucrose and has been considered as responsible for the metabolic effects of these sweeteners [22, 23]. The liver is the major site of fructose metabolism which breaks fructose down into metabolic intermediates that enter promptly the triose pool in a process that bypasses the rate-limiting phosphofructokinase step. The expansion of triose phosphate pool is responsible for metabolic 
adaptations to acute fructose load while the responses to long-term load will depend on enzymatic adaptation [23]. In the liver of fed animals, the increase in the flux through the glycolytic pathway leads to lactate production, activation of pyruvate dehyderogenase, and enhancement of oxidative pathway with carbon dioxide and ketone body production [23]. This metabolic milieu also favors esterification of non-esterified fatty acids (NEFAs) augmenting the liver production and secretion of very low density lipoprotein (VLDL) [23]. In starved animals, activation of gluconeogenesis enzymes leads to formation of glucose from fructose [23]. Long-term load of fructose causes the liver to form more glucose and glycogen from fructose and respond more intensely to the actions of fructose in promoting VLDL output. In adipose tissue, fructose impairs both glucose utilization and esterification of fatty acids. This raises NEFAs concentration and increases VLDL production. Increased concentration of triglyceride and NEFAs impairs glucose utilization in skeletal muscle [23]. The consequence is increased insulin resistance, hyperinsulinemia, and formation of a vicious cycle in which insulin resistance will stimulate the already increased VLDL production by the liver. Thus, chronic fructose feeding will produce metabolic derangement similar to those found in the MetS.

Ingestion of fructose or maltodextrin has been shown to suppress the exercise-induced glucose transporter type 4 (GLUT4) adaptive response in rat skeletal muscle [24]. Motivated by this work, we conducted the present study to investigate if ingestion of fructose can impair the expression of genes involved in post-exercise muscle remodeling which is our primary aim in this study. The secondary aim of this study is to assess the effects of fructose ingestion and physical training on expression of selected genes involved in protein degradation in skeletal muscle.

\section{Methods}

\section{Animals and experimental protocol}

Eight-week-old male Wistar rats were provided by the University of São Paulo School of Medicine's Animal Facility which keeps the animals in cages with four to five animals and feeds them with standard chow from weaning to the moment they started the protocol. The animals were randomly allocated into the following groups: sedentary control $(\mathrm{C}, n=6)$, exercise-only (E, $n$ $=7)$, sedentary fructose $(F, n=8)$, and fructose + exercise $(\mathrm{FE}, n=8)$ and treated accordingly for 8 weeks. The pretreatment weight of the rats ranged from 194.64 to $342.0 \mathrm{~g}$, and there was no inter-group difference $(F(3$, $29)=2.23, p=0.110)$. The animals were kept in cages with four to five animals under a 12-h light/dark cycle and were given ad libitum access to food and water. Standard chow $(2990 \mathrm{kcal} / \mathrm{kg})$ was given as a solid diet.
The rats assigned to fructose treatment ( $\mathrm{F}$ and $\mathrm{FE}$ groups) were given a $15 \%$ fructose solution as drinking solution. The fructose treatment began on the same day as the exercise training (see the next section). The quantity and volume of unconsumed food and fluid for each cage were verified each morning. The daily consumption of food and fluid was calculated as a difference between what was provided on previous day and what was left unconsumed. Due to limited quantity of tissue and blood samples, biochemical and molecular analyses were not performed in all the animals.

This study was approved by the Ethics Committee of University of São Paulo School of Medicine under the number 073/13, and all animal experiments were performed according to the procedures approved at our institution.

\section{Treadmill exercise protocol}

The rats in exercise training groups were initially acclimatized to the treadmill (KT 400, Imbramed, RS, Brazil) for 3 days $(10 \mathrm{~min} /$ day, $0.3 \mathrm{~km} / \mathrm{h})$. Afterwards, a maximal exercise capacity test was performed with an initial velocity of $0.3 \mathrm{~km} / \mathrm{h}$ for 5 min followed by an increase of $0.1 \mathrm{~km} / \mathrm{h}$ every $1.5 \mathrm{~min}$ until animal exhaustion which was defined as the moment when an animal sat at the lower end of the treadmill and was unresponsive to 10 gentle taps to continue running. Total test time, velocity, and distance were recorded for each rat. The rats were trained at moderate intensity ( $60 \%$ of maximal velocity achieved in exercise capacity test) for $60 \mathrm{~min} /$ day, 5 days a week for 8 weeks. After 8 weeks, the maximal exercise capacity test was repeated. One of us (NGG) oversaw personally all treadmill trainings and, whenever necessary, provided with stimulation to any animal that was running slower than the speed established by the treadmill. No electrical shock was applied to the animals throughout the training period.

\section{Tissue collection and biochemical analysis}

The rats were euthanized 1 day after the last training session. After an overnight fast, the animals were anesthetized with intraperitoneal injection of $75 \mathrm{mg} / \mathrm{kg}$ ketamine and $10 \mathrm{mg} / \mathrm{kg}$ xilazine. Blood was collected by cardiac puncture. Following blood collection, the rats were euthanized by decapitation, and the quadriceps femoris was dissected and preserved in RNAlater (Ambion) while blood samples were centrifuged at $5000 \mathrm{rpm}$ at $4{ }^{\circ} \mathrm{C}$ and the resulting serum samples transferred to a fresh microcentrifuge tube. Both muscle and serum specimens were stored at $-80{ }^{\circ} \mathrm{C}$ until use.

Serum insulin levels were measured with an ELISA kit (Millipore) as per the manufacturer's instructions. Serum triglyceride and glucose levels were measured by 
enzymatic colorimetric assay in the Cobas c111 analyzer (Roche Diagnostics).

We used the HOMA2 model $[25,26]$ to evaluate insulin resistance (HOMA2-IR), pancreatic beta cell reserve (HOMA2-\%B), and insulin sensitivity (HOMA2-\%S). The indexes were calculated with the Oxford HOMA calculator [27].

\section{RNA extraction and gene expression analysis}

Total RNA from quadriceps muscle was isolated with TRI Reagent (Sigma-Aldrich) as per the manufacturer's instructions. Genomic DNA was removed by treating the RNA samples with DNase I for $20-30$ min at $37{ }^{\circ} \mathrm{C}$. RNA was reversely transcribed into complementary DNA with a commercial kit (High Capacity cDNA Reverse Transcription Kit, $\mathrm{ABI}$ ) as per the manufacturer's instructions. Gene expression analysis was performed using quantitative real-time polymerase chain reaction in assay buffer which contains EvaGreen fluorescent dye (5× HOT FIREPol ${ }^{\circ}$ EvaGreen $^{\circ}$ qPCR Mix Plus (ROX), Solis BioDyne, Tartu, Estonia) using the primers listed in Table 1. Relative gene expression was calculated using procedures reported previously [28], and cyclophilin A (CурA) was adopted as internal normalization control. A sample collected from an untreated control was used as a calibrator in all real-time PCR quantification experiments.

\section{Statistical analysis}

All data are presented as mean \pm SEM. Normality of samples was assessed with Shapiro-Wilk test. Homoscedasticity (homogeneity of variances) was assessed with Fligner-Killeen test due to robustness of this test [29]. Since there was no violation of normality or homogeneity of variances, no transformation of original data was necessary. Differences among groups of weight, metabolic profile, and exercise capacity were assessed by analysis of variance (ANOVA). The status of fructose ingestion and exercise training were used as factors and factorial ANOVA was used to assess the effect of each treatment on gene expression. This study has a power of 0.34 when an effect size of 0.4 (a large conventional effect size according to Cohen [30]) is used in the calculation. All statistical analyses were performed in $\mathrm{R}$ version 3.3.1. Study power was calculated using $R$ packages pwr and pwr2 [31, 32]. A value of $p<0.05$ was considered statistically significant.

\section{Results}

Effect of fructose and exercise on food, water, and calorie intake

Food and water intake were measured daily. The animals were kept in cages with four or five rats; therefore, it was not possible to perform statistical analysis of food, water, and calorie intake, only the means were compared. The animals assigned to groups F and FE ingested

Table 1 Primer pairs used in real-time PCR

\begin{tabular}{|c|c|c|}
\hline Gene & Forward & Reverse \\
\hline PGC-1a1 & GGACATGTGCAGCCAAGACTCT & CACTTCAATCCACCCAGAAAGCT \\
\hline FNDC5 & ATGAAGGAGATGGGGAGGAA & GCGGCAGAAGAGAGCTATGACA \\
\hline CAMK IV & AGGAGACCTCCAGTATGGTGC & СTCCTCAGTCATGGGGTCCAT \\
\hline NR4A3 & TCAGCCTTTTTGGAGCTGTT & TGAAGTCGATGCAGGACAAG \\
\hline ERRa & GCAGGGCAGTGGGAAGCTA & CCTCTTGAAGAAGGCTTTGCA \\
\hline PPAR $\delta$ & СTCCTGCTCACTGACAGATG & TCTCCTCCTGTGGCTGTTC \\
\hline FoxO3A & GCAAGCCGTGTACCGTGGA & CGGGAGCGCGATGTTATCT \\
\hline GLUT4 & GCAGCGAGTGACTGGAACA & CCAGCCACGTTGCATTGTAG \\
\hline Atg6/beclin1 & TGAATGAGGGCGACAGTGAACA & GCATCTGGTTCTCTACACTCTTG \\
\hline Atg7 & GCTCCTCACTITTTGCCAACA & GGAGCCACCACATCATTGC \\
\hline Atg9 & CAGTTTGACACTGAATACCAGCG & AATGTGGTGCCAAGGTGATTT \\
\hline LC3 & CGTCCTGGACAAGACCAAGT & AGTGCTGTCCCGAATGTCTC \\
\hline Lamp-2 & TGGCTCAGCTTTCCTTGTTTC & CATATAAGAACTTCCCAGAGGAGCAT \\
\hline Atg12 & CACCACTGCACCTGCCTCATTITAAATC & ATGGCACACATGGCTGAGGACTACTCTG \\
\hline Ctsl1 & CTATCGCCACCAGAAGCACA & AACCACACTGGCCCTGATTC \\
\hline Murf-1/TRIM63 & ACCTGCTGGTGGAGAACATC & CTTCGTGTTCCTTGCACATC \\
\hline MAFBx/Atrogin-1 & TGGGTGTATCGAATGGAGAC & TCAGCCTCTGCATGATGTTC \\
\hline Bnip3 & TTCCACTAGTACCTTTTGATGA & GAACACCGCATTTACAAAACAA \\
\hline CypA & TATCTGCACTGCCAAGACTGAGTG & CTTCTTGCTGGTCTTGCCATTCC \\
\hline
\end{tabular}


less food than groups $\mathrm{C}$ and $\mathrm{E}$. On the other hand, $\mathrm{F}$ and FE consumed more water than $\mathrm{C}$ and $\mathrm{E}$, resulting in higher calorie intake in the former (data not shown). These data agree with previous study [33].

\section{Effect of fructose and exercise in body weight}

The animals were weighted before the diet/exercise protocols started (week 0) and again after the end of the diet/exercise protocols (week 8). There was no difference between groups in pre-treatment weight $(F(3,29)=2.23$, $p=0.110)$. At the end of the 8th week, the rats in $\mathrm{E}$ group presented with the lowest while the rats in FE group with the highest body weight (Table 2). A main effect of fructose ingestion on body weight $(F(1,30)=$ 6.885, $p=0.01354$ ) as well as an interaction between fructose and exercise $(F(1,30)=7.791, p=0.00905)$ were detected.

\section{Effect of fructose in metabolic profile of the animals}

To assess the metabolic profile of the animals, after the end of the diet/exercise protocols, serum glucose, insulin, and triglyceride levels were measured. HOMA2 model was used to evaluate insulin resistance (HOMA2IR), pancreatic beta cell reserve (HOMA2-\%B), and insulin sensitivity (HOMA2-\%S). No significant effect of fructose ingestion or exercise training was detected for serum insulin (respectively, $F(1,25)=0.397, p=0.534$ and $F(1,25)=0.121, p=0.731$ ), glucose levels (respectively, $F(1,25)=1.226 p=0.279$ and $F(1,25)=1.401, p=$ 0.248 ), HOMA2-IR (respectively, $F(1,25)=1.042, p=$ 0.317 and $F(1,25)=0.627, p=0.436$ ), HOMA2-\%S (respectively, $F(1,25)=0.488, p=0.491$ and $F(1,25)=$ $0.560, p=0.461$ ), or HOMA2-\%B (respectively, $F(1,25)$ $=0.002, p=0.963$ and $F(1,25)=0.002, p=0.966)$. In contrast, there is a main effect of fructose ingestion on serum triglyceride levels $(F(1,25)=4.601, p=0.0418)$, Table 2.

\section{Effect of exercise in the physical conditioning}

To evaluate their physical conditioning, the animals underwent a maximal exercise capacity test before the diet/exercise protocols started and after the end of the protocols. In the initial maximal exercise capacity test, there was no statistical difference between the groups
$(F(3,24)=1.08, p=0.379)$. After 8 weeks of treadmill training, groups $\mathrm{E}$ and $\mathrm{FE}$ were both able to run significantly faster than the non-trained groups $\mathrm{C}$ and $\mathrm{F}$ ( $F(3$, $24)=37.24, p<0.001)$ and to reach higher speeds than they did during the initial test (E: $p=0.047$; FE: $p=$ 0.001). Interestingly, non-trained animals performed poorer in the final test relative to the initial test (C: $p=$ 0.001 ; F: $p=0.035$, Fig. 1a). The same trend is seen both in duration and distance. There were no between group differences regarding the duration of running $(F(3,24)=$ $0.59, p=0.660)$ and traveled distance $(F(3,24)=2.28, p$ $=0.090)$ at the initial assessment. After 8 weeks of training, both $\mathrm{E}$ and $\mathrm{FE}$ improved the duration (E: $p<0.001$; FE: $p=0.001$ ) and distance (E: $p<0.001$; FE: $p<0.001$ ). Both groups $\mathrm{E}$ and $\mathrm{FE}$ also ran for longer time $(F(3,24)$ $=58.66, p<0.001)$ and a greater distance $(F(3,24)=$ $42.34, p<0.001)$ than their littermates assigned to sedentary groups $(\mathrm{C}$ and $\mathrm{F})$. The non-trained animals (groups $\mathrm{C}$ and $\mathrm{F}$ ) also performed poorer relative to their own initial test in both duration (C: $p=0.003 ; \mathrm{F}: p=0.008$, Fig. 1b) and traveled distance (C: $p=0.005 ; \mathrm{F}: p=0.009$, Fig. 1c). This degradation of exercise capacity of $\mathrm{C}$ and $\mathrm{F}$ is probably a result of physical deconditioning that the untrained animals underwent after 8 weeks of sedentarism.

\section{Impact of fructose ingestion and exercise training on expression of PGC-1 $a$ and FNDC5}

Ingestion of fructose negatively affected expression of both PGC- $1 \alpha$ and FNDC5 in rat skeletal muscle regardless of their exercise status. Fructose-ingesting sedentary rats exhibited a less intense expression of PGC- $1 \alpha$ and FNDC5 than littermates that did not ingest fructose (Fig. 2a, b). Furthermore, expression of these two genes after exercise is also decreased in the fructose-fed animals when compared to the exercised animals that did not ingest fructose (Fig. 2a, b). Indeed, fructose was the only treatment that affected the expression of both PGC- $1 \alpha$ and FNDC5 $(F(1,9)=11.720, p=0.00759$ and $F(1,9)=11.310$, $p=0.00835$, respectively, PGC- $1 \alpha$ and FNDC5).

To gain further insight on the effects of fructose ingestion on molecular mediators of beneficial effects of exercise training, we studied the expression of transcription factors nuclear receptor subfamily 4 group A member 3 (NR4A3/Nor-1), estrogen-related receptor alpha (Err $\alpha$ ),

Table 2 Body weight and metabolic profile after week 8 of fructose ingestion or treadmill training

\begin{tabular}{llllllll}
\hline & Body weight $(\mathrm{g})$ & Glucose $(\mathrm{mg} / \mathrm{dL})$ & Triglyceride $(\mathrm{mg} / \mathrm{dL})$ & Insulin $(\mathrm{mUl} / \mathrm{mL})$ & HOMA2-IR & HOMA2-\%B & HOMA2-\%S \\
\hline C (6) & $479.77 \pm 8.87$ & $168.43 \pm 8.06$ & $46.01 \pm 6.42$ & $17.13 \pm 0.44$ & $2.51 \pm 0.06$ & $53.19 \pm 4.02$ & $40.17 \pm 1.07$ \\
E (7) & $429.25 \pm 8.11$ & $160.29 \pm 5.93$ & $41.05 \pm 1.49$ & $17.31 \pm 0.49$ & $2.54 \pm 0.09$ & $52.75 \pm 2.80$ & $39.8 \pm 1.47$ \\
F (8) & $475.93 \pm 12.93$ & $191.14 \pm 19.49$ & $52.3 \pm 6.45$ & $18.13 \pm 0.77$ & $2.82 \pm 0.17$ & $53.28 \pm 8.77$ & $36.68 \pm 2.33$ \\
FE (8) & $493.82 \pm 7.29$ & $166.86 \pm 5.87$ & $62.76 \pm 5.40$ & $17.36 \pm 0.92$ & $2.54 \pm 0.13$ & $53.20 \pm 2.32$ & $40.33 \pm 2.06$ \\
\hline
\end{tabular}

Results are presented as mean \pm SEM. The numbers in parenthesis represent the number of animals included in the experiment. A main effect of fructose ( $p=0.01354)$ and an interaction between fructose and exercise $(p=0.00905)$ on animals' weight were observed. There is also an effect of fructose on serum triglycerides $(p=0.0418)$. See the text for more details 

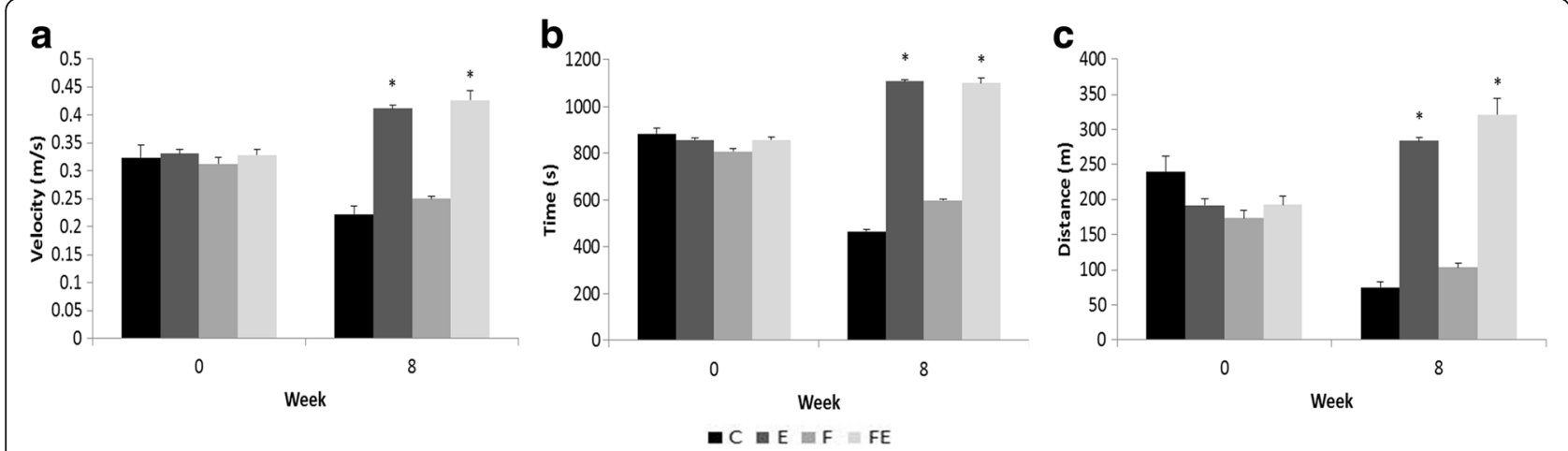

Fig. 1 Maximal exercise capacity before (week 0) and after (week 8) 8 weeks of treadmill training or fructose ingestion. Groups: C control, $E$ exercise, $F$ fructose, FE fructose + exercise. Results are presented as mean \pm SEM. a Velocity. b Duration of exercise. c Traveled distance. Exercised animals (E and FE) displayed higher exercise capacity than their non-exercised littermates $\left({ }^{*} p<0.001\right)$ after 8 weeks in all parameters. E and FE rats also improved their exercise capacity at week 8 compared to week 0 (see text for more details)

and peroxisome proliferator activated receptor $\delta$ (Ppar $\delta)$ which are induced in skeletal muscle by endurance exercise. Although average expression of NR4A3/Nor-1 was higher in rats undergoing physical training, no statistically significant effect of treadmill running was observed among rats that did not ingest fructose. In contrast, fructose-treated (F and FE) rats exhibited a $80 \%$ decrease in expression of NR4A3/Nor-1 when compared to the littermates that did not ingest fructose ( $\mathrm{C}$ and $\mathrm{E}$ groups, $p=0.027$, Fig. 2c). In fact, an effect of fructose on expression of NR4A3/Nor-1 was noted $(F(1,8)=7.651$, $p=0.0244)$. Expression of Err $\alpha$ and Ppar $\delta$ exhibited a very similar pattern. Both were strongly induced by treadmill running in skeletal muscle $(79$ and $66 \%$, respectively, Erro and Ppar $\delta$, Fig. 2c). There are main effects of fructose ingestion, exercise training, and interaction between fructose and exercise on expression of both Erro (respectively, $F(1,11)=17.61, p=0.001494$, $F(1,11)=47.38, p=2.64 \times 10^{-05}$, and $F(1,11)=29.61, p$ $=0.000203)$ and Ppar $\delta$ (respectively, $F(1,10)=20.43, p=$ $0.00111, F(1,10)=14.54, p=0.00341$, and $F(1,10)=$ $19.26, p=0.00136)$. We also assessed how fructose ingestion affects expression of calcium/calmodulin-dependent protein kinase type IV (CAMK IV) in skeletal muscle as
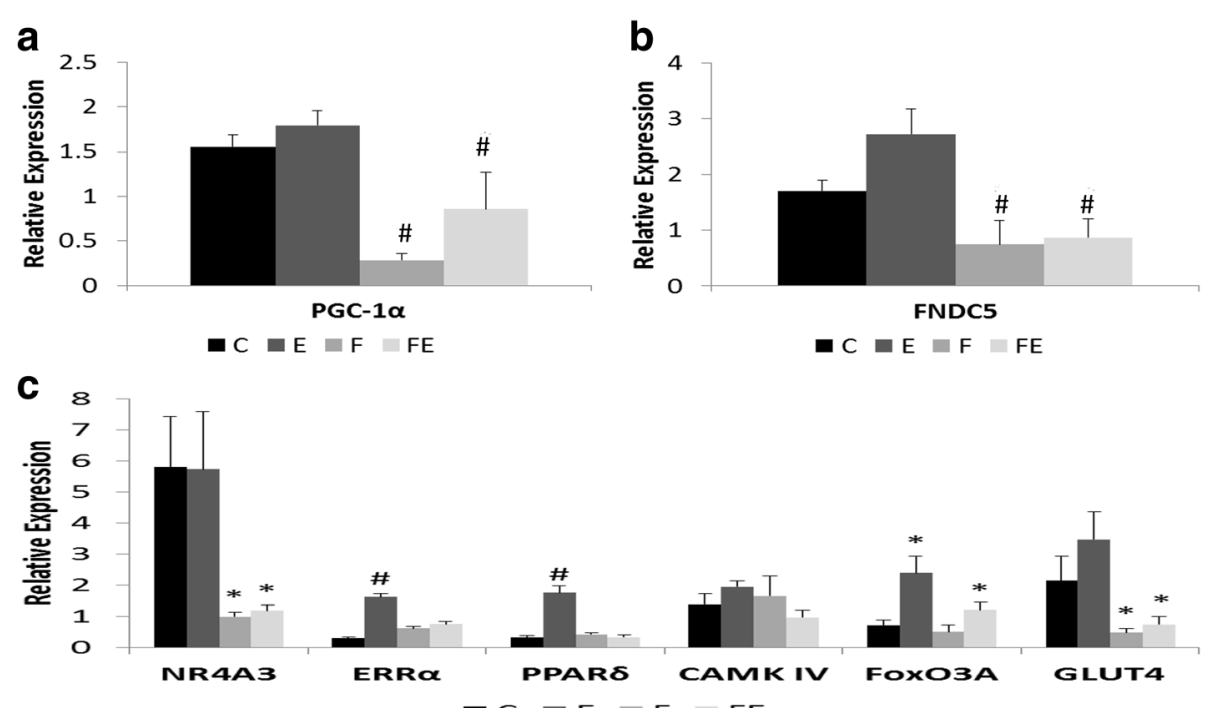

Fig. 2 Impact of aerobic training or fructose ingestion on expression of genes involved in regulation of mitochondrial biogenesis in rat skeletal muscle. a PGC-1a1. b FNDC5. c Transcriptional regulators of skeletal muscle adaptive response to exercise training and GLUT4. Groups: C control, E exercise, $F$ fructose, FE fructose + exercise. Relative expression was calculated using methods described by Livak and Schmittgen. Results are presented as mean \pm SEM. A main effect of fructose on expression of PGC-1a1, FNDC5, NR4A3/Nor-1, and GLUT4 was detected. In addition to the main effect of fructose, there is also a main effect of exercise and an interaction fructose exercise on expression of Erra and Ppar $\delta$. In contrast, there is a main effect of exercise on expression of FoxO3A. (see the text for further details). ${ }^{*} p<0.040, \# p<0.001$ 
this kinase is reported to transduce muscle contraction into a regulatory signal for the expression of PGC- $1 \alpha$ [34]. No effect of fructose ingestion or treadmill training on expression of CAMK IV was observed $(F(1,11)=$ $0.712, p=0.417$ and $F(1,11)=0.001, p=0.982$; Fig. $2 \mathrm{c})$. We also assayed the expression of GLUT4 which is induced by exercise training and is responsible for the enhanced muscle glucose uptake caused by chronic exercise. Fructose ingestion attenuated expression of GLUT4 by $78 \%$ in skeletal muscle of either sedentary or exercised rats ( $p=0.0156$, Fig. 2c), and a significant main effect of fructose ingestion on GLUT4 expression was detected $(F(1$, $12)=5.848, p=0.0324)$. Therefore, ingestion of fructose globally attenuates expression of key genes involved in metabolic adaptation of skeletal muscle to physical exercise.

Expression of forkhead box O3 (FoxO3A)-a transcriptional factor reported to interact with PGC- $1 \alpha 1$ to regulate expression of oxidative stress genes [35] — was also assessed in the skeletal muscle. While fructose showed no effect $(F(1,16)=2.055, p=0.1710$; Fig. $2 \mathrm{c})$ a main effect of aerobic training on the expression of FoxO3A was detected $(F(1,16)=5.711, p=0.0295)$.

\section{Expression of genes involved in protein degradation}

The results on the expression of PGC- $1 \alpha$ and FNDC5 and their transcriptional regulators led us to seek whether fructose ingestion might affect other molecular pathways that also mediate adaptive metabolic response of skeletal muscle to physical exercise. Should this be the case attenuation of exercise-induced remodeling of skeletal muscle might be, in addition to excessive caloric accumulation, a relevant mechanism underlying metabolic derangement associated with fructose ingestion. Autophagy and ubiquitin-proteasome pathways are major protein degradation pathways in the skeletal muscle. In addition to regulating the net amount and the quality of muscle protein, autophagy (basal and acute, exercise-induced) has been shown to play a critical role in exercise-induced muscle remodeling and improvement of insulin sensitivity $[16,36]$.

We observed a statistically significant main effect of exercise training on expression of autophagy-related protein $6($ Atg6/beclin 1) $(F(1,11)=23.856, p=0.000484)$, autophagy-related protein 7 (Atg7) $(F(1,13)=27.609, p=$ $0.000156)$, and autophagy-related protein 12 (Atg12) $(F(1$, $15)=8.157, p=0.012$ ), and they all showed significant induction in skeletal muscle after treadmill running (Fig. 3c). No significant effect for fructose ingestion or interaction between exercise and fructose ingestion was observed on expression of these genes. In contrast, autophagy-related protein 9 (Atg9) expression in both sedentary and exercised rats was impaired by fructose ingestion (Fig. 3c), and there was a significant main effect of fructose $(F(1,14)=$ 28.972, $\left.p=9.66 \times 10^{-05}\right)$ and interaction between exercise and fructose $(F(1,14)=4.653, p=0.0489)$ on expression of Atg9. Expression of microtubule-associated protein 1 light chain 3 isoform B (LC3B)-a marker of autophagosome accumulation was not affected by physical training or fructose (respectively, $F(1,20)=0.951, p=0.341$ and $F(1$, $20)=0.811, p=0.378$; Fig. 3a). However, ingestion of fructose impaired expression of lysosome-associated
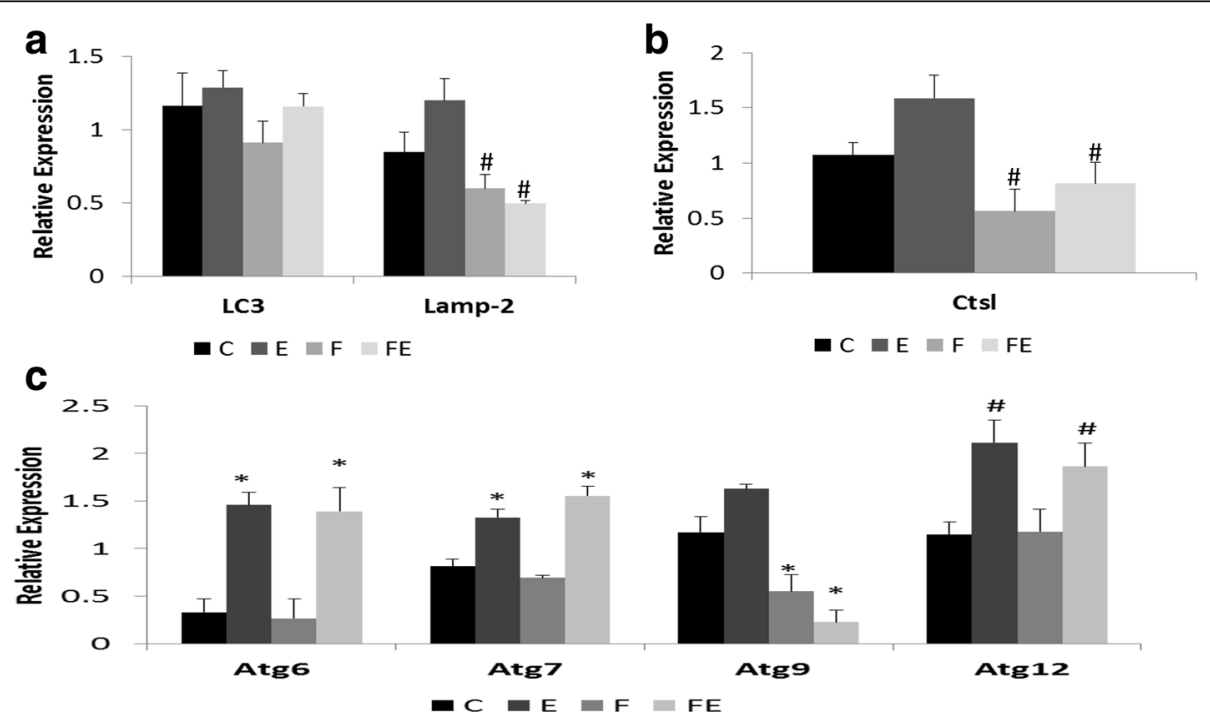

Fig. 3 Impact of aerobic training or fructose ingestion on expression of autophagy genes. a Marker of autophagosome accumulation LC3 and Iysosomal-associated membrane glycoprotein Lamp-2. b Lysosomal cathepsin L Ctsl. c Atg genes. Groups: C control, E exercise, F fructose, FE fructose + exercise. Results are presented as mean \pm SEM. A statistically significant main effect of exercise on expression of Atg6, Atg7, and Atg12 was observed. There is also a main effect of fructose ingestion on expression of Atg9, Lamp-2, and Ctsl as well as an interaction between fructose and exercise on expression of Atg9. See the text for further details. ${ }^{*} p<0.001$, $\# p<0.030$ 
membrane protein 2 (Lamp-2, $F(1,17)=7.750, p=0.0127$; Fig. 3a). Fructose ingestion also attenuated expression of lysosomal cathepsin L (Ctsl) in skeletal muscle $(F(1,14)=$ $6.768, p=0.0209$, Fig. 3b). No statistically significant main effect for exercise or fructose on expression of BCL2/ adenovirus E1B interacting protein B (Bnip3)-a marker of mitochondrial autophagy-was detected except for a trend for interaction between exercise and fructose $(F(1$, 11) $=3.401, p=0.0923$, Fig. 4a).

Effects of exercise and fructose ingestion on ubiquitinproteasome pathway were also evaluated by studying the expression of E3 ubiquitin ligases muscle RING-finger protein-1 (Murf-1) and muscle atrophy F-box (MAFBx, also known as atrogin-1) (Fig. 4b). There was a main effect of fructose on expression of both Murf-1 $(F(1,19)$ $=12.181, p=0.00245)$ and $\operatorname{MAFBx}(F(1,17)=4.897, p=$ $0.0409)$ and a marginally significant interaction between exercise and fructose on expression of Murf-1 $(F(1,19)$ $=4.000, p=0.05999$ ).

\section{Discussion}

The main finding of this study is that fructose ingestion impairs the expression of genes involved in transcriptional regulation of both oxidative metabolism and mitochondrial biogenesis and of genes of proteolytical pathways in the skeletal muscle. This negative effect of fructose ingestion was seen in both sedentary and exercised animals for most of these genes, but a few of these genes showed blunted expression only in treadmilltrained animals. Our results not only confirm the finding of a previous work which reported that fructose consumption impairs adaptive response of GLUT4 [24] but also suggest that ingestion of fructose might impair other responses of skeletal muscle to exercise.

Our results are similar to a recent study with human volunteers in which failure to upregulate mitochondrial fuel oxidation genes was shown as the mechanism behind the inability of human subjects to improve their insulin sensitivity upon aerobic training [37]. Like our study, the skeletal muscle of those who were unable to respond to aerobic training displayed deficient exerciseinduced expression of PGC- $1 \alpha$, ERR $\alpha$, and of 5 -AMPactivated protein kinase catalytic subunit alpha-2 (AMPK $\alpha 2)$ [37]. This study and ours highlighted the importance of oxidative muscle fibers in the genesis of insulin resistance and related metabolic diseases. Decreased oxidative phosphorylation in skeletal muscle has been reported as the earliest defect leading to insulin resistance and glucose intolerance in elderly subjects and non-diabetic offspring of type 2 diabetes patients $[38,39]$. In fact, the latter group also displayed a reduced ratio of inorganic phosphate to phosphocreatine in soleus muscle which is compatible with a diminished content of type I (oxidative) fibers relative to type II fibers [39]. Content of type I fibers has also been shown to correlate inversely with fat body mass and positively with the response to weight loss intervention [40]. Therefore, our results open the possibility that a dietary factor might lead to disorders associated to insulin resistance via reduction of number or function of mitochondria in skeletal muscle.

Interestingly, in our study, fructose feeding also prevented exercise induction of selected autophagy genes and muscle-specific E3 ubiquitin-protein ligases Murf-1 and MAFBx. A functioning autophagy pathway seems to be required for muscle mass maintenance, muscle regeneration, and exercise-induced muscle remodeling [14, 16, 36] while both expression of E3 ligases and proteasome activity in skeletal muscle have been reported to increase with either acute or chronic endurance exercise [14]. Such activation of proteasomal proteolysis might be an adaptive response as it allows for removal of damaged proteins and facilitates myofilament restructuring [14]. Therefore, fructose ingestion seems to affect multiple cellular functions that are related to skeletal muscle remodeling and metabolic adaptation to endurance training.

Intriguingly, in the present study, the fructose-loaded rats that underwent treadmill training (FE group) improved their exercise capacity to a similar extent as did
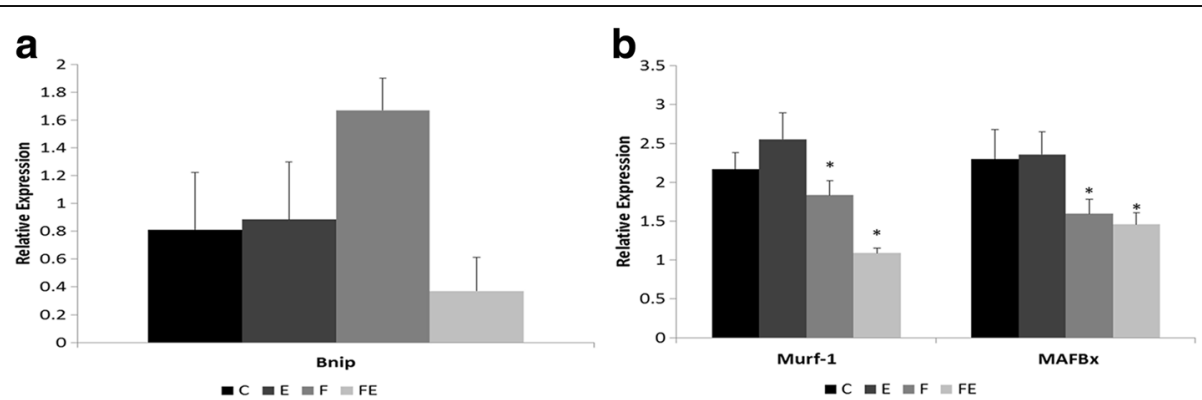

Fig. 4 Impact of fructose ingestion and exercise on expression of a mitophagy marker Bnip3 and $\mathbf{b}$ E3 ubiquitin ligases Murf-1 and MAFBx. Groups: $C$ control, E exercise, $F$ fructose, FE fructose + exercise. Results are presented as mean \pm SEM. There is a main effect of fructose ingestion on expression of Murf-1 and MAFBx (see the text for more details) 
their exercise-only counterparts (E group). Such finding is not what one might predict considering the altered gene expression exhibited by FE rats and evidences from overexpression experiments regarding the effects of PGC- $1 \alpha$ on mitochondrial biology and energy metabolism. Possible explanations include the existence of other transcriptional co-activators that might provide redundancy for PGC- $1 \alpha$ signaling or that PGC- $1 \alpha$ might not be mandatory for some of training-induced adaptations. In fact, PGC- $1 \alpha$ is a prototypical member of a family of transcriptional coactivators that regulates mitochondrial biogenesis and energy production, and there seems to be a redundancy between members of this family [41, 42]. Also, loss-of-function studies have shown that PGC- $1 \alpha$ might not be mandatory for some of training-induced responses in skeletal muscle $[11,13,43]$. It is noteworthy that in the study by Bohm et al. [37], no group of volunteers showed significant training-related improvement of $\mathrm{VO} 2_{\max }$ regardless of their ability (or inability) to improve insulin sensitivity with aerobic exercise or to induce expression of PGC- $1 \alpha$, ERR $\alpha$, and AMPK $\alpha 2$.

One might speculate the mechanism underlying the defective induction of genes related to skeletal muscle response to aerobic training in fructose-fed animals. These observed effects of fructose ingestion are probably mediated by transcriptional mechanism as the affected genes encompass multiple cellular processes. Cyclooxygenase 2-mediated inflammation have been reported to be the underlying mechanism of fructose-induced insulin resistance in rats $[44,45]$. A persistent inflammation caused by fructose ingestion might lead to defective activation of PGC-1 $\alpha$ and other transcriptional regulators of skeletal muscle adaptation via a TGF $\beta$-dependent mechanism like the one underlying the defective activation of PGC- $1 \alpha$ and AMPK $\alpha 2$ in individuals who failed to improve insulin sensitivity upon aerobic training [37]. This hypothesis, however, contradicts the existing evidence of anti-inflammatory properties of chronic aerobic exercise in rodent models of diabetes and tobacco smoking [46-48]. Alternatively, fructose might impair exercise-induced skeletal muscle remodeling by interfering with post-exercise glycogen accumulation in skeletal muscle. Exercise-induced activation of Ppar $\delta$ - a known activator of PGC-1 $\alpha$ transcription [49]-varies inversely with the glycogen content of muscle fiber [50]. Also, exercise-trained rats that ingest fructose exhibit higher content of both liver and muscle glycogen content than their exercise-trained, control diet-fed littermates [51]. Therefore, ingestion of fructose might impair the activation of Ppar $\delta$ and its downstream transcription targets including PGC- $1 \alpha$ by enhancing the accumulation of glycogen in skeletal muscle. Whether Pparo functions as an upstream transcriptional regulator of proteolytic pathways remains to be determined. Fructose ingestion might also affect expression PGC-1 $\alpha$ and training-induced adaptive genes responses by promoting the accumulation of lactate or lipids. In the liver, where most of absorbed fructose is metabolized, fructose is first phosphorylated by fructokinase to form fructose-1phosphate then broken down to glyceraldehyde and dihydroxyacetone phosphate by aldolase B [23]. The glyceraldehyde thus generated is phosphorylated to glyceraldehyde-3-phosphate by triokinase after which it can follow any triose phosphate metabolic pathway including conversion to lactate $[23,52]$. Conversion to lactate is a means to release fructose-derived carbon from liver for extrahepatic utilization, and about a quarter of ingested fructose is converted to lactate [53]. Thus, lactate might be a fructose-derived metabolic intermediate that causes the muscle to impair exerciseinduced gene response. The caveat for this hypothesis is the fact that exposure to lactate has been reported to promote expression of PGC- $1 \alpha$ and genes involved in mitochondrial biogenesis in both cultured L6 cells [54] and C57BL/6J mice [55]. Finally, excessive exposure of skeletal muscle to lipids results in muscle insulinresistance and accumulation within muscle fiber of fatty acid metabolites [56]. Since, by both augmenting lipid synthesis and decreasing lipid clearance, fructose loading increases plasma triglyceride and NEFAs [23, 53], metabolic overload of skeletal muscle mitochondria might impair the training-induced gene expression in skeletal muscle.

This study presents a number of limitations that should be mentioned. Firstly, we did not include isocaloric controls of other sugar preparations. For this reason, we could not test whether the observed effects on gene expression is specific to fructose ingestion or is a general phenomenon associated to excessive carbohydrate (or caloric) consumption. Second, animal's insulin sensitivity status was assessed only after the treatment/training period, and this hinders inferences that can be made regarding the effect of training or fructose on insulin sensitivity. Third, we used maximal exercise capacity on treadmill running to evaluate the effect of training instead of $\mathrm{VO} 2_{\max }$. Since exercise capacity is determined by a combination of factors which include $\mathrm{VO} 2_{\max }$ [57], we might not have captured adequately the impact of altered gene response on the physiology of skeletal muscle. Fourth, we did not allow the animals in this study to perform voluntary physical activity. For this reason, it is possible that our test for exercise capacity was comparing physical conditioning with physical deconditioning. The latter two deficiencies of our study might also be the reason why no apparent difference in exercise capacity between $\mathrm{E}$ and FE animals was detected. Finally, in view of the limited power of this study, we might have failed to detect an effect of fructose or exercise. To assess how the design of this study would affect our ability 
Table 3 Effect size of treatments (fructose or exercise) on expression of genes involved in skeletal muscle metabolic adaptation

\begin{tabular}{|c|c|c|}
\hline Gene & Effect size of fructose & Effect size of exe \\
\hline \multicolumn{3}{|c|}{ Pgc1alpha/irisin pathway } \\
\hline PGC-1a & 0.553419169 & 0.003713567 \\
\hline FNDC5 & 0.548825642 & 0.000276319 \\
\hline \multicolumn{3}{|c|}{ Genes involved in muscle metabolic adaptation } \\
\hline NR4A3 & 0.488632964 & $7.47831 \times 10^{-05}$ \\
\hline Erra & 0.166772854 & 0.448667531 \\
\hline PPARS & 0.317994819 & 0.226420844 \\
\hline CAMK IV & 0.052895965 & $3.55006 \times 10^{-05}$ \\
\hline FoxO3A & 0.083590432 & 0.232332765 \\
\hline GLUT4 & 0.307669308 & 0.044401256 \\
\hline
\end{tabular}

Genes involved in regulation of autophagy and proteasome pathways

\begin{tabular}{lll} 
Atg6 & 0.00014622 & 0.684310572 \\
Atg7 & 0.025548069 & 0.634666028 \\
Atg9 & 0.606486173 & 0.003040394 \\
Atg12 & 0.013919095 & 0.343627664 \\
LC3 & 0.037156357 & 0.043599656 \\
Lamp2 & 0.283530513 & 0.031508723 \\
Ctsl1 & 0.290616142 & 0.096971505 \\
Murf1 & 0.341522128 & 0.013641133 \\
MAFBx & 0.222860389 & 0.000315577 \\
Bnip & 0.029478458 & 0.132199546 \\
\hline $2\left(\right.$ SS $_{\text {Effect }} /$ SS $\left._{\text {Total }}\right)$ & was used as an estimate of effect size
\end{tabular}

to detect an effect of treatment factors on gene expression, we calculated the power using as parameters the effect sizes obtained from our PGC- $1 \alpha$ and FNDC5 expression data (Table 3). Post hoc power analysis showed that the power of this study to detect an effect of fructose on PGC-1 $\alpha$ or FNDC5 is 0.8 but only 0.05 for effect of exercise on either gene. Importantly, we were able to detect interaction between fructose and exercise on expression of a few genes despite of small effect size attributable to exercise (Table 3). In our opinion, the limitations mentioned here do not invalidate the main conclusion of our study regarding the possibility of excessive ingestion of a macronutrient impairing beneficial adaptive responses in skeletal muscle.

\section{Conclusion}

Our results suggest that fructose might impair exercise induction of genes involved in regulation of metabolic adaptation of the skeletal muscle. This finding indicates the need for a more detailed examination of the role of dietexercise interaction in the pathophysiology of cardiometabolic diseases. Further studies are needed to elucidate the mechanisms underlying the impairment of skeletal muscle metabolic adaptation induced by fructose consumption.

\begin{abstract}
Abbreviations
AMPKa2: 5'-AMP-activated protein kinase catalytic subunit alpha-2; Atg12: Autophagy-related protein 12; Atg6/beclin 1: Autophagy-related protein 6; Atg7: Autophagy-related protein 7; Atg9: Autophagy-related protein 9; Bnip3: BCL2/adenovirus E1B interacting protein B; CAMK IV: Calcium/calmodulin dependent protein kinase type IV; Ctsl: Lysosomal cathepsin L; CypA: Cyclophilin A; Erra: Estrogen-related receptor alpha; FNDC5: Fibronectin type III domain-containing protein 5; FoxO3A: Forkhead box O3A; GLUT4: Glucose transporter type 4; Lamp-2: Lysosome-associated membrane protein 2; LC3B: Microtubule-associated protein 1 Light Chain 3 Isoform B; MAFBx/atrogin-1: Muscle atrophy F-box; Murf-1: Muscle RINGfinger protein-1; NR4A3/Nor-1: nuclear receptor subfamily 4 group $A$ member 3; PGC-1a: Peroxisome proliferator receptor- $\gamma$ co-activator-1a;

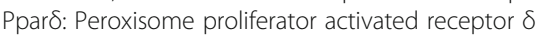

\section{Acknowledgements}

Not applicable.

Funding

This is study was supported by FAPESP - Fundação de Amparo à Pesquisa do Estado de São Paulo (Grant Number 2013/06720-5).

\section{Availability of data and materials}

The datasets used and/or analyzed during the current study are available from the corresponding author on reasonable request.

\section{Authors' contributions \\ NGG designed the study, performed the experiments, performed the statistical analysis, interpreted the results, and wrote the manuscript. SHC performed the gene expression experiments and drafted the manuscript. CAP participated in the interpretation of the results and contributed to the writing of the definitive version of the manuscript. MAM designed the exercise protocol, interpreted the results, and contributed to the writing of the definitive version of the manuscript. CJL designed the study, performed the statistical analysis, interpreted the results, and wrote the manuscript. All authors read and approved the final manuscript.}

\section{Ethics approval and consent to participate}

This study was approved by the Ethics Committee of University of São Paulo School of Medicine under the number 073/13, and all animal experiments were performed according to procedures approved at our institution.

\section{Consent for publication}

Not applicable.

\section{Competing interests}

The authors declare that they have no competing interests.

\section{Publisher's Note}

Springer Nature remains neutral with regard to jurisdictional claims in published maps and institutional affiliations.

\section{Author details}

${ }^{1}$ Department of Pathology, School of Medicine, University of São Paulo, São Paulo, Brazil. ²Department of Internal Medicine, School of Medicine, University of São Paulo, São Paulo, Brazil.

Received: 14 June 2017 Accepted: 20 November 2017

Published online: 08 December 2017

\section{References}

1. Mercken EM, Carboneau BA, Krzysik-Walker SM, de Cabo R. Of mice and men: the benefits of caloric restriction, exercise, and mimetics. Ageing Res Rev. 2012;11(3):390-8.

2. Booth FW, Roberts CK, Laye MJ. Lack of exercise is a major cause of chronic diseases. Compr Physiol. 2012;2(2):1143-211.

3. Myers J, Prakash M, Froelicher V, Do D, Partington S, Atwood JE. Exercise capacity and mortality among men referred for exercise testing. N Engl J Med. 2002;346(11):793-801. 
4. Laukkanen JA, Zaccardi F, Khan H, Kurl S, Jae SY, Rauramaa R. Long-term change in cardiorespiratory fitness and all-cause mortality: a populationbased follow-up study. Mayo Clin Proc. 2016;91(9):1183-8.

5. Koch LG, Britton SL. Development of animal models to test the fundamental basis of gene-environment interactions. Obesity (Silver Spring). 2008;16(Suppl 3):S28-32.

6. Coffey VG, Hawley JA. The molecular bases of training adaptation. Sports Med. 2007;37(9):737-63.

7. Mann N, Rosenzweig A. Can exercise teach us how to treat heart disease? Circulation. 2012;126(22):2625-35.

8. Hawley JA, Hargreaves M, Joyner MJ, Zierath JR. Integrative biology of exercise. Cell. 2014;159(4):738-49.

9. Liang H, Ward WF. PGC-1alpha: a key regulator of energy metabolism. Ady Physiol Educ. 2006;30(4):145-51.

10. Bostrom P, Wu J, Jedrychowski MP, Korde A, Ye L, Lo JC, Rasbach KA, Bostrom EA, Choi JH, Long JZ, et al. A PGC1-alpha-dependent myokine that drives brown-fat-like development of white fat and thermogenesis. Nature. 2012;481(7382):463-8.

11. Leick L, Wojtaszewski JF, Johansen ST, Kiilerich K, Comes G, Hellsten Y, Hidalgo J, Pilegaard H. PGC-1alpha is not mandatory for exercise- and training-induced adaptive gene responses in mouse skeletal muscle. Am J Physiol Endocrinol Metab. 2008;294(2):E463-74.

12. Adhihetty PJ, Uguccioni G, Leick L, Hidalgo J, Pilegaard H, Hood DA. The role of PGC-1alpha on mitochondrial function and apoptotic susceptibility in muscle. Am J Phys Cell Phys. 2009;297(1):C217-25.

13. Geng T, Li P, Okutsu M, Yin X, Kwek J, Zhang M, Yan Z. PGC-1alpha plays a functional role in exercise-induced mitochondrial biogenesis and angiogenesis but not fiber-type transformation in mouse skeletal muscle. Am J Phys Cell Phys. 2010;298(3):C572-9.

14. Bell RA, Al-Khalaf M, Megeney LA. The beneficial role of proteolysis in skeletal muscle growth and stress adaptation. Skelet Muscle. 2016;6:16.

15. Masiero E, Agatea L, Mammucari C, Blaauw B, Loro E, Komatsu M, Metzger D, Reggiani C, Schiaffino S, Sandri M. Autophagy is required to maintain muscle mass. Cell Metab. 2009;10(6):507-15.

16. Lira VA, Okutsu M, Zhang M, Greene NP, Laker RC, Breen DS, Hoehn KL, Yan Z. Autophagy is required for exercise training-induced skeletal muscle adaptation and improvement of physical performance. FASEB J. 2013;27(10): 4184-93.

17. Malenfant P, Joanisse DR, Theriault R, Goodpaster BH, Kelley DE, Simoneau JA. Fat content in individual muscle fibers of lean and obese subjects. Int $J$ Obes Relat Metab Disord. 2001;25(9):1316-21.

18. Gavin TP, Stallings HW 3rd, Zwetsloot KA, Westerkamp LM, Ryan NA, Moore RA, Pofahl WE, Hickner RC. Lower capillary density but no difference in VEGF expression in obese vs. lean young skeletal muscle in humans. J Appl Physiol (1985). 2005;98(1):315-21.

19. Gueugneau M, Coudy-Gandilhon C, Theron L, Meunier B, Barboiron C, Combaret L, Taillandier D, Polge C, Attaix D, Picard B, et al. Skeletal muscle lipid content and oxidative activity in relation to muscle fiber type in aging and metabolic syndrome. J Gerontol A Biol Sci Med Sci. 2015;70(5):566-76.

20. Elmore $\mathrm{CJ}$ : Investigating the potential relationship between skeletal muscle atrophy and obesity The University of lowa; 2012.

21. Bollinger LM, Powell JJ, Houmard JA, Witczak CA, Brault JJ. Skeletal muscle myotubes in severe obesity exhibit altered ubiquitin-proteasome and autophagic/lysosomal proteolytic flux. Obesity (Silver Spring). 2015;23(6):1185-93.

22. Malik VS, FB H. Fructose and cardiometabolic health: what the evidence from sugar-sweetened beverages tells us. J Am Coll Cardiol. 2015;66(14):1615-24.

23. Mayes PA. Intermediary metabolism of fructose. Am J Clin Nutr. 1993:58(5 Suppl):754S-65S

24. Goyaram V, Kohn TA, Ojuka EO. Suppression of the GLUT4 adaptive response to exercise in fructose-fed rats. Am J Physiol Endocrinol Metab. 2014:306(3):E275-83.

25. Matthews DR, Hosker JP, Rudenski AS, Naylor BA, Treacher DF, Turner RC. Homeostasis model assessment: insulin resistance and beta-cell function from fasting plasma glucose and insulin concentrations in man. Diabetologia. 1985;28(7):412-9.

26. Wallace TM, Levy JC, Matthews DR. Use and abuse of HOMA modeling. Diabetes Care. 2004;27(6):1487-95.

27. HOMA Calculator [https://www.dtu.ox.ac.uk/homacalculator/]

28. Livak KJ, Schmittgen TD. Analysis of relative gene expression data using real-time quantitative PCR and the 2(-Delta Delta C(T)) method. Methods. 2001;25(4):402-8.
29. Conover WJ, Johnson ME, Johnson MM. A comparative-study of tests for homogeneity of variances, with applications to the outer continental-shelf bidding data. Technometrics. 1981;23(4):351-61.

30. Cohen J. Statistical power analysis for the behavioral sciences second edition edn. New Jersey, United States of America: LAWRENCE ERLBAUM ASSOCIATES, PUBLISHERS; 1988.

31. Champely S, Ekstrom C, Dalgaard P, Gill J, Weibelzahl S, Anandkumar A, Ford C, Volcic R, De Rosario H: pwr: basic functions for power analysis. 2017.

32. Lu P, Liu J, Koestler D: pwr2: power and sample size analysis for one-way and two-way ANOVA models. 2017.

33. Panchal SK, Poudyal H, lyer A, Nazer R, Alam MA, Diwan V, Kauter K, Sernia C, Campbell F, Ward L, et al. High-carbohydrate, high-fat diet-induced metabolic syndrome and cardiovascular remodeling in rats. J Cardiovasc Pharmacol. 2011;57(5):611-24.

34. Wu H, Kanatous SB, Thurmond FA, Gallardo T, Isotani E, Bassel-Duby R, Williams RS. Regulation of mitochondrial biogenesis in skeletal muscle by CaMK. Science. 2002;296(5566):349-52.

35. Olmos Y, Valle I, Borniquel S, Tierrez A, Soria E, Lamas S, Monsalve M. Mutual dependence of Foxo3a and PGC-1alpha in the induction of oxidative stress genes. J Biol Chem. 2009;284(21):14476-84.

36. He C, Bassik MC, Moresi V, Sun K, Wei Y, Zou Z, An Z, Loh J, Fisher J, Sun Q, et al. Exercise-induced BCL2-regulated autophagy is required for muscle glucose homeostasis. Nature. 2012:481(7382):511-5.

37. Bohm A, Hoffmann C, Irmler M, Schneeweiss P, Schnauder G, Sailer C, Schmid V, Hudemann J, Machann J, Schick F, et al. TGF-beta contributes to impaired exercise response by suppression of mitochondrial key regulators in skeletal muscle. Diabetes. 2016;65(10):2849-61.

38. Petersen KF, Befroy D, Dufour S, Dziura J, Ariyan C, Rothman DL, DiPietro L, Cline GW, Shulman GI. Mitochondrial dysfunction in the elderly: possible role in insulin resistance. Science. 2003:300(5622):1140-2.

39. Petersen KF, Dufour S, Befroy D, Garcia R, Shulman Gl. Impaired mitochondrial activity in the insulin-resistant offspring of patients with type 2 diabetes. N Engl J Med. 2004;350(7):664-71.

40. Tanner CJ, Barakat HA, Dohm GL, Pories WJ, MacDonald KG, Cunningham PR, Swanson MS, Houmard JA. Muscle fiber type is associated with obesity and weight loss. Am J Physiol Endocrinol Metab. 2002;282(6):E1191-6.

41. Finck BN, Kelly DP. PGC-1 coactivators: inducible regulators of energy metabolism in health and disease. J Clin Invest. 2006;116(3):615-22.

42. Scarpulla RC. Metabolic control of mitochondrial biogenesis through the PGC1 family regulatory network. Biochim Biophys Acta. 2011;1813(7):1269-78.

43. Rowe GC, Patten IS, Zsengeller ZK, El-Khoury R, Okutsu M, Bampoh S, Koulisis N, Farrell C, Hirshman MF, Yan Z, et al. Disconnecting mitochondrial content from respiratory chain capacity in PGC-1-deficient skeletal muscle. Cell Rep. 2013;3(5):1449-56.

44. Liu TT, Shih KC, Kao CC, Cheng WT, Hsieh PS. Importance of cyclooxygenase 2-mediated low-grade inflammation in the development of fructoseinduced insulin resistance in rats. Chin J Phys. 2009;52(2):65-71.

45. Rutledge AC, Adeli K. Fructose and the metabolic syndrome: pathophysiology and molecular mechanisms. Nutr Rev. 2007:65(6 Pt 2):S13-23.

46. Teixeira de Lemos E, Pinto R, Oliveira J, Garrido P, Sereno J, MascarenhasMelo F, Pascoa-Pinheiro J, Teixeira F, Reis F. Differential effects of acute (extenuating) and chronic (training) exercise on inflammation and oxidative stress status in an animal model of type 2 diabetes mellitus. Mediat Inflamm. 2011;2011:253061.

47. Codella R, Lanzoni G, Zoso A, Caumo A, Montesano A, Terruzzi IM, Ricordi C, Luzi L, Inverardi L. Moderate intensity training impact on the inflammatory status and glycemic profiles in NOD mice. J Diabetes Res. 2015;2015:737586.

48. Toledo AC, Magalhaes RM, Hizume DC, Vieira RP, Biselli PJC, Moriya HT, Mauad T, Lopes F, Martins MA. Aerobic exercise attenuates pulmonary injury induced by exposure to cigarette smoke. Eur Respir J. 2012;39(2):254-64.

49. Coen PM, Jubrias SA, Distefano G, Amati F, Mackey DC, Glynn NW, Manini TM, Wohlgemuth SE, Leeuwenburgh C, Cummings SR, et al. Skeletal muscle mitochondrial energetics are associated with maximal aerobic capacity and walking speed in older adults. J Gerontol Ser a-Biol Sci Medl Sci. 2013;68(4):447-55.

50. Philp A, MacKenzie MG, Belew MY, Towler MC, Corstorphine A, Papalamprou A, Hardie DG, Baar K. Glycogen content regulates peroxisome proliferator activated receptor-partial differential (PPAR-partial differential) activity in rat skeletal muscle. PLoS One. 2013:8(10):e77200.

51. Murakami T, Shimomura Y, Fujitsuka N, Sokabe M, Okamura K, Sakamoto S. Enlargement glycogen store in rat liver and muscle by fructose-diet intake and exercise training. J Appl Physiol (1985). 1997;82(3):772-5. 
52. Rosset R, Egli L, Lecoultre V. Glucose-fructose ingestion and exercise performance: the gastrointestinal tract and beyond. Eur J Sport Sci. 2017; 17(7):874-84.

53. Sun SZ, Empie MW. Fructose metabolism in humans-what isotopic tracer studies tell us. Nutr Metab (Lond). 2012;9(1):89.

54. Hashimoto T, Hussien R, Oommen S, Gohil K, Brooks GA. Lactate sensitive transcription factor network in L6 cells: activation of MCT1 and mitochondrial biogenesis. FASEB J. 2007;21(10):2602-12.

55. Kitaoka Y, Takeda K, Tamura Y, Hatta H. Lactate administration increases mRNA expression of PGC-1a and UCP3 in mouse skeletal muscle. Appl Physiol Nutr Metab. 2016:41(6):695-8.

56. Koves TR, Ussher JR, Noland RC, Slentz D, Mosedale M, Ilkayeva O, Bain J, Stevens R, Dyck JR, Newgard CB, et al. Mitochondrial overload and incomplete fatty acid oxidation contribute to skeletal muscle insulin resistance. Cell Metab. 2008;7(1):45-56.

57. Shaw AJ, Ingham SA, Atkinson G, Folland JP. The correlation between running economy and maximal oxygen uptake: cross-sectional and longitudinal relationships in highly trained distance runners. PLoS One. 2015;10(4)::0123101.

Submit your next manuscript to BioMed Central and we will help you at every step:

- We accept pre-submission inquiries

- Our selector tool helps you to find the most relevant journal

- We provide round the clock customer support

- Convenient online submission

- Thorough peer review

- Inclusion in PubMed and all major indexing services

- Maximum visibility for your research

Submit your manuscript at www.biomedcentral.com/submit 